\title{
I. Einleitung: Gegenstand, Fragestellungen, Ziele und Methoden
}

\author{
1. Annäherungen: \\ Problemaufriß, Erkenntnisinteressen und Zielhorizont
}

In seinen Weltgeschichtlichen Betrachtungen befand Jacob Burckhardt, daß die „Geschichte... ja überhaupt die unwissenschaftlichste aller Wissenschaften" sei, „nur daß sie viel Wissenswürdiges überliefert. "Symptomatisch für diese Beobachtung erschien ihm die Differenz zwischen philosophisch-logischer und historischer Begriffsbildung: „Scharfe Begriffsbestimmungen gebören in die Logik, aber nicht in die Geschichte, wo Alles schwebend und in beständigen Übergängen und Mischungen existirt. “Philosophische Begriffe seien daher „so fest und geschlossen als möglich“ zu fassen, historische dagegen „so flüssig und offen als möglich ... Beide sind wesentlich verschiedener Art und verschiedenen Ursprungs". 1

Burckhardts Diktum erscheint unlösbar mit einer anderen grundlegenden Zeiterfahrung verbunden: In kaum verhohlener Skepsis resümierte der Schweizer Historiker 1871, „daß eigentlich Alles bis auf unsere Tage lauter Revolutionzeitalter ist. “ Im „großen Drama“ der geschichtlichen Umwälzungen seit 1789 erkannte er nunmehr „Eine Bewegung ..., die im Gegensatz zu aller bekannten Vergangenheit unseres Globus stebt". ${ }^{2}$ Bereits in seinen historischen Vorlesungen von 1829 hatte Barthold Georg Niebuhr bei der Suche nach einem „Wort für die Zeit im allgemeinen" auf den Terminus der Revolution zurückgegriffen und dabei in der Französischen Revolution zwar noch den „Mittelpunct der letzten vierzig Jabre " erkannt. Die Folgewirkungen reichten aber weit über den unmittelbaren Kontext von 1789 hinaus: Damals, so Niebuhr, seien „die comprimierten Mächte ... freigelassen“ worden, seitdem aber sei „selbst das alte und älteste, das sich für unverändert ausgibt, ... durch die große Epoche verändert worden oder in andere Verhältnisse gestellt". ${ }^{3}$ Damit löste sich der Revolutionsbegriff aus dem spezifischen Kontext eines bestimmbaren historischen Ereignisses, indem er nunmehr als bereits den Zeitgenossen adäquat erscheinendes Epochenetikett firmierte. Der Begriff bezog seine Wirkungsmacht nicht länger aus einer bloß temporären Außerkraftsetzung politisch-gesellschaftli-

1 Jacob Burckhardt, Über das Studium der Geschichte. Der Text der Weltgeschichtlichen Betrachtungen auf Grund der Vorarbeiten von ERNST ZIEGLER nach den Handschriften hrsg. von PETER GANZ, München 1982, S. 293.

2 Jacob BurckhardT, Das Revolutionszeitalter, in: Ders., Historische Fragmente, hrsg. von EMIL DÜRR, Neudruck Stuttgart 1942, S. 194-240, hier S. 200.

3 Barthold Georg Niebuhr, Geschichte des Zeitalters der Revolution. Vorlesungen an der Universität zu Bonn im Sommer 1829, Bd. 1, Hamburg 1845, S. 41 f. 
cher Ordnungsgefüge. Die Rückkehr zu einem status quo ante auf dem Wege einer vermeintlichen Restauration erwies sich damit als unmöglich. Erst vor diesem Hintergrund entfaltete sich eine neue semantische Verortung von Zeitbegriffen: Selbst wo sich Restauration als echte Rückkehr zum Ancien régime bald als Utopie erwies, galt der Begriff den fortschrittlichen Zeitgenossen „als die nach rückwärts gerichtete Reform der Reaktionäre“. ${ }^{4}$ Gegenüber dem belasteten Revolutionsbegriff und der als Reaktion verstandenen Restauration etablierte sich der Begriff der Reform als semantische Vermittlung zwischen gesellschaftlicher Dynamik und politisch-konstitutioneller Statik. ${ }^{5}$

Indem Revolution weit über die chronologischen und nationalen Grenzen der Französischen Revolution ausgriff, geriet sie zeitgenössischen Beobachtern zum Symbol für tiefgreifende Umbrüche. Dieses Symbol läßt sich analytisch als Deutungsmuster sozialen Wissens erfassen, also als übergreifendes sprachliches Paradigma der Wirklichkeitswahrnehmung und -interpretation. Es sei, so Alexander Hill Everett, amerikanischer Diplomat am niederländischen Hof, eben nicht nur Europa, sondern „der ganze Erdkreis ... durch eine Art von Convulsion bis in das Innerste erschüttert“ worden. Alle Bemühungen um eine Rückführung der Verhältnisse nach 1815 schienen insofern vergeblich, als die Ursache der Veränderungen eben kein momentaner Umsturz war, sondern die ebenso tiefgreifende wie neuartige Entdeckung, „daß die Revolution ... nach und nach durch die Veränderungen, welche in dem Zustande der Gesellschaft vorgegangen sind und die eine Wirkung ... der Zivilisation waren, hervorgebracht ist. In dieser Veränderung des Zustandes der Gesellschaft bestebt die wabre Revolution".6 Mit der Entstehung des Deutungsmusters Revolution als Epochenbegriff verbanden die Zeitgenossen ihre eigene Gegenwart mit dem Einsetzen fundamentaler Umbrüche seit dem letzten Drittel des 18. Jahrhunderts, begriffen sich mithin als postrevolutionäre Gesellschaft, in der die Revolution allenfalls dialektisch, aber nicht mehr restaurativ aufgehoben werden konnte. Ein Ende der Revolution war in diesem Sinne nicht mehr absehbar und ließ die eigene Gegenwart als Periode des beschleunigten Übergangs, der dau-

4 Panajotis Kondylis, Reaktion, Restauration, in: OtTo Brunner, Werner ConZe und ReInHart Koselleck (Hrsg.), Geschichtliche Grundbegriffe. Historisches Lexikon zur politisch-sozialen Sprache in Deutschland, Bd. 5, Stuttgart 1984, S. 179-230, hier S. 197.

5 Vgl. Eike Wolgast, Reform, Revolution, in: Brunner et al. (Hrsg.), Bd. 5, S. 313-60 sowie Hans-Peter Ullmann und Clemens Zimmermann, Einleitung, in: Dies. (Hrsg.), Restaurationssystem und Reformpolitik. Süddeutschland und Preußen im Vergleich, München 1996, S. 7-15, hier S. 7 f.

6 [Alexander Hill EveretT] Europa oder Uebersicht der Lage der Europäischen Hauptmächte im Jahre 1821. Von einem amerikanischen Diplomaten (Mr. Alex. H. Everett, Chargé d'affaires der Vereinigten Staaten am Königl. Niederländischen Hofe). Aus dem Englischen mit (im Sinne der monarchischen Grundsätze) erläuternden und berichtigenden Anmerkungen des Uebersetzers, Erster Theil, Bamberg 1823, S. 29 und 7. 
ernden Bewegung oder permanenten Krise erscheinen. Alexis de Tocqueville resümierte 1850:

Ce qui est clair pour moi, c'est qu'on s'est trompé depuis soixante ans en croyant voir le but de la révolution... Il est évident que le flot continue à marcher... que non-seulement nous n'avons pas vu la fin de l'immense révolution qui a commencé avant nous, mais que l'enfant qui naît aujourd'bui ne la verra vraisemblablement pas.

Es sei eben nicht mehr nur eine „modification“ sondern eine strukturelle „transformation du corps social“, 7 die für diese langfristigen Wirkungen verantwortlich sei.

Die von Thomas Carlyle in seinem 1829 veröffentlichten Essay über Signs of the Times konstatierte "grinding collision of the New with the Old“, als deren Symptom die Französische Revolution gelten konnte - „not the parent of this mighty movement, but its offspring "8 - war keine Beobachtung isolierter Umbruchserscheinungen, sie erfaßte gerade auch die politisch-soziale Sprache im komplexen Spannungsfeld von neuen Erfahrungen und Erwartungen. ${ }^{9}$ Erst dies ließ aus dem „Zeitalter der Revolutionen "10 zugleich „bei dem babylonischen Thurmbau einer neu zu schaffenden Ordnung der Dinge eine babylonische Sprachverwirrung “ entstehen. ${ }^{11}$

\section{a) Ideen, Begriffe und Sprachverwirrung:}

Zur Transformationsgeschichte politisch-sozialer Sprache im 19. Jahrhundert

Joseph von Görres entwarf 1804 ein symbolträchtiges Panorama des aufbrechenden neuen Verhältnisses von Ideen und Begriffen, als er deren Zusammentreffen in der eigenen Gegenwart beschrieb. Als „große Begebenheit der Zeit“ erkannte er die Herabkunft der Ideen, "die seit langem sich in sich selbst zurückgezogen hatten und nur von Zeit zu Zeit als Fremdlinge, von wenigen geseben, auf die Erde herabgestiegen waren. "Auf der Erde treffen die Ideen, die „in der Kunst, der Wissenschaft und überall ibr Erbe, die Herrschaft des Irdischen “ zurückfordern, auf die Begriffe, die dort „alles in Feldmarken eingeteilt und abgezäunt" haben. ${ }^{12}$ Die bisher unangefochtene Herrschaft der über-

7 Brief Tocquevilles an Eugène Stoffels vom 28. April 1850, in: AleXIS DE TocQUEville, Euvres et correspondance, hrsg. von Gustave de Beaumont, Bd. 1, Paris 1861, S. 460 f.

8 [Thomas Carlyle] Signs of the Times, in: Edinburgh Review 49 (1829), S. 439-59, hier S. $458 \mathrm{f}$.

9 Vgl. ReINHART KOSELleCK, „Erfahrungsraum“ und „Erwartungshorizont“-zwei historische Kategorien (1976), in: DERS., Vergangene Zukunft. Zur Semantik geschichtlicher Zeiten, Frankfurt a.M. 1989, S. 349-75.

10 EVERETT, Erster Theil, S. 28.

11 Johann Ignatz Weitzel, Hat Deutschland eine Revolution zu fürchten?, Wiesbaden 1819, S. $19 \mathrm{f}$.

12 Joseph VON Görres, Die Herabkunft der Ideen und das Zeitalter (1804/05), in: Ders., Ausgewählte Werke und Briefe, hrsg. von Wilhelm Schellenberg, Bd. 1, 
kommenen Begriffe wird durch die „stolzen Fremdlinge" schließlich abgelöst: "Und sie [die Begriffe] traten zusammen und wäblten sich die Ideen zu ibren Heerfübrern und vertrauten ibnen die Lenkung des gemeinen Wesens und verpflichteten sich, ibnen zu glauben und zu folgen in allem." Aber die derart geschaffene Harmonie zwischen herrschenden Ideen und dienenden Begriffen gerät schon bald in Unordnung. Aus der Revolte der unterdrückten Begriffe erwächst die Revolution, da das Volk nicht mehr an die „Unsterblichkeit der Fremdlinge" glaubt, nachdem es "nur einmal den ersten Kopf auf der Pike dahergetragen sab. "Damit setzt der folgenschwere Kampf von Ideen und Begriffen ein, in dem die Volksmasse endlich neue "Geister" beschwört, „um die Begriffe vollends zu verwirren und zu verhetzen und sie dann anzufübren im Kampf gegen die Ideen". 13

Görres griff bei seiner suggestiven Metapher für den Kampf zwischen tradierten und neuen Zeitkräften, der seit 1789 augenfällig geworden war, kaum zufällig auf Ideen, Begriffe und Geister als Akteure zurück. Das überkommene System begrifflicher Ordnung, die die Erde in Marken und Felder einteilte, geriet bei ihm mit dem Aufkommen neuer Ideen in Bewegung, die schließlich die Leitungsherrschaft gewannen und die doch schon bald im öffentlichen Räsonnement wieder in Frage gestellt wurden. Den für Görres entscheidenden Einschnitt markierte der Umschlag des zunächst berechtigten Widerstandes - denn "der Hochmut der Ideen ward drückend für die Begriffe" - in die gewaltsame Revolution, in der die „Lügengeister“, von der Masse beschworen und herbeigerufen, zu Verkehrung und Verdammnis führen. In diesem „Kampf des Himmels mit der Hölle um das Irdische" sah Görres das bestimmende Zeichen der Epoche. Die eigene Gegenwart erschien nicht allein vom Kampf der Ideen und Bewegungen geprägt, es ging eben auch um die Auseinandersetzungen auf sprachlich-kommunikativer Ebene, um Verwirrung der Begriffe durch falsche Geister, die als „gefallene, verstoßene Engel“ selbst Ergebnis der Revolution und zugleich Kampfmittel waren. ${ }^{14}$ Damit wurde das Zeitereignis Revolution in metaphorisch-suggestiver Verkleidung zur Ursache der von Görres erkannten Begriffsverwirrung.

Aus dieser Perspektive erscheint die politisch-soziale Revolution auch als Umwälzung der politischen Sprache. Begreift man die Relation von Ideen, Begriffen und öffentlichem Diskurs als substanzielles Kennzeichen politischer Sprache, so wird hier deutlich, wie sich die überkommene statische Ordnung im Verhältnis von Ideen und Begriffen in der Wahrnehmung der Zeitgenossen verändert und welche aktive Eigenmacht dem Kampf zwischen Ideen und Lügengeistern um die Begriffe zukommt. Dieser Konflikt um Begriffe reflektiert zugleich den gewandelten Kontext des öffentlichen Raumes für den Diskurs

Kempten 1911, S. 98, zitiert nach Walther Killy (Hrsg.), Zeichen der Zeit. Ein deutsches Lesebuch in vier Bänden, Bd. 2: 1786-1832, Darmstadt 1981, S. 28-31, hier S. 28.

13 Ebd. S. $29 f$.

14 Ebd., S. $30 f$. 
und die potentielle Gefahr falscher Berufungen. Während Görres indes noch auf eine ideelle wie begriffliche Neuwerdung im Kampf gegen die Lügengeister hoffte, eine dialektische Katharsis moralischer Qualität, die aus der Dichotomie von positiven Ideen und negativen Geistern hervorgehen sollte, ${ }^{15}$ unterschied Adam Müller in seinen Vorlesungen über die Elemente der Staatskunst skeptisch zwischen dynamischen Ideen und statischen Begriffen. Während die Idee "das Leben allenthalben hin begleiten und auf dasselbe wirken" könne, „weil sie selbst lebendig ist“, bleibe der Begriff immer zurück und komme stets zu spät. Die Erfahrung der Französischen Revolution bestand für ihn nicht zuletzt in einer neuen destruktiven Wirkungsmacht der Begriffe. Wiederum stand die spannungsreiche Beziehung zwischen Idee und Begriff im Zentrum einer neuen historischen Erfahrung, und wiederum war ein wesentliches neues Kennzeichen der Revolution in der Macht neuer Begriffe zu suchen. Der Begriff, so Müller, könne „nur zerstören und tödten ... wie wir es in der Französischen Revolution geseben haben, wo ibm ein Wirkungskreis eingeräumt wurde, der groß genug war".16

Den revolutionären Wandel der Sprache neben den sichtbaren politischkonstitutionellen Veränderungen registrierten nachgerade französische Zeitgenossen:

La langue éprouva le même bouleversement que les lois, le gouvernement et les institutions monarchiques. Les nouvelles idées amenèrent une foule de nouveaux mots. Les mots anciens perdirent leur acception, et furent conduits jusqu'à un sens tout-à-fait opposé. Il en résulta une langue qui étoit l'inverse du bon sens. ${ }^{17}$

Die sich dynamisch entfaltende Pluralität von Ideen und Interessen stellte nicht allein das überkommene Verständnis der societas civilis als Identität von Bürgern und Staat ${ }^{18}$ in Frage und markierte insofern den folgenreichen historischsemantischen Beginn der bürgerlichen Gesellschaft als Bezugspunkt der politischen, gesellschaftlichen und kulturellen Transformationen des 19. und 20. Jahrhunderts, sondern forderte im offenen Kampf um Begriffe zugleich alle tradierten Definitions- und Deutungsmonopole heraus. Die unmittelbarste Konsequenz solcher sprachlich-kommunikativer Mobilisierung war ein $\mathrm{Ne}$ -

15 Vgl. ebd., S. 31.

16 Adam H. MÜller, Die Elemente der Staatskunst. Öffentliche Vorlesungen (1809), hrsg. von JAKOB BAXA, Jena 1922, S. 42.

17 Du Langage révolutionnaire (1814/1815), in: Tableau politique et littéraire de la France en 1814 et 1815, extrait des meilleurs écrits de cette heureuse époque, Bd. 2, Paris 1820, S. 311-7, hier S. 311.

18 Vgl. MANFred Riedel, Gesellschaft, bürgerliche, in: BrunNer et al. (Hrsg.), Bd. 2, S. 719-800, hier S. $737 \mathrm{ff}$. Zum unterschiedlichen Bedeutungswandel von der societas civilis zur bürgerlichen Gesellschaft in England gegenüber Frankreich und Deutschland vgl. WeRnER CONZE, Staat und Gesellschaft in der frührevolutionären Epoche Deutschlands, in: Hanns Hubert Hofmann (Hrsg.), Die Entstehung des modernen souveränen Staates, Köln 1967, S. 297-320, hier S. 298 ff. sowie NikLAS LuHMANN, Die Unterscheidung von Staat und Gesellschaft, in: DERS., Soziologische Aufklärung 4. Beiträge zur funktionalen Differenzierung der Gesellschaft, Opladen 1987, S. 67-73. 
beneinander von wachsendem Bedürfnis nach begrifflicher Orientierung und semantischer Verbindlichkeit einerseits, um so Wegmarken in einer unübersichtlich gewordenen Umwelt zu gewinnen, und der Erfahrung einer wachsenden Verwirrung und Unklarheit der politisch-sozialen Sprache andererseits, einer zunehmenden Unschärfe und Unbestimmtheit, einer Inflation definitorischer Angebote, die die semantische Gültigkeit und den Wirkungskreis solcher Bestimmungsversuche immer mehr beschränkte. Sören Kierkegaard gab dieser Erfahrung pointierten Ausdruck, als er 1837 in seinem Tagebuch nicht in den politischen Umwälzungen Europas den „totalen Bankerott“ aufziehen sah, sondern das „scheinbar unentrinnbare Fallit in geistiger Hinsicht“ ins Zentrum stellte:

eine Sprachverwirrung, weit gefährlicher als jene babylonische ..., als jene auf den babylonischen Versuch des Mittelalters gefolgte National- und Dialektverwirrung - eine Verwirrung nämlich in den Sprachen selbst, ein Aufrubr, der gefährlichste von allen, der Worte nämlich, die, losgerissen von der Herrschaft der Menschen, verzweifelt gleichsam aufeinander losstürzen, und aus diesem Chaos greift der Mensch gleichsam wie aus einem Glückshafen das erste beste Wort, um seine vermeintlichen Gedanken auszudrücken ... Vergebens suchen einzelne große Männer, neue Begriffe zu münzen und sie in Zirkulation zu setzen - das nützt nichts. Einen Augenblick nur und sie sind verbraucht, und das nicht einmal von vielen, und tragen so bloß dazu bei, die Verwirrung noch schlimmer zu machen; denn eine Idee scheint die fixe des Zeitalters geworden zu sein, es ist diese: über seinen Vorgänger hinausgekommen zu sein. ${ }^{19}$

George Cornwall Lewis begründete 1832 die Notwendigkeit der „explanations and distinctions" von politischen Begriffen mit ihrer zunehmenden Ungenauigkeit, die durch den intensivierten öffentlichen Diskurs noch multipliziert werde. Ihm ging es dabei schon nicht mehr a priori um eine normativ-verbindliche Begriffsdefinition, sondern zunächst um den Erweis der semantischen Pluralisierung selbst:

The following researches ... relate, not to the truth of any particular propositions, but to the meaning of certain terms used in political reasoning; which being often employed with different senses in the premises and conclusion, have given rise to countless inconclusive arguments, and have thus caused fallacies of argument in the proper meaning of the word. ${ }^{20}$

Lewis' Ziel lag damit nicht mehr in einer Homogenisierung der semantischen Reichweite politischer Begriffe, sondern in der Schärfung des sprachlichen Herrschaftswissens über die Vielzahl von Bedeutungen, in denen sich der Pluralismus der Meinungen niederschlug: "where all people talk on the same subject, they should be agreed about the vocabulary with which they discuss it: or, at any rate, they should be aware that they are not agreed". 21

In Deutschland konstatierte zur selben Zeit Carl von Rotteck im Staatslexikon „eine fast babylonische Sprachverwirrung, welche in Folge des blind leiden-

19 Eintragung vom 17. Januar 1837, in: SÖREN KIERKEGAARD, Die Tagebücher, hrsg. von THEODOR HAECKER, Bd. 1: 1834-1848, Innsbruck 1923, S. 58 f.

20 George Cornwall Lewis, Remarks on the Use and Abuse of some political terms, London 1832, S. V, XX und VI.

21 Ebd., S. XX. 
schaftlichen Parteienkampfs eintrat",22 und Alfred Rutenberg beklagte 1842 die „Sprachmengerei und Begriffsverwirrung ... in Deutschland... gerade auf dem Gebiete der Politik" ${ }^{23}$ In diesen Beobachtungen schlug sich weniger das vordergründige Fehlen einer verbindlichen Nomenklatur nieder, mit der sich auf dem politischen Massenmarkt des Vormärz politische Gruppen oder bereits „Parteien“ hätten definieren lassen. Sprachmengerei und Begriffsverwirrung konturierten vielmehr die Erfahrung eines fundamental neuen Stellenwerts und einer veränderten Wirkungsmacht von politisch-sozialer Sprache, in deren neuen Leitbegriffen sich veränderte Wahrnehmungsweisen und Handlungsmuster abbildeten. Bereits die Zeitgenossen bemühten sich um eine Erklärung dieses Phänomens und erkannten den wesentlichen Grund für die Sprachverwirrung in ganz Europa in der Veränderung des Verhältnisses zwischen überkommenen Deutungsmustern und neuen Ideeninhalten und der daraus resultierenden Fermentierung von ambivalenten Begriffsgehalten, in denen sich Vergangenheit und Gegenwart gleichsam ineinander verschränkten:

Or questa perniciosa confusione di lingue è quella, che da qualche tempo si è con sorpresa universale scoperta in quasi tutte le lingue dell'Europa. Egli è certo che le voci sono le medesime, ed è certo altresi che moltissime voci e vocaboli, e dei più importanti, non corrispondono piu a quelle idee che esprimevano per lo passato; anzi un grandissimo numero spiegano ora idee contradditorie, incerte, confuse, e stravolte di ciò che facevano in passato. ${ }^{24}$

Signifikant aus der konservativen Perspektive, welche die italienischen Autoren des Nuovo Vocabolario einnahmen, war vor allem die enorme Wirkungsmacht der politischen Sprache: Die scheinbare begriffliche Verschleierung ideologischer Ziele diente längst als Instrumentalisierung und Mobilisierung der Öffentlichkeit und war damit zu einem Machtfaktor geworden, von dem eine Instabilisierung des gesellschaftlichen Systems auszugehen schien:

Dietro a tal fatale confusione di voci e d'idee è venuto un universale sconvolgimento sociale. Molti popoli ingannati da falsi vocaboli, e mal intesi, hanno corso dietro a tutto ciò che in realtà detestavano, e trovarono Schiavitù, Oppressione, Angustie, e Miserie, dove credevano trovare il Porto della Libertà, del comando, e della Felicità. ${ }^{25}$

22 Carl von Rotteck, Demokratisches Prinzip, in: Ders. und Carl Theodor WelCKER (Hrsg.), Staats-Lexicon oder Encyclopädie der Staatswissenschaften, in Verbindung mit vielen der angesehensten Publicisten Deutschlands, Bd. 4, Altona 1837, S. 252-63, hier S. 252 f.

23 Adolf Rutenberg, Radical, Radicalismus, in: RotTeck und Welcker (Hrsg.), Bd. 13, 1842, S. 408-20, hier S. 408.

24 Nuovo Vocabolario Filosofico-Democratico indispensabile per chiunque brama intendere la nuova lingua rivoluzionaria. Terza edizione fatta su quella di Firenze del 1849. Riveduta e disposta per ordine alfabetico, Neapel 1850, S. 9. Die erste Ausgabe des Wörterbuchs erschien 1799 in zwei Bänden in Venedig und trug wesentlich zum Export des neuen politischen Wortschatzes der französischen Revolution in Italien bei. Eine zweite Ausgabe erschien 1849 in Florenz. Es ist signifikant, daß die konservativen Autoren das Wissen um die Begriffsdefinition des politischen Gegners als unerläßlich einschätzten, um ihm adäquat begegnen zu können.

25 Ebd., S. 9f. 
Indem Politik aufhörte, „eine Sache nur von Hof und Regierung, von ständischen und kirchlichen Institutionen zu sein, von denen die Bürger ausgeschlossen" 26 waren, übertrug sich das politisch-gesellschaftliche Emanzipationsstreben auch auf Begriffe und Diskurse. ${ }^{27}$ Die Herausgeber eines zeitgenössischen italienischen Dizionario Politico begründeten die Notwendigkeit ihres Werkes mit dem gegenüber dem Absolutismus der Vergangenheit veränderten Anspruch auf politische Partizipation, neue Aktionsformen, Institutionen sowie freien öffentlichen Diskurs. Der Anspruch, die Politik als Wissenschaft zu fassen, firmierte zugleich als Motiv für eine überparteiliche Bestimmung ihrer Begriffe:

La politica è la scienza di ben governare. Nelle monarchie assolute, egli basta che la conosca il principe e la conoscano i pochi ch'egli adopera a consigliarlo e a servirlo nelle cose di Stato ... Ma nelle monarchie costituzionali e nelle repubbliche democratiche, le assemblee deliberanti, le elezioni e la libertà della stampa chiamano ogni individuo a prender parte od almeno interesse ed amore alle faccende dello Stato ... Laonde la presente utilità ed opportunità di un Dizionario politico non richiede altre prove ... Chi conosce il valore delle voci di una scienza, già possiede buona parte di essa. Avverta però bene il lettore che questo è un Dizionario, e non un'Enciclopedia, nè tanto meno un Catechismo ad uso di una fazione. ${ }^{28}$

Während Carl von Rotteck und Alfred Rutenberg mit dem publizistischen Großprojekt des Staatslexikons ein bildungsbürgerliches Forum fortschrittlicher Deutungsmuster anbieten konnten, von dessen verbindlicher Aktualisierung sie selbstbewußt die Antwort auf Sprachmengerei und Begriffsverwirrung erwarteten, blieb zumal nach der Erfahrung der Revolution 1848/49 dem skeptischen Publizisten Wilhelm Heinrich Riehl im Rückblick auf die vermeintliche Verbindlichkeit der Begriffe nurmehr die Feststellung, daß „hinter der Verwirrung der Begriffe und Standpunkte ... eine tiefe Ironie" lauere, die sich im Bekenntnis niederschlug, "daß eben jene hergebrachten Parteigruppen bloße Schatten, todte Formeln geworden sind, die keine Macht mehr haben angesichts der Ereignisse".29

Vor diesem Hintergrund kam dem Verständnis für die Funktion politischsozialer Leitbegriffe und die verdichtete Repräsentation außersprachlicher Verschiebungen in den Veränderungen der Sprache selbst eine neue hermeneutische Dimension zu. Das „Auftauchen neuer Worte in der Sprache, ibr häufiger Gebrauch und die wechselnde Bedeutung, die ibnen durch den Stempel der

26 Thomas Nipperdey, Deutsche Geschichte 1800-1866. Bürgerwelt und starker Staat, 2. Aufl. München 1984, S. 286.

27 Vgl. Karl GrieWANK, Der neuzeitliche Revolutionsbegriff. Entstehung und Entwicklung. Aus dem Nachlaß hrsg. von INGEBORG HorN-STAIgER, Neudruck Frankfurt a. M. 1992 sowie ReInHART Koselleck, Revolution, in: BrunNER et al. (Hrsg.), Bd. 5, S. $653-788$.

28 Dizionario Politico nuovamente compilato. Ad uso della gioventù italiana, Turin 1849, o.S.

29 Wilhelm Heinrich Riehl, Die bürgerliche Gesellschaft, 3. Aufl. Stuttgart 1855, Neudruck Stuttgart 1861, S. 13. 
herrschenden Meinung aufgeprägt wird“, sei, so Wilhelm Schulz 1841, „ein nicht zu verachtender Zeiger an der Uhr der Zeit" ${ }^{30}$ Sprache als Faktor und Indikator für außersprachliche Umbruchserfahrungen wurde also bereits von den Zeitgenossen wahrgenommen und thematisiert. Politisch-soziale Leitbegriffe waren selbst Bestandteil der Brüche und Transformationen, indem sie als kausale Faktoren wirkten, und sie fungierten zugleich als empfindliche seismographische Indikatoren dieser krisenhaften Veränderungen. Sie begleiteten in ihrer historischen Genese und langfristigen semantischen Transformation seit dem Ausgang des 18. Jahrhunderts auf sprachlich-kommunikativer Ebene den komplexen und spannungsreichen Übergang von der altständischen Lebenswelt zur modernen Gesellschaft. ${ }^{31}$

\section{b) Liberalismus und Liberalismen:}

Vom retrospektiven Ideensingular zur historisch-semantischen Pluralisierung

Innerhalb des Spannungsfeldes zwischen persistenten Strukturen der altständischen Gesellschaft und der seit dem letzten Drittel des 18. Jahrhunderts einsetzenden politisch-konstitutionellen wie sozial-ökonomischen „Doppelrevolution" 32 kommt dem politisch-sozialen Grundbegriff Liberalismus eine zweifache historische Deutungsdimension zu, die zugleich auch Grundzüge der Erforschung des historischen Phänomens Liberalismus charakterisiert.

Zunächst steht Liberalismus für „einen der wichtigsten Traditionszusammenhänge, aus denen die moderne westliche Demokratie entstanden ist“ ${ }^{\text {“ }} 33$ Hier bezeichnet Liberalismus in klassisch-ideengeschichtlicher Perspektive eine fundamentale Traditionslinie Europas, ohne den die politisch-konstitutionelle Entstehungsgeschichte der Gegenwart nur unvollkommen verstanden werden kann. ${ }^{34}$ Dazu zählen sowohl die parlamentarische Demokratie als auch

30 Zitiert nach ReinHart Koselleck, ,Neuzeit'. Zur Semantik moderner Bewegungsbegriffe (1977), in: Ders., Vergangene Zukunft, S. 300-48, hier S. 300.

31 Vgl. Klaus EDER, Geschichte als Lernprozeß? Zur Pathogenese politischer Modernität in Deutschland, Frankfurt a. M. 1991, S. $123 \mathrm{ff}$.

32 Vgl. Eric J. Hobsbawm, The Age of Revolution. Europe 1789-1848 (1962), London 1988, S. 11 sowie Hans-Ulrich WeHler, Deutsche Gesellschaftsgeschichte, Bd. 2: Von der Reformära bis zur industriellen und politischen „Deutschen Doppelrevolution“ 1815-1845/49, 2. Aufl. München 1989, S. 3 f.

33 Volker Sellin, Liberalismus, in: Sowjetsystem und demokratische Gesellschaft, Bd. 4, Freiburg i.Br. 1971, Sp. 51-77, hier Sp. 51; vgl. ferner HeInRICH August WinKLER, Liberalismus: Zur historischen Bedeutung eines politischen Begriffs (1975), in: Ders., Liberalismus und Antiliberalismus. Studien zur politischen Sozialgeschichte des 19. und 20. Jahrhunderts, Göttingen 1979, S. 13-9.

34 Vgl. Guido De Ruggiero, Storia del liberalismo europeo (1925), Rom 1984; Ders., Geschichte des Liberalismus in Europa, München 1930, Neudruck Aalen 1964; Ders., Liberalism, in: International Encyclopedia of the Social Sciences, Bd. 9, New York 1957, S. 435-42; H. LASKI, The Rise of European Liberalism, London 1936; ANTHONY Arblaster, The Rise and Decline of Western Liberalism, Oxford 1984 sowie die Quellensammlungen E. K. BRAmsted und K. J. Melhuish (Hrsg.), Western Libera- 
der moderne gewaltenteilige Verfassungs- und Rechtsstaat westlichen Typs. Im Zentrum dieser ideengeschichtlichen Zielrichtung stehen langfristige Konzepte politischer Theoretiker wie Montesquieu, Locke und Rousseau sowie die mit den Daten 1776 und 1789 verbundene Umsetzung solcher Konzepte. Daraus ensteht in retrospektiver Sicht eine zugleich epochale wie universell bestimmbare Ideengröße, der sich ein scheinbar verbindlicher Kanon politischer, sozialer oder ökonomischer Wertvorstellungen zuordnen läßt. Daß dessen Beginn in jedem Falle vor die Epochenwende des Jahres 1789 fällt, läßt die Verwendung des Begriffes Liberalismus gerade aus historiographischer Sicht zum Teil ebenso unbegründet wie inflationär erscheinen. ${ }^{35}$

Vor dem Hintergrund einer solchen ideengeschichtlichen Kanonisierung werden dem Liberalismus grundlegende konstitutionelle und ökonomische Elemente der Modernisierung wie Parlament, Verfassung, Gewaltenteilung, Menschen- und Bürgerrechte, Gewerbefreiheit und Freihandel zugeordnet. Hier gerät die Geschichte des Liberalismus allzu leicht zu einer geradlinigen Vorgeschichte der Gegenwart, in der er als ideologischer Erfüllungsgehilfe der Moderne erscheint. Dies kann bis zu einer modellhaften Konstruktion einer ungebrochenen Erfolgsgeschichte des liberalen Ideenvorrats reichen, die zwar eindeutige Pioniere, Nachzügler und Verlierer produziert, aber angesichts der vermeintlich ungebrochenen positiven Kontinuitäten die bruchreiche Entwicklungsgeschichte politischer Emanzipation und Partizipation übersieht.

Zumal angesichts der prägenden Erfahrungen totalitärer Diktaturen und des Ost-West-Konflikts ließen sich solche Wertvorstellungen aus amerikanischer Sicht zur konsensualen Gegenkultur einer Liberal Tradition der USA ${ }^{36}$ oder aus europäischer Perspektive zu einem modellhaft-verbindlichen „liberalen System" verdichten, das Ernst Nolte programmatisch in Abgrenzung zu Bolschewismus und Faschismus und zugleich als historische und logische Voraussetzung des Totalitarismus bestimmt hat. ${ }^{37}$ Es ist kennzeichnend, daß diese Deu-

lism. A History in Documents from Locke to Croce, London 1978; LOTHAR GALL und RAINER KOCH (Hrsg.), Der europäische Liberalismus im 19. Jahrhundert. Texte zu seiner Entwicklung, 4 Bde., Frankfurt a.M. 1981 sowie [Pierre Manent (Hrsg.)] Les libéraux. Textes choisis et présentés par Pierre Manent, 2 Bde., Paris 1986.

35 Vgl. Uwe Wilhelm, Der deutsche Frühliberalismus. Von den Anfängen bis 1789, Frankfurt a.M. 1995 und zur Kritik die Rezension von REINHARD BLÄNKNER, in: JbLibF 8 (1996). S. 255-57, hier S. 256 f.

36 Vgl. Louis HarTz, The Liberal Tradition in America, San Diego 1955; Richard HofSTADTER, The American Political Tradition and the Men Who Made it (1948), New York 1973; Ders., The Progressive Historians. Turner, Beard, Parrington, Chicago 1968; HANS Vorländer, Hegemonialer Liberalismus: Politisches Denken und politische Kultur in den USA 1776-1920, Frankfurt a. M. 1997, S. 62 ff. sowie die Rezension von JÖRN LEONHARD in: JbLibF 10 (1998), S. 278-82; vgl. zur Frage des amerikanischen exceptionalism R. GREW, The comparative Weakness of American History, in: JIH 16 (1985/86), S. 87-101 sowie BRYON E. SHAFER (Hrsg.), Is America Different? A New Look at American Exceptionalism, Oxford 1991.

37 Vgl. ERnst Nolte, Die Krise des liberalen Systems und die faschistischen Bewegungen, München 1968, S. 13. 
tung methodisch die Form einer universalistischen „Ideologiegeschichte als historisch-philosophische Phänomenologie“ annahm, die der ideengeschichtlich grundierten „Hauptlinie des europäischen Geschichtsdenkens, von Montesquieu über Guizot und Tocqueville zu Max Weber“ folgte. ${ }^{38}$ In einer solchen Bestimmung hat das „liberale System“ nicht nur wesentlich zum Selbstverständnis der modernen westlichen Demokratien beigetragen, von ihm erwartete man nach den Umwälzungen von 1989/90 vielerorts auch eine Anziehungskraft als scheinbar universell übertragbares Modell. Die politisch-konstitutionelle „Heilsgeschichte“ des Liberalismus schien mit dem Zusammenbruch der Staaten des realexistierenden Sozialismus realpolitisch die „Richtigkeit“ seiner Prämissen erwiesen $\mathrm{zu}$ haben und sich dabei gleichsam totgesiegt $\mathrm{zu}$ haben. ${ }^{39}$

Neben diese klassisch ideengeschichtliche Sichtweise, die nicht von ihrer zuweilen zeitgebundenen, systemlegitimierenden Identitätsstiftung für die parlamentarische Demokratie zu trennen ist, tritt das ideologiekritische Verständnis von Liberalismus im Spannungsfeld von Programm und sozialer Praxis des europäischen Bürgertums. Dies lehnt sich an ideengeschichtliche Fragen an, transzendiert sie jedoch insofern, als einer nicht hinterfragten Erfolgsgeschichte von Aufklärung und Modernisierung der seit dem Ende des 18. Jahrhunderts aufbrechende gesellschaftliche Interessenpluralismus mit seinen inhärenten Konfliktpotentialen entgegengesetzt wird. Damit wird der Liberalismus aus der politiktheoretischen Schwebe oberhalb der gesellschaftlichen Ebene befreit und stärker aus seinen je spezifischen historischen Kontexten heraus verstanden. Diese Sichtweise leistet wesentliche Differenzierungen, indem sie zunächst ideologiekritisch nach den Wirkungsrichtungen von Ideen und Programmen einerseits und konkreten politisch-sozialen Interessenlagen andererseits fragt und darüber hinaus die universelle Ideengröße Liberalismus mit seiner realhistorischen Gestalt konfrontiert. In enger Anlehnung an diese Sichtweise läßt sich Liberalismus auf einer dritten Ebene schließlich „nicht nur als geistige, sondern auch als konkrete politisch-soziale Bewegung“ auffassen, ${ }^{40}$

38 ERnST NOLTE, Über den historischen Begriff des „Liberalen Systems“, in: HannsMartin-Schleyer-Stiftung (Hrsg.), Hans-Martin-Schleyer-Preis 1984 und 1985, Veröffentlichungen, Bd. 19, Köln 1985, S. 59; vgl. dazu HORST Möller, Ernst Nolte und das „Liberale System“, in: Thomas NipPerdey, Anselm Doering-ManTEuffel und Hans-Ulrich Thamer (Hrsg.), Weltbürgerkrieg der Ideologien. Antworten an Ernst Nolte. Festschrift zum 70. Geburtstag, Frankfurt a.M. 1993, S. 57-72, hier S. 62 und 71.

39 Vgl. Hans Vorländer, What's liberal? Der Liberalismus zwischen Triumph und Erschöpfung, in: APuZ 10 (3. März 1995), S. 29-38, hier S. 29; DERS., Hat sich der Liberalismus totgesiegt? Deutungen seines historischen Niedergangs, in: DeRs. (Hrsg.), Verfall oder Renaissance des Liberalismus? Beiträge zum deutschen und internationalen Liberalismus, München 1987, S. 9-34 sowie DERS., Der ambivalente Liberalismus. Oder: Was hält die liberale Demokratie zusammen?, in: ZfP 42 (1995), S. 250-67.

40 Lothar Gall, Einleitung, in: Ders. (Hrsg.), Liberalismus, 3. Aufl. Königstein/Taunus 1985, S. 9-19, hier S. 17. 
als Verfassungs-, soziale Protest- oder allgemeine Oppositionsbewegung mit heterogenen Zielen, Strategien und Trägerschichten.

Gemeinsam ist allen Sichtweisen die zumeist retrospektive Verwendung des Liberalismus-Begriffes und die damit einhergehende, häufig implizite oder explizit formulierte Unsicherheit bei der Verwendung des Etiketts, seine Vagheit und Schemenhaftigkeit, seine oszillierende Bedeutungsvielfalt und die aus ihr erwachsende Schwierigkeit, den Begriff historisch präzise einzusetzen. Der Grund für das Unbehagen vieler Historiker ist dabei nur zu offensichtlich: Die ex-post Perspektive, in der die heutige Definition dessen, was unter Liberalismus zu verstehen ist, dominiert - auch wenn gerade diese Definition bereits wiederum Ergebnis historischer Entwicklungen ist -, kollidiert in jeder historischen Interpretation mit der konkreten ex-eventu Perspektive der Zeitgenossen. Aus der Konfrontation zwischen vergangener Deutung und Bedeutung einerseits und gegenwärtiger Definition andererseits resultiert eine semantische Fermentierung, also eine Überlagerung von historischen und gegenwärtigen Bedeutungselementen, die den Begriff ebenso facettenreich wie unbestimmt und damit unbrauchbar zur trennscharfen historischen Analyse zu machen scheint.

Zumal in den Diskussionen um den frühen Liberalismus in Deutschland fließt häufig die positive umgangssprachliche Konnotierung des heutigen Begriffes im Sinne von „tolerant“ und „freiheitlich“ oder gar verfälschend in Anlehnung an „demokratisch“ ein. ${ }^{41}$ Die Ausblendung der zeitgenössischen Begriffsgeschichte führt dabei zu zwangsläufigen Verzerrungen und Mißdeutungen und insbesondere zu einer Aushöhlung der methodischen Schärfe des Liberalismus-Begriffes. ${ }^{42}$ Auch die in der Forschung zu konstatierende funk-

41 Vgl. Rudolf Vierhaus, Liberalismus, in: Brunner et al. (Hrsg.), Bd. 3, S. 741-85, hier S. $741 \mathrm{f}$. und 785.

42 Vgl. Christina von Hodenberg, Die Partei der Unparteiischen. Der Liberalismus der preußischen Richterschaft 1815-1848/49, Göttingen 1996, S. 334-6 sowie die Rezension von JÖRN LEONHARD in: JbLibF 9 (1997), S. 254-7. Wolfgang Siemanns Einordnung der gemäßigten Konstitutionalisten von 1848 als „Konservative“ macht das Bekenntnis zu uneingeschränkten Menschenrechten sowie zur ungeteilten Volkssouveränität zum Maßstab für die Berechtigung des Liberalismus-Begriffes; vgl. WolfRAm SiemanN, Die Frankfurter Nationalversammlung 1848/49 zwischen demokratischem Liberalismus und konservativer Reform. Die Bedeutung der Juristendominanz in den Verfassungsverhandlungen des Paulskirchenparlaments, Frankfurt a. M. 1976, S. $282 \mathrm{ff}$. Diese nur von einer äußersten radikal-demokratischen Minderheit der Frankfurter Nationalversammlung vertretene Position zum Kriterium zu erheben, hieße aber, den vormärzlichen Liberalismus auf eine Marginalie zu reduzieren. Vgl. zur Minderheitenposition der radikal-demokratischen Linken und ihren begrenzten Handlungsspielräumen in der Frankfurter Nationalversammlung JÖRN LEONHARD, Christian Kapp, in: Frank Engehausen und Armin Kohnle (Hrsg.), Gelehrte in der Revolution. Heidelberger Abgeordnete in der deutschen Nationalversammlung. Georg Gottfried Gervinus - Robert von Mohl - Gustav Höfken - Karl Mittermaier Karl Theodor Welcker - Karl Hagen - Christian Kapp, Ubstadt-Weiher 1998, S. 183-207. 
tionale Unterscheidung einzelner Liberalismen wie Beamtenliberalismus, Adelsliberalismus, Gutsbesitzerliberalismus oder Gemeindeliberalismus führt zu Verzerrungen, vereinigt sie doch, ungeachtet des zeitgenössischen politischen Diskurses und seiner semantischen Bestimmungen, denkbar unterschiedliche und nicht selten auch entgegengesetzte politisch-gesellschaftliche Phänomene unter dem Dach eines vagen Begriffes, der sich dem Verdacht der Beliebigkeit aussetzt, wenn er für die reformkonservativen Gutsbesitzer genauso wie für Teile des Adels oder zur Charakterisierung einer letztlich traditional-modernisierungsfeindlichen, genuin gemeindebürgerlichen Identität reklamiert wird. ${ }^{43}$ Nur das Kriterium der Oppositionshaltung reicht zur trennscharfen Bestimmung nicht aus, denn in dieser Perspektive müssen dann die Grenzen zwischen liberal und demokratisch bzw. radikal endgültig verwischen. ${ }^{44}$ Der Vieldeutigkeit des historischen Phänomens Liberalismus in seinen zeitgenössischen historisch-semantischen Entwicklungen nachzugehen, heißt von daher auch, den Unterschied zwischen dem aktuellen Deutungsmuster und dem zeitgebundenen Politikdiskurs der Vergangenheit stärker herauszustellen und damit den Begriff näher an seine inhärente Zeitlichkeit zu führen.

Aus der Differenz zwischen einer ex-eventu und einer ex-post Semantik von Liberalismus, läßt sich mithin eine weitere Dimension ableiten, die der historisch-semantischen Genese und Transformation von Liberalismus in seinen jeweils spezifischen, historisch faßbaren Kontexten. Sie liegt der vorliegenden Studie zugrunde und bedarf vor ihrer konkreten methodischen Konzeptionalisierung der Abgrenzung gegenüber den bisher vorgestellten Verständnisweisen von Liberalismus.

Als zeitgenössisches Deutungsmuster fokussierte der Begriff Liberalismus jene grundlegenden Strukturwandlungen, Umbrüche und Krisenerfahrungen, die den Prozeß industriell-gewerblichen Wachstums, sozialen und kulturellen Wandels und politischer Partizipation kennzeichneten. Damit war der Liberalismus Teil des nuancenreichen Spannungsfeldes zwischen traditionaler Beharrung und langfristiger Transformation, das seit dem Ausgang der politischkonstitutionellen und sozioökonomischen Doppelrevolution im letzten Drittel des 18. Jahrhunderts die widerstreitenden Zeitkräfte, Konfliktpotentiale und Deutungsschemata zwischen Ideenmacht und Interessenrealität kennzeich-

43 Vgl. Hodenberg, Partei, S. 335 f.; Herbert Obenaus, Gutsbesitzerliberalismus. Zur regionalen Sonderentwicklung der liberalen Partei in Ost- und Westpreußen während des Vormärz, in: GG 14 (1988), S. 304-28, hier S. 328; Christof Dipper, Adelsliberalismus in Deutschland, in: DieTER LANGEwIESCHe (Hrsg.), Liberalismus im 19. Jahrhundert. Deutschland im europäischen Vergleich, Göttingen 1988, S. 172-92, hier S. $185 \mathrm{ff}$. sowie Paul Nolte, Gemeindebürgertum und Liberalismus in Baden 1800-1850. Tradition - Radikalismus - Republik, Göttingen 1994, S. 16 und 428 f. sowie Ders., Gemeindeliberalismus. Zur lokalen Entstehung und sozialen Verankerung der liberalen Partei in Baden 1831-1855, in: HZ 252 (1991), S. 57-93.

44 Vgl. Nolte, Gemeindebürgertum, S. $424 \mathrm{f}$. 
nete. ${ }^{45}$ Diese Sicht stellt die klassische ideengeschichtliche Perspektive des historischen Phänomens Liberalismus in Frage: Es geht nicht um den retrospektiven Erweis universeller Postulate und Institutionen, die scheinbar losgelöst vom konkreten politischen Diskurs der Vergangenheit existieren. Als postrevolutionäres Deutungsmuster von historischer Erfahrung und politisch-sozialer Zukunftserwartung markierte der Begriff Liberalismus den Schwellen- und Krisencharakter der Epoche. Dabei lieferte er keine ideengeschichtlich sanktionierte verbindliche Interpretation der Ereignisse und Ergebnisse von 1789, sondern stellte eine zumindest temporär formative semantische Reflexionsfläche dar, auf der sich Zeiterfahrungen und Zukunftserwartungen in ihren Ambivalenzen, Überlagerungen und Ungleichzeitigkeiten und damit moderne Ideologien als neue Faktoren der politischen Kultur abbildeten. ${ }^{46}$ Erst in der ex-post Perspektive und in historischer Kenntnis der Evolution einer politisch-sozialen Moderne ließ sich dann eine ideengeschichtliche Kontinuität des historischen Phänomens Liberalismus im Sinne einer Leitidee Europas im 19. Jahrhundert formulieren. Eine derart retrospektive Sicht vermittelte dem Begriff mehr Klarheit und Verbindlichkeit, als ihm zumal in seiner semantischen Inkubationszeit jemals zukommen konnte. Dies ebnete mithin die komplexe Genese von neuen zeitgenössischen Bedeutungsinhalten und ihre Fermentierung mit alten Elementen ein.

Daraus ergibt sich die grundlegende Prämisse der vorliegenden Studie: Indem nicht von einer retrospektiven Dimension von Liberalismus ausgegangen wird, sondern von der historisch-semantischen Pluralisierung des Begriffes in zeitlich-diachroner und zugleich komparativer Hinsicht, wird dem historischen Deutungsmuster nicht a priori ein statischer Rahmen von Inhalten, Werten und Zielen unterlegt. Vielmehr geht es um die Frage, wie sich in Liberalismus als einem formativen semantischen Grund politische und soziale Brüche und Konflikte, sozioökonomische Krisen und der komplexe Prozeß von organisatorischer und programmatischer Verfestigung einer politischen Freiheitsund Emanzipationsbewegung abzeichneten und welche Rückschlüsse dies im weiteren Sinne auf den Stellenwert spezifischer Erfahrungshintergründe und Erwartungshorizonte in verschiedenen Kontexten zuläßt. Eine solche semantische Analyse „epochaler, zeitgebundener ,Liberalismen“" 47 markiert den Spannungsbogen zwischen der ex-post Bedeutung des europäischen Liberalismus als ideengeschichtlicher Präfigurierung der Moderne und dem differenzierten

45 Vgl. M. Rainer Lepsius, Soziologische Theoreme über die Sozialstruktur der „Moderne“ und die „Modernisierung“, in: ReINHART KosEllecK (Hrsg.), Studien zum Beginn der modernen Welt, Stuttgart 1977, S. 10-29, hier S. 10 sowie REINHARD BENDIX, Modernisierung in internationaler Perspektive, in: WolfGANG ZAPF (Hrsg.), Theorien des sozialen Wandels, 4. Aufl. Königstein/Taunus 1979, S. 505-12.

46 Vgl. Clifford GeerTz, Ideology as a Cultural System, in: DerS., The Interpretation of Cultures: Selected Essays, New York 1973, S. 193-233, hier S. 218 f.

47 Dieter Langewiesche, Europa zwischen Restauration und Revolution 1815-1849, 2. Aufl. München 1989, S. 135. 
Spektrum je spezifischer Erscheinungsformen, der ex-eventu-Ebene vergangener Bedeutungsgehalte von Liberalismus.

Clifford Geertz beschreibt Ideologien als „maps of problematic social reality and matrices for the creation of collective conscience“.48 Diese Metapher läßt sich im weiteren Sinne auch auf die historische Semantik anwenden und dabei noch weiter differenzieren: Ideologische historische Grundbegriffe bilden als Deutungsmuster eine historische Struktur je nach Standpunkt und Interesse jeweils verschieden ab. Solche Landkarten können politische und soziale Erfahrungen und Erwartungen von Vergangenheit immer nur abstrakt und unvollständig abbilden. ${ }^{49}$ Indem die Begriffe jeweils spezifische Bedeutungsaspekte fokussieren, beeinflussen sie zugleich die Wahrnehmung der Ideologie auf dem Wege der Perzeption der Landkarte durch ihre Benutzer. Sie prägen auf der hermeneutischen Ebene die Sicht auf vergangene Umwelt: „Moreover, formulation of ideologies, like the making of maps, presupposes a certain estrangement between people and their environment." Vor allem aber steht hinter dieser Perspektive die Erfahrung von historischem Wandel: „For the cartographer, this estrangement comes from movement, for the ideologist from change. One does not draw maps of one's village or create an ideological picture of a static society. Maps imply travel, ideologies historical transformation. “50

Den Wandel historisch-semantischer Bedeutungsmuster läßt nur eine Aufeinanderfolge vieler Momentaufnahmen erkennbar werden. Die Vielgestaltigkeit der Begriffsgeschichten von Liberalismus, also die synchrone Betrachtung der semantischen „Landkarten“ unterschiedlicher politisch-sozialer „Landschaften“ einerseits und die längsschnitthafte Nachzeichnung der Veränderung von Bedeutungslinien andererseits, wird hier deutlich. Die Faszination einer historisch-semantischen „Landkarte“ erschließt sich vor diesem Hintergrund aus der Verdoppelung des Beobachtungspunktes, aus dem synchron-länderübergreifenden Vergleich politisch-sozialer Vokabulare und dem diachronen Längsschnitt.

Der ideologische Charakter der zeitgenössischen „Ismen“ reflektierte zugleich ein grundlegend neues Verhältnis zur Geschichte. Die Auflösung der universellen Einheit in der alteuropäischen Staats- und Gesellschaftsverfassung, der civitas sive societas civilis, durch die europäische Aufklärung auf theoretischer und durch die Amerikanische und Französische Revolution auf der politisch-konstitutionellen Ebene und schließlich durch den evolutionären wirtschaftlichen und sozialen Übergang zum bürgerlich konnotierten „System der Bedürnisse" (Hegel) begründete eine neue Qualität in der kritischen Diskussion um die gewünschte neue Ordnung. Dies ließ die Zeitgenossen vor dem

48 GeERTZ, S. 220.

49 Vgl. zur Definition von Grundbegriff Rolf P. HorstmanN, Kriterien für Grundbegriffe. Anmerkungen zu einer Diskussion, in: Reinhart Koselleck (Hrsg.), Historische Semantik und Begriffsgeschichte, Stuttgart 1979, S. 37-42.

50 James J. Sheehan, German History 1770-1866, Oxford 1989, S. 589 f. 
Hintergrund der Traditionsbrüche die erlebte Geschichte jenseits der hegelianischen Interpretation der Geschichte als „Fortschritt im Bewußtsein der Freibeit" (Hegel) mit dem damit einhergehenden Vernunftsoptimismus und der Annahme eines aufgeklärten Entwicklungskontinuums als diskontinuierlichen Prozeß erfahren. Diese Deutung enthielt zugleich eine Historisierung des politischen Denkens, sei es durch Begründung einer organischen Tradition zur Rekonstruktion der historischen Kontinuität wie im Konservatismus, in der $\mathrm{Zu}$ ordnung einer innerweltlichen Zukunftsprojektion für die eigene Gegenwart im Liberalismus, oder im Versuch des Nationalismus, beide Ebenen miteinander zu verbinden. 51

Wohl kaum ein anderes politisches Etikett ist im Verlaufe seiner langen Wirkungsgeschichte mit so zahllosen Bestimmungsversuchen, Bilanzierungen und mehr oder weniger vorzeitigen Nachrufen versehen worden wie Liberalismus. Zumal im Rückblick auf die deutsche Entwicklung erscheint diese inflationäre Definitionsgeschichte an eine hermeneutische Barriere zu stoßen, die dem Historiker den analytischen Zugriff auf das historische Phänomen verweigert, mindestens aber erheblich erschwert. ${ }^{52}$ Die skeptischen Einschätzungen englischer Historiker weisen in dieselbe Richtung: Mit der Abwendung von der Whig interpretation of history, einer eindimensionalen politisch-konstitutionellen „Heilsgeschichte“ des vorgeblichen englischen Modells, ${ }^{53}$ und ihrer kritischen Historisierung als zeitgebundener Mythos setzt sich auch hier zunehmend die Erkenntnis von der Vielgestaltigkeit des liberal movement in Großbritannien durch. Die vermeintlich modellhafte Erfolgsgeschichte evolutionärer, gewaltfreier Reformierung innerhalb des bestehenden Systems und die Parallelisierung von ökonomischer und politisch-konstitutioneller Modernisierung als Grundlage für innenpolitische Stabilisierung und außenpolitische Expansion, für die die Etikettierung liberalism eine geradezu identifikatorische Funktion anzunehmen schien, ${ }^{54}$ gerät unter diesen Umständen in das Schuß-

51 Vgl. Karl-Georg Faber, Politisches Denken in der Restaurationszeit, in: Helmut Berding und Hans-Peter Ullmann (Hrsg.), Deutschland zwischen Revolution und Restauration, Königstein/Taunus 1981, S. 258-78, hier S. $258 \mathrm{f}$. und WerNER CONZE, Das Spannungsfeld von Staat und Gesellschaft im deutschen Vormärz, in: Ders. (Hrsg.), Staat und Gesellschaft im deutschen Vormärz, 1815-1848, 3. Aufl. Stuttgart 1978, S. 207-69.

52 Wolfgang Kaschuba, Zwischen Deutscher Nation und Deutscher Provinz. Politische Horizonte und soziale Milieus im frühen Liberalismus, in: LANGEWIESCHE (Hrsg.), S. 83-108, hier S. 83

53 Vgl. H. ButTERFIELD, The Whig Interpretation of History (1931), Neudruck London 1965 sowie kritisch J. HART, Nineteenth-Century Social Reform: a Tory Interpretation of History, in: PP 31 (1965), S. 37-51, hier S. 39.

54 Vgl. das klassische Beispiel J. SALWYN SCHAPIRO, Liberalism and the Challenge of Fascism. Social Forces in England and France (1815-1870), New York 1949, S. 1 und zur singulären Stellung Englands ebd., S. 21; vgl. ferner GEORGE L. CHERrY, Early English Liberalism. Its Emergence through Parliamentary Action 1660-1702, New York 1962, passim. 
feld der Kritik. ${ }^{55}$ Die Auflösung des historiographischen Deutungsmusters Whig interpretation zeitigt zugleich ähnliche Konturverwischungen des Phänomens liberalism wie in der deutschen Forschung. ${ }^{56}$ Die Abkehr von tradierten Deutungsschemata geht dabei einher mit einem wachsenden Unbehagen am Begriff und einem zunehmenden Mißtrauen gegenüber seiner analytischen Relevanz. ${ }^{57}$

Die historische Tiefenwirkung eines historischen Leitbegriffs beruht auf der komplexen Anreicherung von Neufassungen nach Brüchen und Krisen, auf der dialektischen Aufhebung und Fermentierung ganz ungleichzeitiger historischer Erfahrungs- und Erwartungskondensate in einem umstrittenen Deutungsmuster, 58 für den ab einer bestimmten historisch-semantischen Schwelle seiner Wirkungsgeschichte Friedrich Nietzsches Fundamentalsatz gilt: „alle Begriffe, in denen sich ein ganzer Prozess semiotisch zusammenfasst, entziehen sich der Definition; definir [sic!] bar ist nur Das, was keine Geschichte hat ".59 Der Begriff Liberalismus reflektiert diese Notwendigkeit semantischer Neubestimmung besonders deutlich: Das enorme Reservoir an Bedeutungselementen und Interpretationen verweist auf einen weiten historischen Spannungsbogen. In der Auseinandersetzung mit dem Begriff steckt insofern direkt oder indirekt immer auch die Frage nach dem Umgang mit seiner historischen Tiefenwirkung und dessen Relevanz für die eigene Gegenwart. Dabei kann das Bedürfnis entstehen, sich von der historischen „Überladung“ eines Begriffes frei zu machen, wenn er für eine politisch-ideologische Aktualisierung unzeitgemäß erscheint. Zumal für den deutschen Liberalismus-Begriff schien dies nach 1945 zuzutreffen: Die Namenswahl „Freie Demokratische Partei“ drückte, so Theo-

55 Vgl. Peter Mandler, Aristocratic Government in the Age of Reform. Whigs and Liberals 1830-1852, Oxford 1990, S. 1; IAN D. C. NewBould, Whiggery and Reform, 1830-1841. The Politics of Government, London 1990 sowie JOHN W. BURROW, Whigs and Liberals: Continuity and Change in English Political Thought, Oxford 1988, passim.

56 Vgl. W. H. Greenleaf, The British Political Tradition, Bd. 2: The Ideological Heritage, London 1983, S. 19 ff.; Alan Bullock und Maurice Shock, Englands liberale Tradition, in: Gall (Hrsg.), Liberalismus, S. 254-82; J. C. D. Clark, English Society 1688-1832. Ideology, social structure and political practice during the ancien régime, Cambridge 1985, S. 348 sowie JOHN BREUILLY, Labour and Liberalism in NineteenthCentury Europe. Essays in Comparative History, Manchester 1992, S. $267 \mathrm{f}$.

57 Vgl. Richard Bellamy, Introduction, in: Ders. (Hrsg.), Victorian Liberalism: Nineteenth-Century Political Thought and Practice, London 1990, S. 1-14, hier S. 1.

58 Vgl. für konservativ WALTER DIRKS, Konservativ und katholisch. Über den fahrlässigen Umgang mit Wörtern, in: Frankfurter Hefte 28 (1973), S. 120-3 sowie HERMANN VON DER DUNK, Zum Problem der Begriffe „konservativ“ und „progressiv“, in: Ralph Melville, Claus Scharf, Martin Vogt und Ulrich Wengenroth (Hrsg.), Deutschland und Europa in der Neuzeit. Festschrift für Karl Otmar Freiherr von Aretin zum 65. Geburtstag, Bd. 1, Stuttgart 1988, S. 3-26.

59 Friedrich Nietzsche, Zur Genealogie der Moral, Zweite Abhandlung: „Schuld“, „schlechtes Gewissen“, Verwandtes, Kapitel 13, in: DERS., Sämtliche Werke. Kritische Studienausgabe in 15 Bdn., hier Bd. 5, hrsg. von Giorgio Colli und MAZZINO MoNTINARI (1967), 3. Aufl. München 1993, S. 317. 
dor Heuss in seiner programmatischen Rede auf dem Gründungstreffen der Liberalen im Dezember 1948, nicht zuletzt die Zweifel der Parteimitglieder aus,

ob das Wort, Liberalismus', in dem ein Stück geschichtlichen Erlebens des 19. Jabrbunderts steckt, noch und wieder fruchtbar werden kann, oder ob es diese Gegenwart vielleicht belastet mit der Erinnerung an die Zeit, da ein Teil der, Liberalen'im Kampf gegen Kirchlichkeit sich übte, oder an die Epoche, da von dem, Manchestertum'kein Weg zu einer eigenmächtigen Sozialpolitik fübrte. ${ }^{60}$

Aus ganz anderer Perspektive hielt auch Thomas Mann 1950 die Selbstbezeichnung Liberaler im Angesicht der postfaschistischen Erfahrung für überholt. Worum es gehe, sei eine Neudefinition der demokratischen Postulate Freiheit und Gleichheit, die vor allem die Gleichheit als „die herrschende Idee der Epoche“ anzuerkennen habe. Der bürgerlich-liberalen Emanzipation des 19. Jahrhunderts müsse eine soziale jenseits des Totalitarismus folgen, auf die das überkommene Etikett liberal nicht mehr zu passen schien:

Die bürgerliche Revolution muß sich ins Ökonomische fortentwickeln, die liberale Demokratie zur sozialen werden. Jeder weiß das im Grunde, und wenn Goethe gegen das Ende seines Lebens erklärte, jeder vernünftige Mensch sei doch ein gemäßigter Liberaler, so beißt das Wort heute: Jeder vernünftige Mensch ist ein gemäßigter Sozialist. Nun weiß ich wobl, daß gerade der, gemäßigte;, der humanistisch gezügelte, der liberale Sozialismus, also die Sozialdemokratie, den totalitären Kommunismus am allerbittersten haßt. Das ist in Amerika nicht anders, als es in Deutschland war. ${ }^{61}$

\section{Wissenschaftshistorische Verortung und forschungs- systematische Bezüge}

Der methodische Ausgangspunkt dieser Studie ergibt sich aus der Kopplung von vergleichenden Ansätzen innerhalb der Bürgertums- und Liberalismusforschung mit solchen, die sich auf die in Deutschland früher und intensiver etablierte Begriffsgeschichte zurückführen lassen. Die Grundlinien dieser Forschungsrichtungen sollen im folgenden im Hinblick auf das Programm dieser Untersuchung skiziert werden.

60 Rede auf dem Gründungstreffen der F.D.P. am 10./11. Dezember 1948, zitiert in Bundesvorstand der Freien Demokratischen Partei (Hrsg.), Zeugnisse liberaler Politik. 25 Jahre F.D.P., Bonn 1973, S. 13 ff.; vgl. HeINO KAACK, Zur Geschichte und Programmatik der Freien Demokratischen Partei. Grundriß und Materialien, 3. Aufl. Meisenheim/Glan 1979, S. 12.

61 Thomas Mann, Meine Zeit (1950), in: Ders., Gesammelte Werke in 13 Bdn., hier Bd. 11: Reden und Aufsätze, Teil 3, Frankfurt a. M. 1990, S. 302-24, hier S. 322 f. 
a) Von einzelstaatlicher Liberalismusforschung zu komparativen Untersuchungsansätzen:

Deutschland im europäischen Vergleich

Die oben beschriebenen Dimensionen des historischen Phänomens Liberalismus - von der ideengeschichtlichen über die ideologiekritisch-sozialhistorische bis zur vergleichenden Perspektive - charakterisieren zutreffend die Innovationen und methodischen Perspektivenwechsel in der Liberalismus-Forschung der vergangenen Jahrzehnte. ${ }^{62}$

Die frühe wissenschaftliche Auseinandersetzungen in Deutschland blieb zunächst noch einer primär ideengeschichtlichen Fragestellung verbunden, die jedoch zugleich von der Frage nach den Gründen für das vermeintliche Versagen und Scheitern wenn nicht gar die „Tragödie“ des deutschen Liberalismus angesichts des Nationalsozialismus bestimmt wurde und sich entsprechend früh auf spezifische "Strukturprobleme“ des Liberalismus in Deutschland konzentrierte. ${ }^{63}$ Etwa seit Mitte der 1970er Jahre wandelte sich dies unter dem Eindruck einer im weitesten Sinne ideologiekritischen Frage nach dem Charakter der frühen liberalen Bewegung im deutschen Vormärz. Der erstmals von Lothar Gall in dieser Zuspitzung thematisierte Zusammenhang von „Liberalismus und bürgerliche[r] Gesellschaft" 64 in all seinen komplexen Schattierungen

62 Vgl. die Gesamtdarstellungen Dieter Langewiesche, Liberalismus in Deutschland, Frankfurt a.M. 1988 sowie James J. SheeHAN, Der deutsche Liberalismus. Von den Anfängen im 18. Jahrhundert bis zum Ersten Weltkrieg 1770-1914 (englisch 1978), München 1983; vgl. zur Forschungsentwicklung zuletzt die Beiträge von ELISABETH Fehrenbach, Dieter Langewiesche und Helmut Seier in: Lothar Gall (Hrsg.), Bürgertum und bürgerlich-liberale Bewegung in Mitteleuropa seit dem 18. Jahrhundert, München 1997.

63 Vgl. zu älteren Liberalismus-Definitionen Wolfgang J. Mommsen, Liberalismus und liberale Idee in Geschichte und Gegenwart, in: KurT SONTHEIMER (Hrsg.), Möglichkeiten und Grenzen liberaler Politik, Düsseldorf 1975, S. 11-45, hier S. 13; SELLIN, Liberalismus, Sp. 51; THeOdor SCHIEDER, Die Krise des bürgerlichen Liberalismus. Ein Beitrag zum Verhältnis von politischer und gesellschaftlicher Verfassung, in: Ders., Staat und Gesellschaft im Wandel unserer Zeit. Studien zur Geschichte des 19. und 20. Jahrhunderts, 3. Aufl. München 1976, S. 58-88, hier S. 59 sowie Ralf DaHRENDORF, Die Chancen der Krise, Stuttgart 1983, S. 37; vgl. ferner zur älteren Literatur FrIEDRICH SEll, Die Tragödie des deutschen Liberalismus (1953), Neudruck 2. Aufl. Baden-Baden 1981; TheOdor SCHIEDER, Der Liberalismus und die Strukturwandlungen der modernen Gesellschaft vom 19. zum 20. Jahrhundert, in: Relazioni del X. Congresso Internazionale di Scienze Storiche V, Florenz 1955, S. 145-72; WALTER Bussmann, Zur Geschichte des deutschen Liberalismus im 19. Jahrhundert, in: HZ 186 (1958), S. 527-57; KARL-GEORG FABER, Strukturprobleme des deutschen Liberalismus im 19. Jahrhundert, in: Der Staat 14 (1975), S. 201-27; HeINRICH AugusT WinkLer, Zum Dilemma des deutschen Liberalismus im 19. Jahrhundert, in: Ders., Liberalismus, S. 20-3 sowie James J. SHeEHAN, Liberalism and Society in Germany, 1815-1848, in: JMH 45 (1973), S. 583-604.

64 Lothar Gall, Liberalismus und „bürgerliche Gesellschaft“. Zu Charakter und Entwicklung der liberalen Bewegung in Deutschland, in: HZ 220 (1975), S. 324-56, wieder in DERs., Bürgertum, liberale Bewegung und Nation. Ausgewählte Aufsätze, hrsg. 
ließ ein erheblich differenzierteres Bild entstehen als es die Beschränkung auf rein programmatische Positionen hatte hervorbringen können. Die kontroverse Diskussion um den Charakter des frühen Liberalismus, die sich an den beiden Polen „klassenübergreifend-traditional oder klassengebunden-modernisierend" festmachen ließ,65 verwies vor allem auf die Notwendigkeit, die traditionelle Analyse politischer Theoriebildung des Liberalismus zugunsten einer sozialhistorischen Konturierung der liberalen Bewegung und überhaupt der Anfänge des Parteiwesens vor $1848 \mathrm{zu}$ transzendieren. ${ }^{66}$ Die inzwischen breit entwickelte Forschung etwa zum vormärzlichen Vereinswesen hat zunächst den insgesamt sozial-integrierenden Charakter der frühliberalen Bewegung in Deutschland erwiesen und damit die einseitige Parallelisierung von frühem Liberalismus und staatsbürgerlicher Honoratiorengesellschaft erheblich relativiert, so sehr deren politische Ziele und kulturelle Werte auch weithin den Kanon liberaler Selbstvergewisserung dominierten. Verknüpft man diese Erkenntnisse mit den inzwischen herausgearbeiteten traditional-vorkapitalistischen Elementen des staatsbürgerlichen Mittelstandsideals, so läßt sich eine ideologisch keimfreie Verortung zumindest der frühen liberalen Bewegung als kapitalistische Bourgeoisie längst nicht mehr aufrechterhalten. ${ }^{67}$ Die aus der

von Dieter Hein, Andreas Schulz und Eckhardt Treichel, München 1996, S. 99-125; vgl. dazu die Rezension von JÖRN LEONHARD in: JbLibF 11 (1999), S. 288-91.

65 CORNelia Foerster, Sozialstruktur und Organisationsformen des deutschen Preßund Vaterlandsvereins von 1832/33, in: WOLFGANG SCHIEDER (Hrsg.), Liberalismus in der Gesellschaft des deutschen Vormärz, Göttingen 1983, S. 147-66, hier S. 149; vgl. zur Kontroverse Wolfgang J. Mommsen, Der deutsche Liberalismus zwischen „klassenloser Bürgergesellschaft“ und „organisiertem Kapitalismus“. $\mathrm{Zu}$ einigen neuen Liberalismusinterpretationen, in: GG 4 (1978), S. 77-90 sowie LOTHAR GALL, Der deutsche Liberalismus zwischen Revolution und Reichsgründung, in: HZ 228 (1979), S. 98-108.

66 Vgl. Gerhard A. RitTer, Die deutschen Parteien 1830-1914, Göttingen 1985, S. 10-4; Hans Fenske, Deutsche Parteiengeschichte. Von den Anfängen bis zur Gegenwart, Paderborn 1994, S. 20 ff. und 40 ff.; HARTWIG BRANDT, Frühkonstitutionalismus und Parteienbildung in Deutschland, in: Adolf M. BiRke und Magnus BReCHTKEN (Hrsg.), Politikverdrossenheit. Der Parteienstaat in der historischen und gegenwärtigen Diskussion. Ein deutsch-britischer Vergleich, München 1995, S. 29-40 sowie Wolfgang Schieder, Probleme einer Sozialgeschichte des frühen Liberalismus in Deutschland, in: DERs. (Hrsg.), S. 9-21, hier S. 12-7.

67 Vgl. exemplarisch WOLFGANG SCHIEDER, Der rheinpfälzische Liberalismus von 1832 als politische Protestbewegung, in: Helmut BERDiNG (Hrsg.), Vom Staat des Ancien régime zum modernen Parteistaat. Festschrift für Theodor Schieder, München 1978, S. 169-95; Cornelia Foerster, Der Preß- und Vaterlandsverein von 1832/33. Sozialstruktur und Organisationsformen der bürgerlichen Bewegung in der Zeit des Hambacher Festes, Trier 1982; RAINER KOCH, „Industriesystem“ oder „bürgerliche Gesellschaft." Der frühe deutsche Liberalismus und das Laissez-faire-Prinzip, in: GWU 29 (1978), S. 605-28; Helmut Sedatis, Liberalismus und Handwerk in Südwestdeutschland. Wirtschafts- und Gesellschaftskonzeptionen des Liberalismus und die Krise des Handwerks im 19. Jahrhundert, Stuttgart 1979, S. 77; Paul Nolte, Der Südwestdeutsche Frühliberalismus in der Kontinuität der frühen Neuzeit, in: GWU 
differenzierten Sicht der liberalen Bewegung im deutschen Vormärz gewonnenen Erkenntnisse, die das weite Spektrum von Bewegungsprofilen, Aktionsräumen, Formationsfaktoren und liberalen Milieus etwa in der Bedeutung der süddeutschen Landtage, der staatlichen Bürokratien, in der Kryptopolitisierung der Öffentlichkeit wie auch im komplexen Verhältnis von Konfession und Liberalismus dokumentieren, haben zugleich weitere Forschungsfelder zukünftiger Liberalismus-Forschung umrissen. Die Ziellinie solcher Differenzbestimmungen markiert die Frage nach einer „Typologie von historischen Erscheinungsformen des Liberalismus“, die nur durch „epochenspezifische Liberalismusdefinitionen“ zu erarbeiten ist, „um die ,chamäleonartigen Allgemeinvorstellungen ' durch empirisch gesicherte, historisch abgrenzbare Bestimmungen zeittypischer ,Liberalismen“ zu ersetzen“. 68

Unstrittig lassen sich auf mindestens drei unterschiedlichen Ebenen weiterführende Differenzbestimmungen des historischen Phänomens Liberalismus erkennen. Dies gilt im Kontext einer stärker kulturgeschichtlichen Öffnung etablierter sozialhistorischer Ansätze für bisher unterbewertete soziokulturelle Formationsfaktoren des liberalen Milieus wie die Rolle der Frau, die Bedeutung der Konfession sowie der liberalen Nationalidee und Nationalbewegung. ${ }^{69}$ Es gilt weiterhin auf einer zweiten Ebene für die von Dieter Langewiesche im selben Zusammenhang angemahnte „,Regionalisierung' der Untersuchungsfelder" ${ }^{70}$ Die Untersuchung des Liberalismus in unterschiedlichen Regionen und im lokalen Kontext hat das Wissen um die Handlungsspielräume der deutschen Liberalen unterhalb der nationalen Ebene erheblich erweitert und damit zumal dem historischen Gewicht partikularer und damit je spezifi-

43 (1992), S. 743-56 sowie Thomas Zunhammer, Zwischen Adel und Pöbel. Bürgertum und Mittelstandsideal im Staatslexikon von Karl v. Rotteck und Karl Theodor Welcker. Ein Beitrag zur Theorie des Liberalismus im Vormärz, Baden-Baden 1995.

68 DieTER LANGEWIESCHE, Gesellschafts- und verfassungspolitische Handlungsbedingungen und Zielvorstellungen europäischer Liberaler in der Revolution von 1848, in: W. SCHIEder (Hrsg.), S. 341-62, hier S. 342 f.; vgl. ferner Faber, Strukturprobleme, S. $210 \mathrm{ff}$. sowie HANS ROSENBERG, Theologischer Rationalismus und vormärzlicher Vulgärliberalismus, in: DeRs., Politische Denkströmungen im deutschen Vormärz, Göttingen 1972, S. 18-50, hier S. 29.

69 Vgl. Sylvia PaletscheK, Frauen und Dissens. Frauen im Deutschkatholizismus und in den freien Gemeinden 1841-1852, Göttingen 1990; UlRICH ENGELHARDT, „... geistig in Fesseln“? Zur normativen Plazierung der Frau als „Kulturträgerin“ in der bürgerlichen Gesellschaft während der Frühzeit der deutschen Frauenbewegung, in: M. RAINER LePSIUS (Hrsg.), Bildungsbürgertum im 19. Jahrhundert. Teil 3: Lebensführung und ständische Vergesellschaftung, Stuttgart 1992, S. 113-75; DIETER LANGEWIESCHE, The Nature of German Liberalism, in: Gordon MARTELl (Hrsg.), Modern Germany Reconsidered, 1870-1945, London 1992, S. 96-116, hier S. 107 ff.; DerS., Die schwäbische Sängerbewegung in der Gesellschaft des 19. Jahrhunderts - ein Beitrag zur kulturellen Nationsbewegung, in: ZWLG 52 (1993), S. 257-301; MANFRED MEYER, Freiheit und Macht. Studien zum Nationalismus süddeutscher, insbesondere badischer Liberaler 1830-1848, Frankfurt a. M. 1994 sowie Jörg ECHTERNKAMP, Der Aufstieg des deutschen Nationalismus 1770-1840, Frankfurt a.M. 1998.

70 LANGEWIESCHE, Handlungsbedingungen und Zielvorstellungen, S. 343. 
scher politischer und sozialer Kontexte in Deutschland Rechnung getragen, die mindestens bis 1871, aber auch darüber hinaus ein erhebliches Gewicht hatten. So grundlegend sich Region und vor allem Stadt als spezifische soziokulturelle Residuen der deutschen Liberalen, zumal auch nach dem relativen Niedergang auf der nationalen Ebene spätestens nach 1878, erwiesen haben, so erscheint doch das Ziel einer Typologie historischer Erscheinungsformen des Liberalismus noch nicht annähernd erreicht. Denn der komparativ-analytische Zugriff, also die Untersuchung verschiedener regionaler Liberalismen unter dem Gesichtspunkt gleicher Fragestellungen, bleibt bisher die Ausnahme. Die inzwischen zahlreichen Arbeiten zum Verhältnis von Programm und sozialer Praxis des deutschen Liberalismus auf regionaler bzw. kommunaler Ebene vermitteln noch häufig den Eindruck einer additiven Aneinanderreihung, bei der der komparativ-typologische Zugriff lediglich der Einleitung oder der Diskussion vorbehalten bleibt. Die bloße Addition von Fallbeispielen ersetzt indes nicht die komparative Analyse..$^{71}$

Diese Beobachtung gilt noch stärker für den dritten Bereich, die Ebene des internationalen Vergleichs als Paradigma der Liberalismus-Forschung.72 Vor dem Hintergrund der kritischen Diskussion um das historiographische Deutungsmuster eines deutschen Sonderwegs, die maßgebliche Impulse von der angelsächsischen Forschung erhielt, ${ }^{73}$ bildete die von Jürgen Kocka programma-

71 Vgl. Rainer Koch, Staat oder Gemeinde? Zu einem politischen Zielkonflikt in der bürgerlichen Bewegung des 19. Jahrhunderts, in: HZ 236 (1983), S. 73-96; LOTHAR GALL (Hrsg.), Stadt und Bürgertum im 19. Jahrhundert, München 1990 sowie DERS. und Dieter Langewiesche (Hrsg.), Liberalismus und Region. Zur Geschichte des deutschen Liberalismus im 19. Jahrhundert, München 1995 sowie die Rezension dazu von CHristina von Hodenberg in: JbLibF 8 (1996), S. 265-7; vgl. ferner JAN PALMOWSKI, Urban Liberalism in Imperial Germany. Frankfurt a.M., 1866-1914, Oxford 1999 sowie die Rezension von JÖRN LEONHARD dazu in: JbLibF 12 (2000), S. 331-5.

72 Vgl. Gall, Einleitung, S. 9f.; JAmes J. Sheehan, Some Reflections on Liberalism in Comparative Perspective, in: H. HöHLER (Hrsg.), Deutschland und der Westen, Berlin 1984, S. 44-59 sowie die Beiträge in LANGEWIESCHE (Hrsg.), vor allem Ders., Deutscher Liberalismus im europäischen Vergleich. Konzeptionen und Ergebnisse, in: ebd., S. 11-9 sowie die Beiträge in JÜRGEN KOCKA (Hrsg.), Bürgertum im 19. Jahrhundert. Deutschland im europäischen Vergleich, 3 Bde., München 1988, vor allem DieTER LANGEwiesche, Liberalismus und Bürgertum in Europa, in: ebd, Bd. 3, S. 360-94; Hartmut Kaelble, Französisches und deutsches Bürgertum, 1870-1914, in: ebd., Bd.1, S. 1-34; HeInZ-Gerhard Haupt, Kleine und große Bürger in Deutschland und Frankreich am Ende des 19. Jahrhunderts, in: ebd., Bd. 2, S. 252-75 sowie MARCo Meriggi, Italienisches und deutsches Bürgertum im Vergleich, in: ebd., Bd. 1, S. 141-59.

73 Vgl. David Blackbourn und Geoff Eley, Mythen deutscher Geschichtsschreibung. Die gescheiterte bürgerliche Revolution von 1848, Frankfurt a.M. 1980; eine erweiterte, die seinerzeitige Diskussion aufnehmende englische Ausgabe erschien 1984: DAVID Blackbourn und GeOfF Eley, The Peculiarities of German History. Bourgeois Society and Politics in Nineteenth-Century Germany, Oxford 1984, insbes. S. $39 \mathrm{ff}$. und 62 ff.; vgl. ERnSt Fraenkel, Deutschland und die westlichen Demokratien (1964), hrsg. von AleXANDer von BRÜnNeck, Frankfurt a.M. 1991; Helga GreBING, Der „deutsche Sonderweg“ in Europa 1806-1945. Eine Kritik, Stuttgart 1986; 
tisch gestellte Frage, inwiefern ein „besonderes Defizit an Bürgerlichkeit“ in Deutschland ${ }^{74}$ im internationalen Vergleich die Sonderwegsthese zur Einordnung der neueren deutschen Geschichte noch legitimiere, den Ausgangspunkt für eine komparative Interpretation von Bürgertum, Bürgerlichkeit und bürgerlicher Gesellschaft im Europa des 19. Jabrbunderts. Von diesem Sonderforschungsbereich sind über die konkreten thematischen Ergebnisse hinaus wesentliche Impulse für die vergleichende Geschichtswissenschaft in Deutschland ausgegangen, die seit den 1980er Jahren insgesamt einen deutlichen Aufschwung erfahren hat. ${ }^{75}$

Die im Rahmen dieses Forschungsprojekts zusammengetragenen komparativen Studien zum deutschen Liberalismus im internationalen Vergleich trugen zunächst der Tatsache Rechnung, daß der Liberalismus für das „Erklärungsmodell ,deutscher Sonderweg' ... stets als bedeutsames Kriterium herangezogen wurde“.76 Als „Pionier-Unternehmen auf ungesichertem Grund“77 und Ausgangsbasis für weitere international vergleichende Studien unterstreichen die unterschiedlichen Beiträge zwar die Vorzüge der komparativen Methode. Aber nicht $\mathrm{zu}$ übersehen ist in aufälliger Parallele zur Erforschung regionaler und lokaler Liberalismen die Neigung zur bloßen Reihung von Einzelbeiträgen, die den systematischen Vergleich anhand eines zuvor definierten Katalogs von Fragen und Kriterien zugunsten einer bloßen Beschreibung des jeweils anderen Liberalismus in den Hintergrund rückt. Hier schlägt sich die insgesamt

Wolfram Fischer, Wirtschafts- und sozialgeschichtliche Anmerkungen zum „deutschen Sonderweg“, in: Jahrbuch des Instituts für deutsche Geschichte Tel Aviv 16 (1987), S. 96-116; JÜRGEN KOCKA, German history before Hitler: the debate about the German „Sonderweg“, in: JCH 23 (1988), S. 3-16; David BlackBOuRN, The German Bourgeoisie: An Introduction, in: Ders. und R. J. Evans (Hrsg.), The German Bourgeoisie. Essays on the social history of the German middle class from the late eighteenth to the early twentieth century, London 1991, S. 1-45 sowie zuletzt HaNSUlRICH WeHleR, „Deutscher Sonderweg“ oder allgemeine Probleme des westlichen Kapitalismus?, in: Ders., Politik in der Geschichte. Essays, München 1998, S. 78-92.

74 JÜRGEN KOCKA, Bürgertum und bürgerliche Gesellschaft im 19. Jahrhundert: Europäische Entwicklungen und deutsche Eigenarten, in: Ders. (Hrsg.), Bd. 1, S. 11-76, hier S. 11; vgl. zur amerikanisch-europäischen Vergleichsebene JAMES J. SHEEHAN, Vorbildliche Ausnahme: Liberalismus in Amerika und Europa, in: JÜRGEN KOCKA, Hans-Jürgen Puhle und Klaus Tenfelde (Hrsg.), Von der Arbeiterbewegung zum modernen Sozialstaat. Festschrift für Gerhard A. Ritter zum 65. Geburtstag, München 1994, S. 236-48.

75 Vgl. Hartmut Kaelble, Vergleichende Sozialgeschichte des 19. und 20. Jahrhunderts: Forschungen europäischer Historiker, in: JbWG (1993), S. 173-200, wieder in Heinz-Gerhard Haupt und Jürgen Kocka (Hrsg.), Geschichte und Vergleich. Ansätze und Ergebnisse international vergleichender Geschichtsschreibung, Frankfurt a. M. 1996, S. 91-130; vgl. zuletzt HaRTMUt Kaelble, Der historische Vergleich. Eine Einführung zum 19. und 20. Jahrhundert, Frankfurt a. M. 1999.

76 LANGEWIESCHE, Handlungsbedingungen, S. 342.

77 Hellmut Seier, Rezension zu DieTer Langewiesche (Hrsg.), Liberalismus im 19. Jahrhundert. Deutschland im europäischen Vergleich, Göttingen 1988, in: HZ 252 (1991), S. 720-2, hier S. 720. 
noch unzureichende Basis an komparativen Liberalismus-Studien, insbesondere im Vergleich zwischen Deutschland und Frankreich oder Italien nieder. ${ }^{78}$

Für die deutsch-englische Vergleichsperspektive dagegen ermöglicht die seit Jahren etablierte kritische Auseinandersetzung mit einseitigen Interpretationsmustern in beiden Ländern eine systematischere Analyse. Die Aufgabe sowohl der Whig interpretation of history als auch des Paradigmas deutscher Sonderweg als äußerste, einander entsprechende Pole eines Geschichtsbildes, in dem die Rollen von vorbildlichem Pionier und stets gefährdetem Nachzügler schon immer feststanden und in dem die „Denkfigur von Großbritannien als Pioniernation" nicht nur ökonomisch, sondern auch politisch-konstitutionell sowie kulturell-gesellschaftlich dominierte, eröffnete für komparative Studien eine offensichtlich vielversprechende Forschungsperspektive. ${ }^{79}$ Einer solchermaßen

78 Vgl. die Beiträge des dritten Teils in LANGewiesche (Hrsg.) zum Liberalismus in den romanischen Ländern, in denen bis auf wenige Ausnahmen das additive Verfahren dominiert, während die Beiträge für den deutsch-englischen Vergleich a priori komparativ angelegt sind; vgl. RuDOLF MuHS, Deutscher und britischer Liberalismus im Vergleich. Trägerschichten, Zielvorstellungen und Rahmenbedingungen, ca. 1830-1870, in: ebd., S. 223-59; GeOFF Eley, Liberalismus 1860-1914. Deutschland und Großbritannien im Vergleich, in: ebd., S. 260-76; HeINZ-GERHARD HAUPT, Ein soziales Milieu des nachrevolutionären Liberalismus in der französischen Provinz: Die Landbesitzer, in: ebd., S. 282-95; HeINZ-GERHARD HAUPT und FrIEDRICH LENGER, Liberalismus und Handwerk in Frankreich und Deutschland um die Mitte des 19. Jahrhunderts, in: ebd., S. 305-31; Rainer Hudemann, Politische Reform und gesellschaftlicher Status quo. Thesen zum französischen Liberalismus im 19. Jahrhundert, in: ebd., S. 332-52; Marco Meriggi, Der Adelsliberalismus in der Lombardei und in Venetien (1815-1860), in: ebd., S. 367-77 sowie HARTMUT UlLRICH, Der italienische Liberalismus von der Nationalstaatsgründung bis zum Ersten Weltkrieg, in: ebd., S. 378-414; vgl. zum deutsch-englischen Vergleich ferner die Magisterarbeit des Verfassers: JÖRN LEONHARD, Liberale und Liberals. Komparative begriffs- und sozialgeschichtliche Studien zum deutschen und englischen Frühliberalismus bis 1848 (MS), Heidelberg 1994.

79 Hartmut Berghoff und Dieter Ziegler, Pionier oder Nachzügler. Kategorien für den deutsch-britischen Vergleich?, in: Dies. (Hrsg.), Pionier oder Nachzügler? Vergleichende Studien zur Geschichte Großbritanniens und Deutschlands im Zeitalter der Industrialisierung. Festschrift für Sidney Pollard zum 70. Geburtstag, Bochum 1995, S. 15-28, hier S. 17; vgl. Wolfgang J. Mommsen, Britain and Germany 1800 to 1914. Two Developmental Paths towards Industrial Society, London 1986, S. 3; BENDIX, Modernisierung, S. 510f. sowie als negatives Beispiel Alexander Gauland, Gemeine und Lords. Porträt einer politischen Klasse, Frankfurt a.M. 1989, S. 7; zur Genese des deutschen Englandbildes vgl. Theodor Wilhelm, Die englische Verfassung und der vormärzliche Liberalismus. Eine Darstellung und Kritik des Verfassungsbildes der liberalen Führer, Tübingen 1928; F. GUNTHER EYCK, English and french influences on german liberalism before 1848, in: JHI 18 (1957), S. 313-41; GÜNTER Hollenberg, Die britische Verfassung aus deutscher Sicht, in: NPL 17 (1972), S. 372-88; Werner Gembruch, Zum England-Bild des Freiherrn vom Stein, in: Lothar Kettenacker, Manfred Schlenke und Hellmut Seier (Hrsg.), Studien zur Geschichte Englands und der deutsch-britischen Beziehungen. Festschrift für Paul Kluke, München 1981, S. 27-47; ECKART PANKOKE, „Englische Freiheit.“ Klassische Deutungsmuster deutscher Englandbilder, in: KARL ROHE (Hrsg.), Engli- 
günstig entwickelten empirischen und methodisch sensibilisierten Infrastruktur für den deutsch-englischen Vergleich verdankt der gelungene analytische Zugriff auf die unterschiedlichen Liberalismen in beiden Ländern wesentliche Anregungen. 80

Demgegenüber ist von der in jüngster Zeit forcierten deutsch-französischen Vergleichsperspektive erst noch zu hoffen, daß sie positiv auch auf vergleichende Liberalismus-Studien wirken wird. ${ }^{81}$ Gerade aus komparativer Per-

scher Liberalismus im 19. und frühen 20. Jahrhundert, Bochum 1987, S. 33-65; MICHAEl EPKENHANS, Aspekte des deutschen Englandbildes 1800-1914: Vorbild und Rivale, in: Westfälische Forschungen 44 (1994), S. 329-42 sowie THOMAS KleINKNECHT, England als Modell: Nachahmung - Kritik - Ablehnung, in: Westfälische Forschungen 44 (1994), S. 1-23.

80 Vgl. Shulamit Volkov, Enactment and Repeal of Combination Acts, England and Prussia Compared, in: Jahrbuch des Instituts für deutsche Geschichte Tel Aviv 9 (1980), S. 309-38, hier S. 311; Hanna SCHISsler, Die Junker. Zur Sozialgeschichte und historischen Bedeutung der agrarischen Elite in Preußen, in: HANS-JÜRGEN Puhle und Hans-Ulrich Wehler (Hrsg.), Preußen im Rückblick, Göttingen 1980, S. 89-122, hier S. 121; Wolfgang J. Mommsen, Preußen/Deutschland im frühen 19. Jahrhundert und Großbritannien in der viktorianischen Epoche. Eine komparative Betrachtung, in: Adolf M. BIRKE und KuRT KluXeN (Hrsg.), Viktorianisches England in deutscher Perspektive, München 1983, S. 31-48; AdOlF M. BIRKE und KuRT Kluxen (Hrsg.), Deutscher und britischer Parlamentarismus, München 1985; EcKHART Hellmuth (Hrsg.), The Transformation of Political Culture. England and Germany in the Late Eighteenth Century, Oxford 1990; Geoffrey CrossicK, And what should they know of England? Die vergleichende Geschichtsschreibung im heutigen Großbritannien, in: HAUPT und KOCKA (Hrsg.), S. 61-75; zur vergleichenden Liberalismus-Betrachtung vgl. GuSTAV SCHMIDT, Politischer Liberalimus, „Landed Interests" und Organisierte Arbeiterschaft, 1850-1880. Ein deutsch-englischer Vergleich, in: Gall (Hrsg.), Liberalismus, S. 232-53; JoHn Breuilly, Liberalism in Mid-Nineteenth-century Britain and Germany, in: DERS., Labour and Liberalism, S. 228-72; DERS., Liberalism and Social Democracy: A Comparison of British and German Labour Politics, c. 1850-1875, in: EHQ 15 (1985), S. 3-42; STEFAN-GEORG SCHNORR, Liberalismus zwischen 19. und 20. Jahrhundert. Reformulierung liberaler politischer Theorie in Deutschland und England am Beispiel von Friedrich Naumann und Leonard T. Hobhouse, Baden-Baden 1990 sowie MuHs, Deutscher und britischer Liberalismus, S. 223 f.; vgl. ferner T. C. W. BlAnNing und PETER WENDE (Hrsg.), Reform in Great Britain and Germany 1750-1850, Oxford 1999, sowie die Rezension dazu von JÖRN LEONHARD in: EHR 116 (2001), S. 147-9.

81 Vgl. Hartmut Kaelble, Französisches und deutsches Bürgertum; HeInZ-Gerhard HAUpt, Kleine und große Bürger; HeInRICH BEST, Die Männer von Bildung und Besitz. Struktur und Handeln parlamentarischer Führungsgruppen in Deutschland und Frankreich 1848/49, Düsseldorf 1990; HARTMUT KaELbLE, Nachbarn am Rhein. Entfremdung und Annäherung der französischen und deutschen Gesellschaft, 1880-1980, München 1991; Rudolf vON Thadden, Aufbau nationaler Identität. Deutschland und Frankreich im Vergleich, in: BERNHARD GIESEN (Hrsg.), Nationale und kulturelle Identität. Studien zur Entwicklung des kollektiven Bewußtseins in der Neuzeit, Frankfurt a.M. 1991, S. 493-509 sowie zuletzt im Überblick ETIENNE FranÇOIS, Hannes Siegrist und Jakob Vogel (Hrsg.), Nation und Emotion. Deutschland und Frankreich im Vergleich. 19. und 20. Jahrhundert, Göttingen 1995 und HeINZ-GER- 
spektive besteht für Frankreich das Problem einer „mangelnden Präzision des Liberalismus-Begriffes“, 82 die in der insgesamt schwächer ausgeprägten Forschung zum französischen Liberalismus zu einer ausgesprochenen Begriffsverwirrung führt:83 So wird der französische Liberalismus willkürlich und ohne nähere Begründung wahlweise mit einem klassisch ideengeschichtlichen Ensemble von Denkern um Constant und Tocqueville oder einem liberalen Republikanismus im 20. Jahrhundert identifiziert oder auch schlicht als Synonym für radicalisme benutzt, wobei der Begriff libéralisme schließlich wegfällt oder aber ohne Überprüfung zeitgenössischer Begriffsbestimmung auf denkbar unterschiedliche politische Gruppierungen angewandt wird, wodurch seine ideologische Bestimmung völlig ausgehöhlt wird. ${ }^{84}$

Auf der deutsch-italienischen Ebene bieten die zahlreichen Veröffentlichungen des Trentiner Istituto Storico Italiano-Germanico zu spezifischen Themen Ansätze, darunter auch zum Liberalismus in beiden Ländern in der zweiten Hälfte des 19. Jahrhunderts. ${ }^{85}$ Diese komparativ intendierten Analysen diffe-

HARD HAUPT, Eine schwierige Öffnung nach außen: Die international vergleichende Geschichtswissenschaft in Frankreich, in: DeRs. und KOCKA (Hrsg.), S. 77-90.

82 Gerd KRUmeICH, Der politische Liberalismus im parlamentarischen System Frankreichs vor dem Ersten Weltkrieg, in: LANGEWIESCHE (Hrsg.), S. 353-66, hier S. 353.

83 Vgl. MarCel GIRARD, Le Libéralisme en France de 1814 à 1848. Doctrine et mouvement, Paris 1970; Jean-Thomas Nordmann, Histoire des Radicaux 1820-1973, Paris 1974; Georges Bureau, Le libéralisme, Paris 1979; W. H. Logue, From Philosophy to Sociology. The evolution of French Liberalism 1870-1914, DeKalb/Ill. 1984; LoUIS GIRARD, Les libéraux français 1814-1875, Paris 1985; ANDRÉ JARDIN, Histoire du libéralisme politique de la crise de l'absolutisme à la constitution de 1875, Paris 1985; Libéralisme chrétien et catholicisme libéral en Espagne, France et Italie dans la prémière moitié du XIX ${ }^{\mathrm{e}}$ siècle. Colloque International, Novembre 1987, Aix-en-Provence 1989; Pierre Manent, Histoire intellectuelle du libéralisme. Dix leçons, Paris 1987. Zum Problem der Begriffsverwirrung vgl. KRumeICH, S. 354; Roland HÖHNE und Ingo KolboOm, Aufstieg, Niedergang und Renaissance des Liberalismus in Frankreich, in: Vorländer (Hrsg.), S. 119-34, hier S. 119; JeAn FranÇOIS REVEL, Frankreich und der Liberalismus. Brief aus Paris, in: MELVIN J. LASKY (Hrsg.), Wie tot ist der Liberalismus? Nachdenken über ein Grundprinzip. Der Monat, N.F. 286 (1983), Weinheim 1983, S. 79-82 sowie JÜrg AltwegG, In Frankreich wollen heute Linke wie Rechte liberal sein, in: FAZ, 12. Januar 1985.

84 Vgl. JacQues A. ZigheRA, „Radicalisme“ in Frankreich, in: Liberal (1974), S. 547-9; BERNHARD SCHMIDT (Hrsg.), Frankreich-Lexikon. Schlüsselbegriffe zu Wirtschaft, Gesellschaft, Politik, Geschichte, Kultur, Presse- und Bildungswesen, Bd. 2, Berlin 1983, S. $152 \mathrm{ff} . ;$ W. H. Logue, Liberalism, in: Historical Dictionary of the Third French Republic, 1870-1940, New York 1986, S. 554-6; PATRICK J. HARRIGAN, Liberal Catholicism, in: Historical Dictionary of France from the 1815 Restoration to the Second Empire, Bd. 1, London 1987, S. 631-4 sowie William E. Echard (Hrsg.), Historical Dictionary of the French Second Empire, 1852-1870, London 1985, S. 359.

$85 \mathrm{Vgl}$. ANgelo ARA, Le correnti conservatrici in Italia, in: UMBERTO CORSINI und RUDOLF LILL (Hrsg.), Istituzioni e ideologie in Italia e in Germania tra le rivolzioni, Bologna 1987, S. 95-125; Sergio LA SALVIA, Il moderatismo in Italia, in: ebd., S. 169-310; ETtore Passerin D’Entrèves und Konrad Repgen (Hrsg.), Il Cattolicesimo politico e sociale in Italia e in Germania dal 1870 al 1914, Bologna 1977; MARCO MERIGGI und Pierangelo Schiera (Hrsg.), Dalla città alla nazione. Borghesie ottocentesche in 
renzieren auch die tradierte italienische Liberalismus-Forschung. Aber auch hier erweist sich der programmatische Vergleichsansatz noch häufig als bloße Addition von Einzelstudien, die unter einem für beide Länder gültigen Sammelthema zusammengetragen werden. Zudem standen Studien zum italienischen Liberalismus allzu lange im Schatten der überkommenen RisorgimentoForschung. ${ }^{86}$ Während sich zu Beginn der 1970er Jahre ein gewisser Stillstand der traditionellen Risorgimento-Forschung mit ihrer dominierenden biographisch-philologischen Perspektive abzuzeichnen begann, konnten erst in jüngster Zeit stärker politik- und sozialgeschichtliche Fragestellungen für die Analyse des Königreichs einbezogen werden, die inzwischen auch auf die italienische Liberalismus-Forschung zurückwirken. ${ }^{87}$ Dennoch ist ein gewisser Nachholbedarf der italienischen Forschung nicht zu übersehen, die aber von der europäisch vergleichenden Bürgertumsforschung schon jetzt wichtige Anregungen erfahren hat.

Italia e Germania, Bologna 1993 sowie Rudolf Lill und Nicola MatTeucci (Hrsg.), Il liberalismo in Italia e in Germania dalla rivoluzione del'48 alla prima guerra mondiale, Bologna 1980.

86 Vgl. zur älteren Forschung: Bibliografia storica dell'età del Risorgimento. In onore di Alberto M. Ghisalberti, 4 Bde., Florenz 1971-1977; Kent RobERTS GreENFIELD, Economia e liberalismo nel Risorgimento. Il movimento nazionale in Lombardia dal 1814 al 1848 (englisch 1934), Rom 1985; E. ROTA (Hrsg.), Questioni di storia del Risorgimento e dell'Unità d'Italia, Mailand 1951; FIORELLA BARTOCCINI, Il movimento liberale e nazionale romano dal 1849 al 1860, Rom 1961; L. BULFERETTI (Hrsg.), Nuove Questioni di storia del Risorgimento e dell'Unità d'Italia, Mailand 1961; Walter MATURI, Partiti politici e correnti di pensiero nel Risorgimento, in: ebd., S. 39-129; Alberto M. Ghisalberti, Il liberalismo moderato nel Risorgimento, in: Atti del XXXVII Congresso di Storia del Risorgimento Italiano, Bari, ottobre 1958, Rom 1961, S. 3-19; Alberto Aquarone, Alla ricerca del'Italia liberale, in: Ders., Alla ricerca del'Italia liberale, Neapel 1972, S. 275-344; G. GALAsso, Potere e istituzioni in Italia. Dalla caduta dell'Impero romano a oggi, Turin 1974, S. 182 ff.; VALERIO ZANONE, Il Liberalismo Moderno, in: LUIGI FIRPO (Hrsg.), Storia delle Idee politiche, economiche e sociali, Bd. 6: Il secolo ventesimo, Turin 1972, S. 191-248 sowie MANLIO Di Lalla, Storia del Liberalismo Italiano dal risorgimento al fascismo, Bologna 1976.

87 Vgl. Giuseppe Bedeschi, Storia del pensiero liberale, Rom 1990; Gino Capponi, Storia e progresso nell'Italia dell'Ottocento, hrsg. von PAOLO BAGNOLI, Florenz 1994; ANTONIO DE FRANCESCO, Ideologie e movimenti politici, in: GIOVANNI SABbATUCCI und VitToRio VidotTo (Hrsg.), Storia d'Italia, Bd. 1: Le premesse dell'unità dalla fine del settecento al 1861, Bari 1994, S. 229-336; RAFFAELE RomANELLI, L'Italia Liberale 1861-1900. Storia d'Italia dall'Unità alla Repubblica, Bd. 2, Bologna 1990; Ders., Il commando impossibile. Stato e società nell'Italia liberale, Bologna 1995; PAOLO POMBENI, Introduzione alla storia dei partiti politici, Bologna 1985; DERS., Trasformismo e questione del partito. La politica italiana e il suo rapporto con la vicenda costituzionale europea, in: DERs. (Hrsg.), La trasformazione politica nell'Europa liberale 1870-1890, Bologna 1986, S. 215-54; DERS., Autorità sociale e potere sociale nell'Italia contemporanea, Venedig 1993; Angelica GeRnerT, Liberalismus als Handlungskonzept. Studien zur Rolle der politischen Presse im italienischen Risorgimento vor 1848, Stuttgart 1990 sowie Thomas Kroll, Die Revolte des Patriziats. Der toskanische Adelsliberalismus im Risorgimento, Tübingen 1999. 
Vor dem Hintergrund der Forderung nach einer Typologie historischer Erscheinungsformen des Liberalismus muß eine Bilanz der bisherigen Liberalismus-Forschung mindestens ambivalent ausfallen: Die Forderung nach interregionalen Vergleichen unterhalb der nationalen Ebene und internationalen Vergleichen hat über additiv angelegte Sammelbände hinaus bisher kaum größer angelegte Studien hervorgebracht, die dem strengen Maßstab eines systematischen Vergleichs anhand eines scharf umrissenen Frage- und Kriterienkatalogs genügten. ${ }^{88}$ Zumal die Kluft zwischen international vergleichenden und kulturalistisch orientierten Bürgertumsstudien auf der einen und komparativen Liberalismus-Forschungen auf der anderen Seite ist bisher nicht überzeugend geschlossen worden. ${ }^{89}$

Hinsichtlich des konkreten Vergleichs europäischer Liberalismen fällt aber eine weitere spezifische Schwierigkeit besonders ins Gewicht. Die Frage, welche Phänomene unter den Begriff Liberalismus fallen, gewinnt bei Vergleichen eine besondere Dimension: Lassen sich die den Begriff konnotierenden Kategorien bei der Verwendung des Begriffes in einem Land ohne weiteres auf ein anderes Land übertragen? Die Klippe des semantischen Nominalismus, also die unreflektierte Übernahme eines Begriffes aus dem politisch-sozialen Vokabular eines Landes und seine semantische Gleichsetzung mit dem vermeintlichen Wortäquivalent aus dem politischen Diskurs eines anderen Landes, die die außerhalb der Übersetzung liegenden Bedeutungsdifferenzen unberücksichtigt läßt, trägt erheblich zur Kommunikationsbarriere bei, die zu den spezifischen Schwierigkeiten bei der Umsetzung des komparativen Ansatzes zählt. Das kommunikative Mißverständnis, die Begriffsverwirrung, setzt genau da an, wo die Übersetzung zur Verständigungsfalle und die historische Semantik zum Erkenntnisproblem wird.

b) Vom historischen Schlagwort zum politisch-sozialen Grundbegriff: Begriffsgeschichte, sozialhistorische Semantik und Diskursanalyse

In Deutschland hat sich die Begriffsgeschichte früher und intensiver als in anderen Ländern als Paradigma der historischen Semantik durchgesetzt. ${ }^{90}$ Ausge-

88 Vgl. als positive Ausnahme Alan S. KaHAn, Aristocratic Liberalism. The Social and Political Thought of Jacob Burckhardt, John Stuart Mill, and Alexis de Tocqueville, Oxford 1992, S. $135 \mathrm{ff}$.

89 Vgl. LANGEWIESCHe, Frühliberalismus und Bürgertum, S. 75.

90 Vgl. Reinhart Koselleck, Einleitung, in: Ders. (Hrsg), Historische Semantik, S. 9-16; ERnST WOLfGang ORTH, Theoretische Bedingungen und methodische Reichweite der Begriffsgeschichte, in: ebd., S. 136-53; HORST GÜNTHER, Auf der Suche nach einer Theorie der Begriffsgeschichte, in: ebd., S. 102-20; REINHART KOSELLECK, Sozialgeschichte und Begriffsgeschichte, in: WolfGANG SCHIEDER und VolKer SELlin (Hrsg.), Sozialgeschichte in Deutschland. Entwicklungen und Perspektiven im internationalen Zusammenhang, Bd.1: Die Sozialgeschichte innerhalb der Geschichtswissenschaft, Göttingen 1986, S. 89-109; ReINHART KOSELleCK, Sprachwandel und Ereignisgeschichte, in: Merkur 43 (1989), S. 657-73; H. G. MEIER, Begriffsge- 
hend vom früh entwickelten Interesse von Historikern an Schlagworten und an der Funktion von Begriffen als „sozialpsycholgische und geistesgeschichtliche Erscheinung" vollzog sich die moderne begriffsgeschichtliche Praxis zunächst in zwei fachwissenschaftlichen Richtungen, denen sich jeweils großangelegte Forschungsprojekte zuordnen lassen. ${ }^{91}$ Der philosophiegeschichtlichen Ausrichtung, aus der das Historische Wörterbuch der Philosophie hervorging, „geht es ,diagnostisch' um die Genese terminologischer Verwirrung und ,therapeutisch' um eine Präzisierung für neuerliche Verwendungen".92 Auf der Ebene der Geschichtswissenschaft haben neben einzelnen monographischen Studien zwei wissenschaftliche Großprojekte die Begriffsgeschichte als eigenständige historiographische Methodik etabliert: die zwischen 1972 und 1997 erschienenen Geschichtlichen Grundbegriffe (GGB) sowie das seit 1985 erscheinende Handbuch politisch-sozialer Grundbegriffe in Frankreich (HPSG). ${ }^{93}$

Die Konzeption der GGB ging von einem grundlegenden semantischen Strukturwandel von vergangenen zu "modernen“ Begriffen in der Zeitphase von ca. 1750 bis 1850 aus, für die Reinhart Koselleck die Bezeichnung Sattelzeit prägte. Diese semantische Transformationsphase war von mehreren spezifischen Erscheinungen gekennzeichnet: der Kollektivierung von zunächst nur im Plural geläufigen Substantiven (Geschichten) zu Allgemeinbegriffen (Ge-

schichte, in: JOACHIM RITTER und KARLFRIED GRÜNDER (Hrsg.), Historisches Wörterbuch der Philosophie, Bd. 1, Stuttgart 1971, S. 788-808; GERD VAN DEN Heuvel, Begriffsgeschichte, Historische Semantik, in: K. BERGMANN et al. (Hrsg.), Handbuch der Geschichtsdidaktik, 3. Aufl. Düsseldorf 1985, S. 194-7; Kari PalOnen, Politics, rhethoric and conceptional history. Studies on modern languages of political theory, Jyväskylä 1994; Ralf Konersmann, Der Schleier des Timanthes. Perspektiven der historischen Semantik, Frankfurt a. M. 1994, S. 42 ff. sowie LuCian HölsCHER, The theoretical Foundations of ,Begriffsgeschichte' (History of Concepts), in: Cultura. Revista de História e Teoria das Ideias 8, 2.a Série, Lissabon 1995, S. 23-38, hier S. 26 ff.; vgl. ferner JÖRN LEONHARD: Vom Schlagwort zum Grundbegriff: Zur Genese der Methodendiskussion zwischen Begriffsgeschichte, sozialhistorischer Semantik und Diskursanalyse, in: AfB (erscheint voraussichtlich 2002).

91 Wilhelm Bauer, Das Schlagwort als sozialpsychologische und geistesgeschichtliche Erscheinung, in: HZ 122 (1920), S. 189-240.

92 Georg Bollenbeck, Bildung und Kultur. Glanz und Elend eines deutschen Deutungsmusters, Frankfurt a. M. 1994, S. 313.

93 Rolf ReICHARDT und Hans-JÜrgEn LÜSEBRINK (Hrsg.), Handbuch politisch-sozialer Grundbegriffe in Frankreich 1680-1820, München 1985 ff.; vgl. als exemplarische Einzelstudien ferner JÜRGEN SCHLUMBOHM: Freiheit - Die Anfänge der bürgerlichen Emanzipationsbewegung in Deutschland im Spiegel ihres Leitwortes (ca. 1760 - ca. 1800), Düsseldorf 1975; KARI PALONEN, Politik als Handlungsbegriff. Horizontwandel des Politikbegriffs in Deutschland, 1890-1933, Helsinki 1985; UlRICH ENGELHARDT, Bildungsbürgertum. Begriffs- und Dogmengeschichte eines Etiketts, Stuttgart 1986; GeRD VAN DEN Heuvel, Der Freiheitsbegriff der Französischen Revolution. Studien zur Revolutionsideologie, Göttingen 1988 sowie HoRST DreITZEL, Monarchiebegriffe in der Fürstengesellschaft. Semantik und Theorie der Einherrschaft in Deutschland von der Reformation bis zum Vormärz, 2 Bde., Köln 1991; vgl. ferner DieTER Langewiesche, Republik und Republikaner. Von der historischen Entwertung eines politischen Begriffs, Essen 1993. 
schichte), der schichtenübergreifenden Rezeption von politisch-sozialen Leitbegriffen über den begrenzten Kreis der Gebildeten hinaus (Demokratisierung), dem zunehmenden Einsatz politisch-sozialer Grundbegriffe als polemischer Waffe mit der Folge größerer semantischer Breite (Ideologisierbarkeit), sowie von der Aufladung von Begriffen mit spezifischen Erwartungen und Zielen, die aus Schlagwörtern auf dem Wege der Verzeitlichung und Politisierung affektive, zukunftsweisende Bewegungsbegriffe machten. ${ }^{94}$

Über dieses Sattelzeit-Konzept hinaus hat Koselleck sich vor allem um eine Etablierung der Begriffsgeschichte in ihrer sozialhistorischen Funktion bemüht. Die Prämisse, daß die Begriffsgeschichte jene „sprachliche Eigenbewegung“ nachvollziehe, „in der sich geschichtliche Erfahrungen sammeln oder Hoffnungen formuliert sein wollen", ließ sich programmatisch als sozialhistorische Leitlinie begriffsgeschichtlicher Forschung zuspitzen: „Die den handelnden Menschen übersteigende Begriffsgeschichte ist insofern eine Variante der Sozialgeschichte“. .95 Gerade das für die deutsche Geschichte des 19. Jahrhunderts so häufig zitierte Interpretationsmuster der „Gleichzeitigkeit des Ungleichzeitigen“ wird in den Begriffen anhand einander überlappender Bedeutungselemente in geradezu seismographischer Qualität erkennbar, indem die Begriffe gleichzeitig ungleichzeitige Erfahrungen und Erwartungen verdichten. ${ }^{96}$

Die Frage, inwiefern die GGB die Funktion der Begriffsgeschichte als eine "conditio sine qua non sozialgeschichtlicher Fragen“ hat einlösen können, ist bei aller auch internationalen Anerkennung des Projekts Gegenstand einer kritisch geführten Diskussion geworden. ${ }^{97}$ In vielen Artikeln, so die Kritik, habe

94 Vgl. ReINHART KOSELleck, Richtlinien für das Lexikon politisch-sozialer Grundbegriffe der Neuzeit, in: AfB 11 (1967), S. 81-99; Ders., Einleitung, in: BRUNNER et al. (Hrsg.), Bd. 1, S. XIII-XXVII; DerS., Begriffsgeschichte und Sozialgeschichte (1972), in: DERS., Vergangene Zukunft, S. 107-29.

95 Reinhart Koselleck, Preußen zwischen Reform und Revolution. Allgemeines Landrecht, Verwaltung und soziale Bewegung von 1791 bis 1848 (1967), 3. Aufl. 1981, Neudruck München 1989, S. 17; vgl. ferner DeRs., Begriffsgeschichte und Sozialgeschichte, S. 114-7.

96 Vgl. Wolfgang Hardtwig, Der deutsche Weg in die Moderne. Die Gleichzeitigkeit des Ungleichzeitigen als Grundproblem der deutschen Geschichte 1789-1871, in: Ders. und Harm-Hinrich Brandt (Hrsg.), Deutschlands Weg in die Moderne. Politik, Gesellschaft und Kultur im 19. Jahrhundert, München 1993, S. 9-31; die Formel selbst geht zurück auf ERNST BLOCH, Ungleichzeitigkeit und Berauschung, in: DERS., Erbschaft dieser Zeit. Erweiterte Ausgabe. Gesamtausgabe Bd. 4, Frankfurt a. M. 1962, S. 45-164; vgl. zur didaktischen Integration begriffsgeschichtlicher Fragestellungen JÖRN LEONHARD, Zwischen Tradition und Moderne: Liberalismus in Deutschland im 19. Jahrhundert, in: RAAbits Geschichte. Impulse und Materialien für die kreative Unterrichtsgestaltung, 15. Ergänzungslieferung, Heidelberg 1996, S. 6 f.; vgl. KOSELLECK, Begriffsgeschichte und Sozialgeschichte, S. 128

97 Vgl. ebd., S. 125 und Werner Conze, Vom „Pöbel“ zum „Proletariat.“ Sozialgeschichtliche Voraussetzungen für den Sozialismus in Deutschland, in: HANS-UlRICH Wehler (Hrsg.), Moderne deutsche Sozialgeschichte, Köln 1966, S. 111-36; vgl. zur Kritik IRMLINDE VeIT-BRAUSE, A Note on Begriffsgeschichte, in: History and Theory 20 (1981), S. 61-7; Niklas LuhmanN, Gesellschaftsstruktur und Semantik. Studien 
der zu weit gespannte Rahmen von der Antike bis zur Gegenwart und die fehlende Berücksichtigung der allen Autoren empfohlenen Quellengrundlage zu einer einseitigen Bevorzugung der klassischen ideengeschichtlichen Theoretiker und einer weitgehenden Ausklammerung der politischen Alltagssprache geführt. ${ }^{98}$ Das nach der Pionierleistung der GGB zweite begriffsgeschichtlichlexikalische Großunternehmen, das seit 1985 von Rolf Reichardt und HansJürgen Lüsebrink herausgegebene Handbuch politisch-sozialer Grundbegriffe in Frankreich, unternimmt den Versuch, das politisch-soziale Vokabular Frankreichs vom Ancien Régime bis zur Restauration zu erfassen. Die Übertragung der begriffsgeschichtlichen Methode auf ein anderes europäisches Land wird dabei programmatisch mit der Konzeption einer eigenen französischen Sattelzeit von ca. 1680 bis 1820 und vor allem einer methodischen Weiterentwicklung der Begriffsgeschichte zur sozialhistorischen Semantik verbunden. ${ }^{99}$ Dabei wird die Funktion der Sprache unterstrichen, „Sinn, Bedeutung, Meinung zu vermitteln, die nicht direkter Ausdruck des Subjektes, ,hier und jetzt ${ }^{\prime}$ sind." Dies erlaubt es dem Individuum, die alltäglichen Sinneseindrücke zu typisieren. ${ }^{100}$ Die wissenssoziologisch abgeleitete Position, daß und wie Sprache als integrales Segment des sozialen Wissens der Zeit und zugleich als handlungsleitender Faktor wirkt, unterstreicht die Konzeption der sozialhistorischen Semantik: Bei ihr, so die Konzeption der Herausgeber des HPSG, stehe nicht der philosophische Erstbeleg und die exakte Definition des Leitbegriffes im Vordergrund, sondern „die gesellschaftliche Verbreitung und dessen sozialspezifische Bedeutungen“, also eine sozialhistorische Konturierung der semantischen Bestimmungen. ${ }^{101}$

zur Wissenssoziologie der modernen Gesellschaft, Bd.1, Frankfurt a.M. 1980, S. 13-21; HeINER SCHUlTz, Begriffsgeschichte und Argumentationsgeschichte, in: Koselleck (Hrsg.), Historische Semantik, S. 43-74; J. Macek, Pour une sémantique historique, in: Mélanges en l'honneur de Fernand Braudel, Toulouse 1973, S. 343-52; N. S. SRuever, The Study of Language and the Study of History, in: JIH 4 (1974), S. 401-15; R. SCHMIDT-WIEGAND, Neue Ansätze im Bereich ,Wörter und Sachen', in: G. WiegelmanN (Hrsg.), Geschichte der Alltagskultur, Münster 1980, S. 87-102 sowie M. Gribaudi, A proposito di linguistica e storia, in: Quaderni storici 46 (1981), S. 236-66.

98 Vgl. Heiner Schultz, Einige methodische Fragen der Begriffsgeschichte, in: AfB 17 (1973), S. 221-31; Helmut BERDING, Begriffsgeschichte und Sozialgeschichte, in: HZ 233 (1976), S. 98-110 sowie James J. SHEEHAn, ,Begriffsgeschichte'. Theory and Practice, in: JMH 50 (1978), S. 312-9.

99 Vgl. Rolf ReICHARDT, Pour une histoire des mots-thèmes socio-politiques en France (1680-1820), in: Mots 5 (1982), S. 189-202; Ders., Zur Geschichte politisch-sozialer Begriffe in Frankreich zwischen Absolutismus und Restauration. Vorstellung eines Forschungsvorhabens, in: Zeitschrift für Literaturwissenschaft und Linguistik 47 (1982), S. 49-72; Ders., Einleitung, in: Ders. und LÜSEBRINK (Hrsg.), Heft 1/2, München 1985, S. 39-148, hier S. 64 ff.

100 P. L. Berger und T. LuCKMANN, Die gesellschaftliche Konstruktion der Wirklichkeit (englisch 1966), 5. Aufl. Frankfurt a.M. 1980, S. 39; vgl. A. SCHÜTZ und T. LuCKMANN, Strukturen der Lebenswelt, Bd. 1, Frankfurt a. M. 1979, S. $224 \mathrm{ff}$.

101 van DEN Heuvel, Freiheitsbegriff, S. 22; vgl. Hans-Ulrich Gumbrecht, Für eine 
Im Kontext des sogenannten linguistic turn sind vor allem in der angelsächsischen Geschichtsschreibung Sprache, Rhetorik und Diskurs erneut in das Zentrum historischer Betrachtung getreten. ${ }^{102}$ Diese im weitesten Sinne kulturgeschichtliche Akzentverschiebung der Geschichtswissenschaft, ihre interdisziplinäre Öffnung gegenüber anthropologischen und kultursoziologischen Positionen und die jüngst geführte Debatte um eine Neubestimmung der Geschichte als Kulturgeschichte bzw. Historische Kulturwissenschaft ${ }^{103}$ hat auch das Interesse an Fragen der historischen Semantik vertieft. Während aber im Zusammenhang mit dem linguistic turn die sprachliche Artikulation häufig methodisch verabsolutiert und zum „Fundament jeder historischen Erkenntnis“ wird, verweisen begriffshistorische Ansätze darauf, daß die Analyse der vergangenen Wirklichkeit nie allein über Texte und Diskurse möglich ist. ${ }^{104}$ Die Semantik als Beziehung zwischen Zeichen und Bedeutung sowie die Pragmatik als Zusammenhang zwischen Zeichen und Benutzer sind aus dieser Perspektive untrennbar miteinander verbunden. ${ }^{105}$

phänomenologische Fundierung der sozialhistorischen Begriffsgeschichte, in: KosELLECK (Hrsg.), Historische Semantik, S. 75-101.

102 Vgl. R. RORTY (Hrsg.), The Linguistic Turn: Recent Essays in Philosophic Method, Chicago 1967; M. JAY, Should Intellectual History Take a Linguistic Turn? Reflections on the Habermas-Gadamer Debate, in: Dominick Lacapra und Steven L. Kaplan (Hrsg.), Modern European Intellectual History. Reappraisals and New Perspectives, Ithaca 1982, S. 86-110; J. E. ToEws, Intellectual History after the Linguistic Turn: The Autonomy of Meaning and the Irreducibility of Experience, in: AHR 92 (1987), S. 879-907; vgl. zur Rezeption in Deutschland GEORGE G. IGgers, Zur „Linguistischen Wende" im Geschichtsdenken und in der Geschichtsschreibung, in: GG 21 (1995), S. 557-70; ERNST HANISCH, Die linguistische Wende. Geschichtswissenschaft und Literatur, in: Wolfgang HaRdTwig und Hans-Ulrich Wehler (Hrsg.), Kulturgeschichte Heute, Göttingen 1996, S. 212-30; JÜrgEN KocKA, Annäherung und neue Distanz. Historiker und Sozialwissenschaftler seit den fünfziger Jahren, in: Manfred HetTling und Paul Nolte (Hrsg.), Nation und Gesellschaft in Deutschland. Historische Essays. Festschrift für Hans-Ulrich Wehler zum 65. Geburtstag, München 1996, S. 15-31, hier S. 25f.; Peter SCHÖTTLER, Wer hat Angst vor dem „linguistic turn“?, in: GG 23 (1997), S. 134-51 sowie UTE DANIEL, Clio unter Kulturschock. Zu den aktuellen Debatten der Geschichtswissenschft, in: GWU 48 (1997), S. 195-218 und 259-78.

103 Vgl. Thomas Mergel, Kulturgeschichte - die neue „große Erzählung“? Wissenssoziologische Bemerkungen zur Konzeptionalisierung sozialer Wirklichkeit in der Geschichtswissenschaft, in: HARDTWIG und Wehler (Hrsg.), S. 41-77 sowie OTTO Gerhard OeXLe, Geschichte als Historische Kulturwissenschaft?, in: ebd., S. 14-40.

104 Wolfgang Hardtwig und Hans-Ulrich Wehler, Einleitung, in: Dies. (Hrsg.), S. 7-13, hier S. 10; vgl. Clemens KNOBLOCH, Überlegungen zur Theorie der Begriffsgeschichte aus sprach- und kommunikationswissenschaftlicher Sicht, in: AfB 35 (1992), S. 7-24.

105 Vgl. Umberto Eco, Semiotik und Philosophie der Sprache, München 1985, S. 30 ff.; DERS., Die Grenzen der Interpretation, München 1995, S. $337 \mathrm{ff}$. und $350 \mathrm{ff}$. sowie BRIGitTe Schlieben-Lange, Linguistische Pragmatik, 2. Aufl. Stuttgart 1979, S. $24 \mathrm{ff}$. und $43 \mathrm{ff}$. 
Eng verknüpft mit dieser kulturgeschichtlichen Neuorientierung der Geschichtswissenschaft ist die diskursanalytische Position. ${ }^{106}$ Gegenüber dem philosophischen Diskursbegriff, der vor allem auf Jürgen Habermas' Konzeption eines rationalen, herrschaftsfreien Gesprächs zwischen aufgeklärten und gleichberechtigten Subjekten zurückgeht und keine Beschreibung einer empirischen Wirklichkeit, sondern eine normative Idee formuliert, ${ }^{107}$,an der sich konkrete empirische Diskurse orientieren sollen",108 begriff Michel Foucault Diskurse als über die Ebene des rein hermeneutisch ergründbaren Textes hinausgehende institutionalisierte oder institutionalisierbare Redeweisen, deren Regeln und Mechanismen einer empirischen Analyse unterzogen werden können. ${ }^{109}$ Die Anhänger dieser Richtung haben der traditionellen Begriffsgeschichte eine grundlegende „sprachtheoretische Unsicherheit“ angelastet, weil sie den historischen Grundbegriffen vorschnell eine qualifizierte Form sprachlicher Zeichen zuspreche anstatt die „Analyse der Voraussetzungen kommunikativen Handelns zu betreiben".110 In diesem Sinne erweise sich, so Peter Schöttler, die Diskursanalyse „breiter“ als die „punktuelle Begriffsgeschichte". 111 Die daraus ableitbaren Postulate, die in der Forderung nach einer sowohl diskursanalytischen als auch sozialhistorischen Erweiterung der Begriffsgeschichte münden, sind inzwischen in historisch-textpragmatischen Studien aufgenommen worden. ${ }^{112}$

106 Vgl. SCHÖTtler, Angst, S. 138 ff.; Ders., Sozialgeschichte, „Erfahrungsansatz“ und Sprachanalyse, in: Kulturrevolution. Zeitschrift für angewandte Diskurstheorie 11 (1986), S. 56-60; DERS., Sozialgeschichtliches Paradigma und historische Diskursanalyse, in: JÜrgen FohrmanN und HARRo MÜller (Hrsg.), Diskurstheorien und Literaturwissenschaft, Frankfurt a.M. 1988, S. 159-99; PETER SCHÖTTLER, Einleitung, in: Gareth Stedman Jones, Klassen, Politik und Sprache. Für eine theoriegeleitete Sozialgeschichte, hrsg. von Peter SCHÖtTler, Münster 1988, S. 9-41 sowie Ders., Mentalitäten, Ideologien, Diskurse. Zur sozialgeschichtlichen Thematisierung der „dritten“ Ebene, in: AlF LÜDTKE (Hrsg.), Alltagsgeschichte. Zur Rekonstruktion historischer Erfahrungen und Lebensweisen, Frankfurt a. M. 1989, S. 85-136.

107 Vgl. JÜrgen Habermas und Niklas Luhmann, Theorie der Gesellschaft oder Sozialtechnologie. Was leistet die Systemtheorie?, Frankfurt a.M. 1971, S. $114 \mathrm{ff}$. und 195 ff. sowie JÜrgen Habermas, Der philosophische Diskurs der Moderne, Frankfurt a.M. 1985 , S. $390 \mathrm{ff}$.

108 SCHÖTTLER, Angst, S. 139.

109 Vgl. Michel Foucault, Interview mit J. J. Brochier (1969), in: Ders., Dits et Ecrits, Bd. 1, Paris 1994, S. 772; Ders., Archäologie des Wissens (1969), 5. Aufl. Frankfurt a. M. 1992, S. 169-71; Ders., Die Ordnung des Diskurses (1971), München 1974, passim sowie Philippe Sarasin, Subjekte, Diskurse, Körper. Überlegungen zu einer diskursanalytischen Kulturgeschichte, in: HARDTWIG und WeHLER (Hrsg.), S. 131-64.

110 Dietrich Busse, Historische Semantik. Analyse eines Programms, Stuttgart 1987, S. 73; vgl. ferner DERS. (Hrsg.), Diachrone Semantik und Pragmatik. Untersuchungen zur Erklärung und Beschreibung des Sprachwandels, Tübingen 1991 sowie DERs., Fritz Hermanns und Wolfgang TeuberT (Hrsg.), Begriffsgeschichte und Diskursgeschichte. Methodenfragen und Forschungsergebnisse der historischen Semantik, Opladen 1994.

111 SCHÖTTLER, Mentalitäten, S. 116; vgl. BOLlENBECK, S. 316.

112 Vgl. Hans-Ulrich Gumbrecht, Historische Textpragmatik als Grundlagenwissen- 
Angesichts der vielversprechenden Anfänge im Kontext der Annales verwundert es, daß französische Arbeiten im Sinne historisch-semantischer Längsschnittanalysen eine Ausnahme geblieben sind. ${ }^{113}$ Signifikant für diesen Sachverhalt ist nicht zuletzt das von deutschen Historikern herausgegebene HPSG. Eine wichtige Ausnahme bilden indes die von Jacques Guilhaumou unternommenen Forschungen zur Bedeutung der Sprache der Französischen Revolution, die eine Vielzahl weiterer Arbeiten angeregt haben. ${ }^{114}$ Ausgehend von diesen Forschungen und den Vorarbeiten des HPSG werden auf deutscher Seite auf der Ebene des semantischen Kulturtransfers die spezifischen Rezpetionswege des französischen Revolutionsvokabulars in Deutschland analysiert. ${ }^{115}$

In der angelsächsischen Forschung kommt Fragen nach dem Verhältnis von Sprache und Geschichte in den letzten Jahren ein immer größer werdender

schaft der Geschichtschreibung, in: Lendemains 6 (1977), S. 125-36; Ders., Fundierung, S. $75 \mathrm{ff}$.; zu empirischen Beipielen vgl. DerS., Funktionen parlamentarischer Rhetorik in der Französischen Revolution. Vorstudien zur Entwicklung einer historischen Textpragmatik, München 1978; G. KalivodA, Parlamentarische Rhetorik und Argumentation. Untersuchungen zum Sprachgebrauch des Ersten Vereinigten Landtags in Berlin 1847, Berlin 1986; WERNER HOLLY, Zur Geschichte parlamentarischen Sprachhandelns in Deutschland. Eine historisch-pragmatische Skizze an Beispielen aus ersten Sitzungen von verfassungsgebenden Versammlungen, in: Zeitschrift für Literaturwissenschaft und Linguistik 47 (1982), S. 10-48 sowie T. CHILDERS, Languages of Liberalism. Liberal Political Discourse in the Weimar Republik, in: K. JARAUSCH und L. E. JONES (Hrsg.), In Search of a Liberal Germany, New York 1990, S. 323-59.

$113 \mathrm{Vgl}$. LuCIEN FebVRE, Les mots et les choses en histoire économique, in: Annales d'histoire économique et sociale 2 (1930), S. 231-4, deutsch: Wörter und Dinge in der Wirtschaftsgeschichte, in: DeRs., Das Gewissen des Historikers, hrsg. von UlRICH RAUlFF, Berlin 1988, S. 23-6, hier S. 23 f.; LuCien Febvre, Zur Entwicklung des Wortes und der Vorstellung von „Civilisation“ (französisch 1930), in: ebd., S. 39-77; L. GIRARD, Histoire et lexicographie, in: Annales 18 (1963), S. 1128-32; Ulrich RAUlfF, Ein Historiker im 20. Jahrhundert: Marc Bloch, Frankfurt a. M. 1995, S. 250 f. sowie SCHÖTTLER, Sozialgeschichtliches Paradigma, S. $159 \mathrm{ff}$.

114 Vgl. Jacques Guilhaumou, Langages et Idéologies. Le Discours comme Objet de l'Histoire, Paris 1974; Ders., Sprache und Politik in der Französischen Revolution, Frankfurt a.M. 1989 sowie M. Tournier, R. Arnault, L. Cavaciuti, A. GefFroy und F. Theuriot, Le vocabulaire de la Révolution. Pour un inventaire systématique des textes, in: Annales historiques de la Révolution française 41 (1969), S. 104-24; Dictionnaire des usages socio-politiques (1770-1815), Bd. 1: Désignants socio-politiques, Bd. 2: Notions-concepts, Bd. 3: Dictionnaires, normes, usages, Bd. 4: Désignants socio-politiques, Bd. 5: Langue, occitan, usages, Paris 1985-1991.

$115 \mathrm{Vgl}$. Rolf ReichardT, „Freymüthigkeit, doch kein Sans-Cülotismus ...“ Transfer und Transformation der Französischen Revolution in Verdeutschungen französischer Revolutionsschriften 1789-1799, in: Michel Espagne und Michael Werner (Hrsg.), Transferts. Les relations culturelles dans l'espace franco-allemand (XVIIIeXIX ${ }^{\mathrm{e}}$ siècle), Paris 1988, S. 273-326; HANs-JÜrgen LÜSEbrink und ROLF ReICHARDT, Histoire des concepts et transferts culturels, 1770-1815. Note sur une recherche, in: Genèses. Sciences sociales et histoire 14 (1994), S. 27-41; JÖRN LEONHARD, von den ,idées libérales' zu den ,liberalen Ideen': Historisch-semantischer Kulturtransfer zwischen Übersetzung, Adaption und Intergration, in: MARC SCHALENBERG (Hrsg.), Kulturtransfer im 19. Jahrhundert, Berlin 1998, S. 13-45. 
Stellenwert zu. Besondere Bedeutung für diese Entwicklung hat insbesondere die sogenannte history of ideas bzw. intellectual history. ${ }^{116}$ Darüber hinaus haben vor allem J. G. A. Pocock, Quentin Skinner und die ihnen zugeordneten Mitglieder der sogenannten Cambridge School mit ihren Arbeiten versucht, die hinter spezifischen Ideologien stehende language zu rekonstruieren. Exemplarisch hat J. G. A. Pocock bei politischen Denkern der englischen Revolution wie Harrington die Sprache des klassischen Republikanismus analysiert. ${ }^{117} \mathrm{Ge}$ genüber solchen Methoden hat sich Skinner vor allem auf den Wandel von Bedeutungen konzentriert. ${ }^{118}$ Wichtig erscheint vor allem, daß sowohl Pocock als auch Skinner an einem grundsätzlich interpretativ-hermeneutischen Zugriff auf Texte festhalten. Daraus ergibt sich trotz zahlreicher Unterschiede auch eine Vielzahl von Berührungspunkten mit der deutschen begriffsgeschichtlichen Tradition.

Ein Dialog zwischen den unterschiedlichen Konzepten, für den sich Melvin Richter in den USA und in Großbritannien intensiv einsetzt, steht erst am Anfang. ${ }^{119}$ J. G. A. Pocock hat in einem direkten Austausch mit Reinhart Kosel-

116 Vgl. William J. BA, Intellectual History in the 1980s: From History of Ideas to History of Meaning, in: JIH 12 (1981), S. 279-91; J. G. A. POCOCK und QUENTIN SKINNER, What is Intellectual History?, in: History Today 35 (1985), S. 46-54 sowie Michael Ermath, Mindful Matters, in: JMH 57 (1985), S. 506-27; für den amerikanischen Zweig vgl. Arthur O. Lovejoy, The Great Chain of Being, Cambridge/Mass. 1948 sowie Philip Wiener (Hrsg.), Dictionary of the History of Ideas, 5 Bde., New York 1973.

117 Vgl. J. G. A. Pососк, Verbalizing a Political Act: Towards a Politics of Speech, in: MICHAEL J. ShaPiro (Hrsg.), Language and Politics, Oxford 1984, S. 25-43; J. G. A. POCOCK, The Concept of a Language and the Métier d'historien: Some Considerations on Practice, in: ANTHONy PAgden (Hrsg.), The Languages of Political Theory in Early-Modern Europe, Cambridge 1987, S. 19-38; J. G. A. Pocock, Machiavelli, Harrington and English Political Ideologies in the Eighteenth Century, in: DERs., Politics, Language and Time, London 1972, S. 104-47. Die wichtigsten Beiträge Pococks sind nunmehr zusammengefaßt in J. G. A. Pососк, Virtue, Commerce, and History. Essays on Political Thought and History, chiefly in the Eighteenth Century, Cambridge 1995; vgl. auch IAIN HAMPSHER-MONK, Review Article: Political Languages in Time The Work of J. G. A. Pocock, in: British Journal of Political Science 14 (1984), S. 89-116; Terence Ball und J. G. A. Pocock (Hrsg.), Conceptional Change and the Constitution, Lawrence/Kansas 1988; TERENCE BALL, JAmes FARR und Russell L. HANSON (Hrsg.), Political Innovation and Conceptional Change, Cambridge 1989 sowie Terence Ball, Transforming Political Discourse: Political Theory and Critical Conceptional History, Oxford 1988; vgl. ferner MONIKA WIENFORT, Monarchie in der bürgerlichen Gesellschaft. Deutschland und England von 1640 bis 1848, Göttingen 1994, S. 15.

118 Vgl. Quentin Skinner, Language and Social Change, in: L. Michaels und C. Ricks (Hrsg.), The State of the Language, Berkeley 1980, S. 562-78; QUENTin SKinNER, Language and Political Change, in: BALL et al. (Hrsg.), Political Innovation, S. 6-23 sowie James Tully und QuenTin SKInNER (Hrsg.), Meaning and Context: Quentin Skinner and His Critics, Princeton 1989.

119 Vgl. Melvin Richter, Zur Rekonstruktion der Geschichte der Politischen Sprachen: Pocock, Skinner und die Geschichtlichen Grundbegriffe, in: HANS ERICH BÖDEKER 
leck zunächst die Diskursanalyse höher als die punktuelle Begriffsgeschichte eingeschätzt und dabei insbesondere den synchronen Aspekt des Untersuchungsansatzes hervorgehoben. ${ }^{120}$

Ein weiterer Kritikpunkt der Cambridge School wendet sich gegen das von Koselleck in den GGB vertretene Konzept der Sattelzeit geschichtlicher Grundbegriffe zwischen 1750 und 1850. Pococks Hinweis auf die ganz andere Sattelzeit des politisch-sozialen Vokabulars in England, für die eher die Phase zwischen 1500 und $1800 \mathrm{zu}$ untersuchen wäre, ${ }^{121}$ führt direkt zur Notwendigkeit vergleichender Analysen, bei der zudem die Bedingungen des Diskurses berücksichtigt werden müssen: Nicht allein die Begriffsgeschichte, sondern auch die diesen Bedingungen nachgehenden methodischen Ansätze seien „historically, culturally, and nationally specific." 122 In der Bilanz seines Konzepts hat Reinhart Koselleck die methodische Funktion der Sattelzeit selbst durchaus kritisch beurteilt. Für begriffsgeschichtliche Analysen stellt sie jedenfalls keine conditio sine qua non dar, und zwar weder im Hinblick auf den deutschen Sprachraum noch für andere nationalsprachliche Diskurse. Eher scheint hier der Begriff der Schwellenzeit angezeigt. ${ }^{123}$

Beim Blick auf die zuletzt vorgestellten französischen und die angloamerikanischen Ansätze läßt sich konstatieren, daß sie zumeist synchron angelegt sind und vor dem Hintergrund der diskursanalytischen Ansätze mit einer Vielzahl von Begriffen operieren, wobei sie allerdings durch die Konzentration auf die „essentially contested concepts“ zu selten auf die Ebene der alltäglichen politischen Argumentation vorstoßen und zumeist bei den großen politischen Theoretikern stehenbleiben. ${ }^{124}$ Auch die fokussierende Wirkung einzelner Grundbegriffe für Erfahrungsräume und Erwartungshorizonte, ihr spezifischer Stellenwert im politisch-sozialen Vokabular sowie vor allem der Bedeutungswan-

und ERNST HinRICHS (Hrsg.), Alteuropa oder frühe Neuzeit? Probleme und Methoden der Forschung, Stuttgart 1990, S. 134-74; MELVIN RiCHTER, Begriffsgeschichte in Theory and Practice: Reconstructing the History of Political Concepts and Language, in: Willem Melching und Wyger Velema (Hrsg.), Main Trends in Cultural History, Amsterdam 1994; Melvin Richter, The History of Political and Social Concepts. A Critical Introduction, New York 1995; vgl. zuletzt die Beiträge in HARTMUT Lehmann und Melvin Richter (Hrsg.), The Meaning of Historical Terms and Concepts. New Studies on Begriffsgeschichte, Washington 1996.

120 Vgl. J. G. A. Pocock, Concepts and Discourses: A Difference in Culture? Comment on a Paper by Melvin Richter, in: LeHMANN und RichTER (Hrsg.), S. 47-51 und 58; Reinhart Koselleck, A Response to Comments on the Geschichtliche Grundbegriffe, in: ebd., S. 59-70 sowie Melvin Richter, Opening a Dialogue and Recognizing an Achievement. A Washington Conference on the Geschichtliche Grundbegriffe, in: AfB 39 (1996), S. 19-26.

121 Vgl. J. G. A. Pocock (Hrsg.), The Varieties of British Political Thought, 1500-1800, Cambridge 1994, passim.

122 Pocock, Concepts and Discourses, S. 58.

123 Vgl. Koselleck, Response, S. 69.

124 Vgl. Willibald SteinmetZ, Das Sagbare und das Machbare. Zum Wandel politischer Handlungsspielräume, England 1780-1867, Stuttgart 1993, S. 32 f. 
del im diachronen Längsschnitt wird weitgehend ausgeblendet oder kommt zu kurz. ${ }^{125}$ Die dominierende synchrone Untersuchungsperspektive und die Rekonstruktion einer language auf dieser Basis verstellt den Blick auf die spezifische Interdependenz zwischen der Kontinuität überindividueller politisch-sozialer Grundbegriffe als unumgängliche Voraussetzungen für jeden Diskurs einerseits und der je spezifischen Konkretion durch Neubestimmung, Rezeption und Transfer in jeweils einmaligen historischen Situationen andererseits.

c) Konkretisierung des Forschungsstandes:

Zur komparativen Einordnung historisch-semantischer Deutungsmuster

In der Liberalismus-Forschung hat sich wie in der Bürgertums-Forschung insgesamt der Vergleich als methodisches Paradigma zwar etablieren können; die meisten Studien leisten aber häufig noch keine echten komparativen Synthesen, sondern stellen mehr oder weniger additiv einzelne Vergleichsfälle nebeneinander. Dies gilt, ungeachtet aller Vorzüge der Einzelbeiträge, sowohl für den regionalen als auch für den internationalen Vergleich des deutschen Liberalismus. Es ist kein Zufall, daß bei diesen Ansätzen der Sammelband die dominierende Publikationsform darstellt. Dies hat nicht zuletzt auch mit den völlig unterschiedlichen Voraussetzungen der Liberalismus-Forschung in den verschiedenen Ländern zu tun, die wiederum auf einen ganz unterschiedlichen Stellenwert des Phänomens hinweisen. Während etwa der deutsche Liberalismus in seinen lokalen und regionalen Ausprägungen auch über 1850 hinaus seit Jahren ein attraktives Forschungsterrain darstellt, konnte Heinz-Gerhard Haupt noch 1989 feststellen, daß ,in Frankreich eine der deutschen Liberalismus-Forschung an Qualität und Umfang ähnliche Diskussion“ fehle.126 Obgleich nicht zu übersehen ist, daß sich die Ausgangsbedingungen sowohl für den deutschenglischen, den deutsch-italienischen und jüngst verstärkt auch für den deutsch-französischen Vergleich erheblich verbessert haben, hat die Liberalismus-Forschung davon erst in Ansätzen profitiert.

Das Dilemma zwischen dem theoretischen Vergleichspostulat und einem ausgesprochenen Manko an empirischen Studien gilt trotz einzelner Ausnahmen gerade auch für den Bereich des Kulturvergleichs. So sehr der linguistic turn der Geschichtswissenschaften in Europa und den USA das Interesse am Verhältnis von Sprache und Geschichte gefördert hat und so sehr Diskussionen um die theoretischen Prämissen und die sozialpsychologisch aufschließende Funktion von Begriffen und Diskursen zugenommen haben, so sehr fällt jenseits der lexikalischen Großunternehmen der eklatante Mangel an länderübergreifenden empirisch fundierten Einzelstudien auf. Gemessen am internationa-

125 Vgl. Reinhart Koselleck, Abstraktheit und Verzeitlichung in der Revolutionssprache, in: Rolf ReIchHardT und Reinhart Koselleck (Hrsg.), Die Französische Revolution als Bruch des gesellschaftlichen Bewußtseins, München 1988, S. 224-6, hier S. 224.

126 Haupt, Soziales Milieu, S. 294, Anmerkung 3. 
len Interesse an Fragen der historischen Semantik erscheint die Anzahl an Studien mit komparativen Fragestellungen weiterhin gering. Lediglich aus einigen über Deutschland hinausgehenden Arbeiten lassen sich verstreute Ansätze international vergleichender Untersuchungen ableiten. ${ }^{127}$ Aufgehellt wird dieses Bild allerdings durch einige neuere komparative Studien zum Bürgertums- und Mittelklasse-Begriff in seinen verschiedenen europäischen Kontexten ${ }^{128}$ sowie durch neuere Ansätze im Rahmen der politikwissenschaftlich-vergleichenden Analyse des Verhältnisses von politischer Sprache und politischer Kultur in Deutschland und Großbritannien. ${ }^{129}$

Für das konkrete Forschungsunternehmen einer komparativen historischen Semantik von Liberalismus ergeben sich entsprechend den ganz unterschiedli-

127 Vgl. Jens A. Christophersen, The Meaning of „Democracy“ as used in European ideologies from the French to the Russian Revolution. An Historical Study in Political Language, Oslo 1966; Arnold J. Heidenheimer, Politics, Policy and Policey as Concepts in English and Continental Languages: An Attempt to Explain Divergences, in: RevPol 48 (1986), S. 3-30; KARI PALONEN, Politik als „chamäleonartiger“ Begriff: Reflexionen und Fallstudien zum Begriffswandel der Politik, Helsinki 1985; Ders., Die Thematisierung der Politik als Phänomen: Eine Interpretation der Geschichte der Politik im Frankreich des 20. Jahrhunderts, Helsinki 1989 sowie J. LEENHARDT und R. PICHT (Hrsg.), Esprit / Geist. 100 Schlüsselbegriffe für Deutsche und Franzosen, München 1989.

128 Vgl. Reinhart Koselleck, Willibald SteinmetZ und Ulrike Spree, Drei bürgerliche Welten? Zur vergleichenden Semantik der bürgerlichen Gesellschaft in Deutschland, England und Frankreich, in: H.-J. PuHLE (Hrsg.), Bürger in der Gesellschaft der Neuzeit, Göttingen 1991, S. 15-58; Willibald STEINMETZ, Gemeineuropäische Tradition und nationale Besonderheiten im Begriff der „Mittelklasse.“ Ein Vergleich zwischen Deutschland, Frankreich und England, in: ReINHART KosellecK und Klaus SCHREINER (Hrsg.), Bürgerschaft. Rezeption und Innovation der Begrifflichkeit vom Hohen Mittelalter bis ins 19. Jahrhundert, Stuttgart 1994, S. 161-236; UlRIKE SPREE, Die verhinderte „Bürgerin“? Ein begriffsgeschichtlicher Vergleich zwischen Deutschland, Frankreich und Großbritannien, in: ebd., S. 274-306; ANDREAS WirSCHING, Bürgertugend und Gemeininteresse. Zum Topos der „Mittelklassen“ in England im späten 18. und frühen 19. Jahrhundert, in: AKG 72 (1990), S. 173-99 sowie zuletzt IAin Hampsher-Monk, Karin Tilmans und Frank van VRee, History of Concepts: Comparative Perspectives, Amsterdam 1998.

129 Vgl. Andreas Dörner und Karl Rohe, Politische Sprache und Politische Kultur. Diachron-kulturvergleichende Sprachanalysen am Beispiel von Großbritannien und Deutschland, in: MANFRED OpP DE HiPT und ERICH LATNIAK (Hrsg.), Sprache statt Politik? Politikwissenschaftliche Semantik- und Rhetorikforschung, Opladen 1991, S. 38-65; KARL RoHe, Zur Typologie politischer Kulturen in westlichen Demokratien. Überlegungen am Beispiel Großbritanniens und Deutschlands, in: HeINZ DoLLINGER, HORST GRÜNDER und AlwIN HANSCHMIDT (Hrsg.), Weltpolitik, Europagedanke, Regionalismus. Festschrift für Heinz Gollwitzer zum 65. Geburtstag, Münster 1982, S. $581 \mathrm{ff}$.; ANDREAS DÖRNER, Politische Lexik in deutschen und englischen Wörterbüchern. Metalexikographische Untersuchungen in kulturwissenschaftlicher Absicht, in: GREgor MEDER und ANDREAs DörNER (Hrsg.), Worte, Wörter, Wörterbücher. Lexikographische Beiträge zum Essener Linguistischen Kolloquium 19831989, Tübingen 1990, S. 123-45 sowie WOlfGang SeCK, Politische Kultur und politische Begrifflichkeit in Deutschland und Großbritannien, Essen 1990. 
chen Schwerpunkten in der Forschung der Vergleichsländer extrem heterogene Voraussetzungen. ${ }^{130}$ Für England, noch mehr für Frankreich und Italien lassen sich allenfalls verstreute Informationen konstatieren, obgleich zumal in der jüngsten englischen Forschung das Unbehagen an der nicht hinreichend geklärten historischen Dimension von liberal und conservative deutlich faßbar ist. ${ }^{131}$ Am günstigsten stellt sich die Situation für Deutschland dar, wo mit den einschlägigen Artikeln der GGB ${ }^{132}$ zumindest die erste Jahrhunderthälfte kein unerschlossenes Terrain mehr darstellt. Für die übrigen Vergleichsländer stellen die großen nationalsprachlichen Wörterbücher und Sprachgeschichten einen ersten Zugang dar. ${ }^{133}$ Für Frankreich ist neben verstreuten Hinweisen ein ent-

130 Vgl. zunächst als Vorarbeiten: Guillaume DE BerTier de SAuvignY, Liberalism, Nationalism, Socialism: The Birth of Three Words, in: RevPol 32 (1970), S. 147-66 sowie Marco Ferrari, Libéral da aggettivo a sostantivo (ed ,ismo'), in: Il Pensiero Politico. Rivista di Storia delle Idee Politiche e Sociali 23 (1990), S. 459-69.

131 Vgl. James J. SACK, From Jacobite to Conservative. Reaction and Orthodoxy in Britain, c. 1760-1832, Cambridge 1993, S. 1-7; Jonathan PARRY, The Rise and Fall of Liberal Government in Victorian Britain, New Haven 1993, S. 1; keine verwertbaren Hinweise dagegen enthalten JOHN VinCENT, The Formation of the British Liberal Party, 1857-1868, London 1966 sowie Alan SyKes, The Rise and Fall of British Liberalism, 1776-1888, London / New York 1997; vgl dazu die Rezension von JÖRN LEONHARD in: JbLibF 11 (1999), S. 276-9.

132 Vgl. Vierhaus, Liberalismus, S. 741 ff.; RUdolf Walther, Wirtschaftlicher Liberalismus, in: Brunner et al. (Hrsg.), Bd. 3, S. 787-815; Peter Wende, Radikalismus, in: ebd., Bd. 5, S. 113-33; Rudolf Vierhaus, Konservativ, Konservatismus, in: ebd., Bd. 3, S. 531-65; PANAJOTIS Kondylis, Konservatismus. Geschichtlicher Gehalt und Untergang, Stuttgart 1986, passim; U. Dierse, H. Dräger und R. K. Hocevar, Liberalismus, in: RitTer und GrÜNDER (Hrsg.), Bd. 5, Sp. 255-72; Helmut Asmus, Liberalismus, Liberale, in: Helmut Reinalter (Hrsg.), Lexikon zu Demokratie und Liberalismus 1750-1848/49, Frankfurt a.M. 1993, S. 200-8; KARL-GEORG FABER, „Konservatorischer Liberalismus“, „umstürzender Liberalismus“, „konservatorischer Obskurantismus." Aus dem Briefwechsel zwischen Marschall und Almendingen (1823), in: Nassauische Annalen 78 (1967), S. 177-208; vgl. für Belegstellen ferner Helene Guyot, Der Liberalismus in Pestalozzis Pädagogik, Göttingen 1935, S. 9f.; Wolf WÜlfing, Schlagworte des Jungen Deutschland. Mit einer Einführung in die Schlagwortforschung, Berlin 1982, passim; PeTER von Polenz, Deutsche Sprachgeschichte vom Spätmittelalter bis zur Gegenwart, Bd. 2, Berlin 1994, S. 394 f.; KURT Sontheimer, Antidemokratisches Denken in der Weimarer Republik (1962), München 1992, S. 143 ff.; WOLFGANG SUCHAROWSKI, „Liberal“ im gegenwärtigen Sprachgebrauch. Linguistische, psycholinguistische und semantische Studien im Jahr 1971, München 1975 sowie Christian SchotTmann, Politische Schlagwörter in Deutschland zwischen 1929 und 1934, Stuttgart 1997, S. 273 ff.

133 Vgl. für England: The Oxford English Dictionary. Prepared by J. A. SimPson and E. S. C. WeINER, Bd. 8, 2. Aufl. Oxford 1989, S. 881-3; für Frankreich: WALTHER vON WARTBURG, Französisches Etymologisches Wörterbuch. Eine darstellung des galloromanischen sprachschatzes [sic!], Bd. 5, Basel 1950, S. 298-300; PAUL ROBERT, Dictionnaire alphabétique et analogique de la Langue Française. Les mots et les associations d'idées, Bd. 4, Paris 1971, S. 88 f.; Trésor de la Langue Française. Dictionnaire de la langue du XIXe et du XX X $^{\mathrm{e}}$ siècle (1789-1960), hrsg. vom Centre National de la Recherche Scientifique / Institut National de la Langue Française Nancy, Bd. 7, Paris 1983, S. 1156-60; FERDINAND BRUNOT, Histoire de la Langue Francaise des origines à 
sprechender Artikel zu libéral/libéralité im HPSG vorgesehen, der aber gemäß der zeitlichen Beschränkung des Projekts nicht über 1820 hinausgehen wird. ${ }^{134}$ Für England liegen neben Vorarbeiten zum deutsch-englischen Vergleich lediglich impressionistische Darstellungen und verstreute Hinweise vor, ${ }^{135}$ wobei hier die Einordnung von liberal und conservative gegenüber den tradierten politischen Etiketten whig und tory eine besondere Herausforderung darstellt. ${ }^{136}$

nos jours, Bd. 3/1: La formation de langue classique, Paris 1966, S. 233; Bd. 6/1: Le XVIIIe siècle. Le mouvement des idées et des vocabulaires techniques, Paris 1966, S. 129 und 477; Bd. 6/2: La langue postclassique, Paris 1967, S. 1232 und 1255; Bd. 9/2: La Révolution et l'Empire. Les événements, les institutions et la langue, Paris 1967, S. $660 \mathrm{ff}$. und 913; Bd. 10/2: La langue classique dans la tourmente. Le retour à l'ordre et à la discipline, Paris 1968, S. 762 und 817 sowie für Italien: Salvatore Battaglia, Grande Dizionario della lingua italiana, Bd. 9, Turin 1975, S. 2-6.

134 Vgl. JeAn Dubois, Le vocabulaire politique et social en France de 1869 à 1872 . A travers les œuvres des écrivains, les revues et les journaux, Paris 1963, S. 76 und $331 \mathrm{ff}$.; Georges Matoré, Le Vocabulaire et la société sous Louis Philippe, Genf 1967, S. 36; Theodore Zeldin, France 1848-1945, Bd. 1: Ambition, Love and Politics, Oxford 1973, S. 506 f. sowie zuletzt JÖRN LEONHARD, „1789 fait la ligne de démarcation“: Von den napoleonischen ,idées libérales' zum ideologischen Richtungsbegriff ,libéralisme“ in Frankreich bis 1850, in: JbLibF 11 (1999), S. 67-105.

135 Vgl. JÖRN LEONHARD, „An odious but intelligible phrase... “- , Liberal“ im politischen Diskurs Deutschlands und Englands bis 1830/32, in: JbLibF 8 (1996), S. 11-41; DerS., Gesinnungsetikett, Parteibegriff oder Weltanschauung? Zur semantisch-komparativen Einordnung von ,liberal' in Deutschland und England im 19. Jahrhundert, in: Comparativ. Leipziger Beiträge zur Universalgeschichte und vergleichenden Gesellschaftsforschung (erscheint 2001) und Ders., From a Whig Attribute to an Utilitarian Basic Concept: Towards a Comparative History of ,liberal' in the English Political Transformation until 1832, in: JHI (erscheint voraussichtlich 2002); vgl. ferner HANS Petersen, Liberal im britischen Englisch. Eine Fallstudie zur historischen Semantik und Begriffsgeschichte, in: RoHe (Hrsg.), S. 101-32; Elie Halévy, A History of the English People in the Nineteenth Century, Bd. 2: The Liberal Awakening 1815-1830, 2. Aufl. London 1949, S. 81 f.; Thomas Patrick Neill, The Rise and Decline of Liberalism, Milwaukee 1953, S. 3ff.; Alan Bullock und Maurice SHock (Hrsg.), The Liberal Tradition, London 1956, S. LIII; I. Jennings, Party Politics, Bd.2: The Growth of the Parties, Cambridge 1961, S. 76; IRENE Collins, Liberalism in Nineteenth-Century Europe, in: W. N. Medlicott (Hrsg.), From Metternich to Hitler. Aspects of British and Foreign History 1814-1939, London 1963, S. 25-46, hier S. 25 f.; AsA BRIGGS, The Age of Improvement 1783-1867, London 1979, S. 218; IAN C. BRAdLeY, The Optimists: Themes and Personalities in Victorian Liberalism, London 1980, S. 17 ff. sowie Frederick Rosen, Bentham, Byron and Greece. Constitutionalism, Nationalism, and Early Liberal Political Thought, Oxford 1992, S. 292-4.

136 Vgl. SACK, S. 4 f.; JOHANN BAPTIST MÜLLER, Liberaler und autoritärer Konservatismus, in: AfB 29 (1985), S. 125-37; ROBERT WILlman, The Origins of , whig' and ,tory ${ }^{6}$ in English Political Language, in: HJ 17 (1974), S. 247-64; JoHN Brewer, Party Ideology and Popular Politics at the Accession of George III., Cambridge 1976, S. 39-54; J. G. A. Pocock, The Varieties of Whiggism, in: Ders., Virtue, S. 215-310 sowie JörN LEONHARD, „True English Guelphs and Ghibellines“: Zum historischen Bedeutungsund Funktionswandel von, whig' und ,tory' im englischen Politikdiskurs seit dem 17. Jahrhundert, in: AKG (erscheint 2002); zur Besonderheit des historischen Parteiwesens in England vgl. Karl RoHe, Parteien und Parteiensystem, in: Hans KastenDIEK, KARL ROHE und ANGelika Volke (Hrsg.), Länderbericht Großbritannien. Ge- 
Für Italien fehlen verwertbare Vorarbeiten weitgehend. Hier sind begriffsgeschichtliche Studien überhaupt erst in den letzten Jahren, angeregt durch die vergleichende Bürgertumsforschung, zunehmend stärker ins Blickfeld gelangt. 137 Der spanische Kontext, in dem von der Selbstbezeichnung liberales für die Konstitutionalisten in den Cortes von Cádiz von 1812 für das moderne politische Adjektiv wesentliche Impulse ausgingen, kann in dieser Untersuchung allenfalls am Rande berücksichtigt werden. ${ }^{138}$ Für die europäisch-amerikanische Vergleichsebene liegen Studien vor, ohne daß diese Perspektive hier aber weiterverfolgt werden kann. ${ }^{139}$ Neben die dominierende einzelstaatliche Perspektive der entsprechenden Artikel in den GGB und im HPSG, die einen Vergleich nicht vorsieht und allenfalls zufällige semantische Berührungspunkte zwischen den politisch-sozialen Vokabularen erfaßt, ${ }^{140}$ tritt als Manko vor allem die zeitliche Beschränkung des Untersuchungszeitraums, die die Phase nach 1850 für Deutschland bzw. nach 1820 für Frankreich allenfalls peripher in den Blick nimmt und damit wesentliche semantische Formationsstufen von

schichte - Politik - Wirtschaft - Gesellschaft, Bonn 1994, S. 213-29, hier S. 213 ff.; Martin Pugh, The Making of Modern British Politics 1867-1939, Oxford 1987; Alan R. Ball, British Political Parties. The Emergence of a Modern Party System, 2. Aufl. London 1987 sowie Hans SetZer, Wahlsystem und Parteiensystem in England. Wege zur Demokratisierung der Institutionen 1832-1948, Frankfurt a. M. 1973.

137 Vgl. Gribaudi, S. 236 ff.; Bruno Migliorini, Profili di Parole (1968), Neudruck Florenz 1970, S. 122-4; Christof DipPeR, Politischer Reformismus und begrifflicher Wandel. Eine Untersuchung des historisch-politischen Wortschatzes der Mailänder Aufklärung (1764-1796), Tübingen 1976; GERHARD KUCK, Italienische Wege des Sozialismus. Sozialismus- und Kommunismuskonzepte im Risorgimento (1765-1857), Frankfurt a. M. 1991; ErASMO Leso, Lingua e Rivoluzione. Ricerche sul Vocabolario Politico Italiano del Triennio Rivoluzionario 1796-1799, Venedig 1991; ANGELO D’Orsi, Guida alla Storia del Pensiero Politico, Florenz 1995, S. 53 ff.; Marco MeRIGGI, Italienisches und deutsches Bürgertum, S. 142 ff.; RAFFAELE ROMANELLI, Borghesia / Bürgertum / Bourgeoisie. Itinerari europei di un concetto, in: JÜRGEN KOCKA (Hrsg.), Borghesie europee dell'Ottocento. Edizione italiana hrsg. von AlBERTO MARio BANTI, Venedig 1989, S. 69-94; RafFaella Gherardi und Gustavo Gozzi (Hrsg.), I concetti fondamentali delle scienze sociale e dello Stato in Italia e in Germania tra Otto e Novecento, Bologna 1992 sowie DiEs. (Hrsg.), Saperi della borghesia e storia dei concetti fra Otto e Novecento, Bologna 1995; vgl. ferner JÖRN LEONHARD, ,Italia liberale' und ,Italia cattolica': Historisch-semantische Ursprünge eines ideologischen Antagonismus im frühen italienischen Risorgimento, in: QuFiAB 80 (2000) S. 495-542.

138 Vgl. J. MARICHal: España y las raíces semánticas del liberalismo, in: Cuadernos. Congresso per la libertad de la cultura (März/April 1955), S. 53-60 sowie L. DIEZ DEL Corral, El liberalismo doctrinario, 2. Aufl. Madrid 1956, S. 423.

139 Vgl. Ronald D. Rotunda, The Politics of Language. Liberalism as Word and Symbol, Iowa City 1986; HANs PeTERsen, Liberal im Amerikanischen. Eine Studie zur historischen Semantik im gesellschaftlichen Kontext, Kassel 1992 sowie LORE BlanKE, Liberalismus in den USA 1776-1996. Ein Überblick im Spiegel der deutschen und amerikanischen Historiographie, in: JbLibF 8 (1996), S. 43-67, hier S. $44 \mathrm{f}$.

140 Vgl. Reinhart Koselleck, Vorwort, in: Brunner et al. (Hrsg.), Bd. 7, S. V-VIII, hier S. VIII. 
Liberalismus ausklammert. Schließlich nötigt die Form des Lexikonartikels zu einer unumgänglich engen Begrenzung des Quellenkorpus, so daß sich die Frage nach der Repräsentativität der Aussagen stellt. Es steht zu erwarten, daß eine Ausweitung und Vertiefung des Quellenmaterials bei einer komparativen Fragestellung hier eine erhebliche Differenzierung zu leisten vermag.

\section{Methodische Grundlegung: Zur Konzeption einer komparativen historischen Semantik}

Die vorliegende Studie ist als komparative Vierländerstudie angelegt, die die historisch-semantische Genese und langfristige Transformation des politischsozialen Deutungsmusters Liberalismus in Frankreich, Deutschland, Italien und England einer systematischen Analyse unterzieht. Sie geht im Gegensatz $\mathrm{zu}$ ideengeschichtlichen Ansätzen nicht von einem universalistisch-zeitlosen Liberalismus-Begriff aus, sondern sucht im zeitgenössisch-diachronen Längsschnitt die historische Semantik vergleichend zu analysieren. Wichtig für diese Methode ist die Prämisse von den „Deplazierungen und Transformationen der Begriffe", die Michel Foucault in Anlehnung an Modellvorstellungen von Georges Canguilhem hervorgehobenen hat:

sie zeigen, daß die Geschichte eines Begriffs nicht alles in allem die seiner fortschreitenden Verfeinerung, seiner ständig wachsenden Rationalität, seines Abstraktionsanstiegs ist, sondern die seiner verschiedenen Konstitutions- und Gültigkeitsfelder, die seiner aufeinander folgenden Gebrauchsregeln, der vielfältigen theoretischen Milieus, in denen sich seine Herausarbeitung vollzogen und vollendet hat. ${ }^{141}$

Auf das konkrete Untersuchungsprogramm angewandt heißt dies, den Liberalismus-Begriff nicht als normativ intendierte unumkehrbare Fortschrittsgeschichte hin zu mehr Freiheit und Demokratie, als unreflektiertes politischkonstitutionelles Abbild einer kontinuierlichen Durchsetzung der Aufklärungs- und Emanzipationsidee zu begreifen, sondern nach seiner je spezifischen Bestimmung im zeitgenössischen Bezugsrahmen politisch-sozialer Auseinandersetzungen, Krisen und Umbrüche zu fragen. Für den entwickelten Bewegungsbegriff Liberalismus gilt dabei das Diktum Carl Schmitts, wonach jeder "politische Begriff ein polemischer Begriff“ sei. ${ }^{142}$ Schmitts programmatische Aussage deutet auf eine zweite Grundannahme des Untersuchungsprogramms hin, nämlich die konkrete Funktion politisch-sozialer Deutungsmuster als Werkzeuge und Kampfmittel in politischen Auseinandersetzungen. Begriffe sind für Schmitt gerade keine „sinnlosen Abstraktionen“ ${ }^{143}$ die als zeit-

141 Foucault, Archäologie, S. 11.

142 Carl SchmitT, Hugo Preuß. Sein Staatsbegriff und seine Stellung in der deutschen Staatslehre, Tübingen 1930, S. 5.

143 Vgl. Sabine Marquardt, Polis contra Polemos. Politik als Kampfbegriff der Weima- 
oder situationsunabhängig zu deuten wären, sondern sie sind eingebettet in die konkrete Sprechsituation und in die sprachliche Ordnung von Diskursen, von der keine historische Semantik abstrahieren kann, die über die Ebene einer lediglich semantisch aufgewerteten Ideengeschichte hinausgelangen will.

Die Charakterisierung der in der begriffsgeschichtlichen Forschung und ihr verwandten Disziplinen bestehenden Positionen hat Defizite in den jeweiligen Methoden erkennen lassen, die durch eine Verknüpfung und Kombination bestimmter Ansätze ausgeglichen werden sollen. Der Ausgangspunkt ist zunächst historisch-semantisch bestimmt, indem in einem durch das Deutungsmuster Liberalismus begrenzten Fokus nach semantischen Bestimmungs- und Interpretationsmustern gefragt und zugleich die diachrone Perspektive verfolgt wird. Erst im diachronen Längsschnitt wird das Spannungsverhältnis zwischen der relativen Kontinuität eines für den politischen Diskurs unverzichtbaren Grundbegriffs des politisch-sozialen Vokabulars und der jeweiligen Einmaligkeit der Neubestimmung des Begriffsfeldes in der Auseinandersetzung mit tradierten Bedeutungselementen deutlich. Diesen Zusammenhang, der aus der paradox anmutenden Existenz eines historistischen und eines antihistoristischen Elements der Sprache entsteht, charakterisiert am ehesten das Bild vom historischen Grundbegriff als semantisch formativem Medium für sich verändernde Erfahrungen und Erwartungen. Daraus ergibt sich zugleich sein Charakter als umstrittener, umkämpfter und polemischer Begriff.

Die sozialhistorische Dimension der Begriffsgeschichte resultiert aus der Konzeption von Sprache als Teil des sozialen Wissens, das sprachlich durch spezifische Bedeutungsträger bzw. Typen konstituiert wird. Liberalismus steht dabei für einen Typus, der durch seinen Abstraktionsgrad, sein semantisches Innovationspotential und die in ihm kondensierten und fermentierten Erfahrungen und Projektionen Rückschlüsse auf die Veränderungen des sozialen Wissens in unterschiedlichen Zeitschichten zuläßt. Genese und Transformation von Liberalismus läßt in diesem Sinne „eine von den historischen Akteuren nicht initiierte oder gesteuerte Transformation von Grundelementen des sozialen Wissens nachvollziehbar" werden. ${ }^{144}$

Aus der diskursanalytischen Perspektive ergibt sich die Frage nach Mechanismen innerhalb des Kommunikationssystems, durch die semantische Argumente und Topoi eine spezifische Ausrichtung erhalten. In einem allgemeinen Sinne soll der Untersuchung zunächst ein Diskursbegriff zugrundegelegt werden, der in erster Linie den Kommunikationszusammenhang von Redner und Adressat und damit die konkreten gesellschaftlichen Bezüge jeder historischen Semantik betont. Im engeren Sinne läßt sich der Diskurs als spezifische Form einer in Quellen nachweisbaren Rede in einem begrenzbaren Zeitraum definieren, der durch einen abgrenzbaren Gegenstand bzw. ein spezifisches Thema ge-

rer Republik, Weimar 1997, S. 14 ff. und 5; vgl. ferner CARL SCHMITT, Der Begriff des Politischen, Hamburg 1933, S. 13.

144 GumbrechT, Fundierung, S. 86. 
kennzeichnet ist und von einer sozial bestimmbaren Trägergruppe oder einem Akteur praktiziert wird. ${ }^{145}$ Für das Funktionieren eines politischen Diskurses ist die Existenz von Grundbegriffen als Fokussierungsinstrumente dabei unverzichtbar. Zugleich werden die semantischen Transformationen von Grundbegriffen selbst erst in Diskursen realisiert, und zwar in der Auseinandersetzung mit überlieferten Begriffen und Bedeutungsinhalten. Politischer Diskurs und politisch-soziale Deutungsmuster stehen von daher in einem engen wechselseitigen Bedingungsverhältnis. Damit wird der Diskurs als die pragmatische Ebene der historisch-semantischen Konkretisierung in die Analyse integriert, als „der Ort der Ausdifferenzierung der Wörter, damit zugleich auch ihrer wechselseitigen Interpretation “. ${ }^{146}$

Schließlich treten in die Analyse der historischen Semantik im weitesten Sinne auch mentalitätsgeschichtliche Fragestellungen ein: Im konkreten langfristigen Bedeutungswandel, gesellschaftlichen Gebrauch, in der Verbreitung des Begriffes und in den zeitgenössichen Definitions- und Abgrenzungsversuchen werden exemplarisch mentale Dispositionen deutlich, in denen sich vergangenes Gegenwartsbewußtsein und Zukunftsprojektionen verdichten: Begriffsgeschichte als semantisch-analytisches Paradigma für die Verarbeitung des Wandels sozialer Wissensbestände vollzieht „die sprachliche Eigenbewegung nach, in der sich geschichtliche Erfahrungen sammeln oder Hoffnungen formuliert sein wollen ". ${ }^{147}$ Auf der Ebene der symbolischen Repräsentation von diachronem Bedeutungswandel fungiert die historische Semantik gleichsam als Modell der Mentalitätsgeschichte:

Die Erlernung der Sprache ist das Muster für die gesellschaftliche Vermittlung von Bedeutungswissen. Indem wir unsere Muttersprache erlernen, übernehmen wir die Weltauslegung, die sie in sich trägt. Umgekehrt schlagen sich Wandlungen der Weltauslegung im Wandel der Sprache, der Begriffe, ihres Gebrauchs und ihrer Bedeutungen nieder. Die Begriffsgeschichte, oder allgemeiner, die historische Semantik, kann daher für die Mentalitätsgeschichte gewissermaßen als Modell dienen. Sie muß allerdings zu einer Art allgemeiner ,Semantik' des kollektiven Verhaltens in der Geschichte erweitert werden. In Analogie zu den Lautzeichen lassen sich auch Verhaltensformen als Symbole verstehen, die noch etwas anderes bedeuten, als was sie selbst sind. ${ }^{148}$

145 Vgl. LuCian Hölscher, Zeit und Diskurs in der Lexikographie der frühen Neuzeit, in: KoselleCK (Hrsg.), Historische Semantik, S. 327-42, hier S. 328.

146 Vgl. Karlheinz Stierle, Historische Semantik und die Geschichtlichkeit der Bedeutung, in: Koselleck (Hrsg.), Historische Semantik, S. 154-89, hier S. 176 sowie MaRQUARDT, S. $22 \mathrm{f}$.

147 Koselleck, Preußen, S. 17.

148 Volker Sellin, Mentalität und Mentalitätsgeschichte, in: HZ 241 (1985), S. 555-98, hier S. $576 f$. 
a) Divergenz, Typologie und historische Argumentation: Methodische Perspektiven der komparativen Analyse

Die komparative Methode hat sich in Deutschland innerhalb der bis in das zweite Drittel des 20. Jahrhunderts vom Historismus dominierten oder maßgeblich beeinflußten Geschichtswissenschaft relativ spät entwickelt. ${ }^{149}$ Es ist kein Zufall, daß es Außenseiter wie Otto Hintze oder historisch arbeitende Sozialwissenschaftler wie Max Weber waren, die sich intensiv mit der vergleichenden Methode auseinandersetzten, bevor im Kontext der „analytischen Wende in der Geschichtswissenschaft" im Verlauf der 1960er und 1970er Jahre durch die Etablierung sozialwissenschaftlicher Analysemethoden auch der Vergleich als innovative Methode einen neuen Aufschwung erlebte. ${ }^{150}$ Die Rezeption Hintzes und Webers für die programmatische Neubestimmung der Geschichtswissenschaft als historische Sozialwissenschaft, das frühe Plädoyer Theodor Schieders von 1965/66 151 und der Hinweis Hans-Ulrich Wehlers auf den Vergleich als „Königsweg“ der Geschichtswissenschaft, der es erlaube, „entweder sehr allgemeine oder sehr spezifische Hypothesen auf ihre Validität zu überprüfen“, 152 spiegelten ein gesteigertes Interesse an komparativen Fragestellungen wider, das aber bis zu den 1980er Jahren ein weitgehend uneingelöstes Desiderat blieb.

Obgleich Hans-Ulrich Wehler noch jüngst das „scharfe Säurebad des Vergleichs, dieses einzigen, unübertrefflichen Ersatzes für das naturwissenschaftliche Expriment" hervorhob, stellen geschichtswissenschaftliche Vergleiche weiterhin die methodische Ausnahme dar. ${ }^{153}$ Hinsichtlich der generellen Zielrich-

149 Vgl. JÜRgen KockA, Historische Komparatistik in Deutschland, in: Haupt und KOCKA (Hrsg.), S. 47-60 sowie F. JAEGER und JÖRN RÜSEN, Geschichte des Historismus. Eine Einführung, München 1992.

150 KockA, Historische Komparatistik, S. 49; vgl. JÜrgen KocKA, Otto Hintze, in: Hans-Ulrich Wehler (Hrsg.), Deutsche Historiker, Göttingen 1973, S. 275-98 sowie Wolfgang J. Mommsen, Max Weber, in: ebd., S. 299-324.

151 Theodor Schieder, Möglichkeiten und Grenzen vergleichender Methoden in der Geschichtswissenschaft, in: DERs., Geschichte als Wissenschaft. Eine Einführung, München 1965, S. 187-211; DeRs., Typologie und Erscheinungsformen des Nationalstaats in Europa (1966), in: DeRs., Nationalismus und Nationalstaat. Studien zum nationalen Problem im modernen Europa, hrsg. von OTTO DANN und HANS-UlRICH WeHLER, 2. Aufl. Göttingen 1992, S. 65-86.

152 Hans-Ulrich Wehler, Einleitung, in: Ders., Geschichte und Soziologie, Köln 1972, S. 11-31, hier S. 24.

153 Wehler, Deutscher Sonderweg, S. 91; vgl. Reinhold BiChler, Die theoretische Einschätzung des Vergleichens in der Geschichtswissenschaft, in: Franz HAMPL und INGOMAR WeILER (Hrsg.), Vergleichende Geschichtswissenschaft. Methode, Ertrag und ihr Beitrag zur Universalgeschichte, Darmstadt 1978, S. 1-71; IngOMAR WeILER, Der Vergleich und vergleichende Aspekte in der Wirtschafts- und Sozialgeschichte, in: ebd., S. 243-83; HANS-JÜRgen PUHLE, Theorien in der Praxis des vergleichenden Historikers, in: JÜrgen KockA und ThOMAS NipPerdeY (Hrsg.), Theorie und Erzählung in der Geschichte, München 1979, S. 119-36; JoHN BREuILLY, Introduction: Making Comparisons in History, in: Ders., Labour, S. 1-25; JÜrgeN KocKA, Pro- 
tung von Vergleichen läßt sich zwischen kontrastierenden und generalisierenden Analysen unterscheiden, bei denen entweder die Divergenzen oder die Konvergenzen zwischen den Vergleichsfällen untersucht werden. ${ }^{154}$ Beide Positionen gehören seit John Stuart Mills Unterscheidung einer method of difference und method of agreement bis hin zu Charles Tillys contrasting type und universalizing type zu den grundlegenden Kategorien komparativen Vorgehens. ${ }^{155}$ Auch Otto Hintze hat sie 1929 beschrieben: „Man kann vergleichen, um ein Allgemeines zu finden, das dem Verglichenen zugrunde liegt; man kann vergleichen, um den einen der möglichen Gegenstände in seiner Individualität schärfer zu erfassen und von dem anderen abzuheben." 156 Grundsätzlich fragt die vorliegende Arbeit zunächst und primär nach Unterschieden und individuellen Kennzeichen der historischen Semantik von Liberalismus in den verschiedenen Vergleichsländern. Dennoch läßt sich im Hinblick auf die wenn auch phasenverschobene Herausforderung der Moderne für alle vier Länder die Frage nach allgemeinen Kennzeichen der semantischen Genese und Transformation im Längsschnitt stellen. Dies steht hinter der Diskussion um die Berechtigung eines gemeineuropäischen Liberalismus-Begriffes und der Differenzierung je spezifischer Liberalismen auf der Grundlage einer historisch-semantischen Analyse.

Vergleiche können mit dem Ziel angestellt werden, die spezifische Geschichte des eigenen Landes besser zu erfassen. Diese „Instrumentalisierung des Fremden“ zur geschärften Eigenerkenntnis, so wie Max Weber im Blick auf die asiatischen Hochkulturen die spezifischen Kennzeichen der okzidentalen Kultur in ihrer rational-modernen Ausprägung analysiert hat, folgt einem asymmetrischen Vergleichsverfahren, das mit Verzerrungen einhergeht. ${ }^{157}$ Letztlich folgt auch die Auseinandersetzung mit Sonderwegsthesen einem solchen asymmetrischen Verfahren, das selten eine ergebnisoffene Analyse leistet, sondern die Ergebnisse des Vergleichs gleichsam vorstrukturiert, indem häufig nur noch solche Aspekte selektiert werden, die die gewünschte Sonderentwick-

bleme einer europäischen Geschichte in komparativer Absicht (1988), in: Ders., Geschichte und Aufklärung. Aufsätze, Göttingen 1989, S. 21-8; DERs., Comparative Historical Research: German Examples, in: International Review of Social History 38 (1993), S. 369-79; ERNST Wilhelm MÜLleR, Plädoyer für die komparativen Geisteswissenschaften, in: Paideuma. Mitteilungen zur Kulturkunde 39 (1993), S. 7-23 sowie Heinz-Gerhard Haupt, Geoffrey Crossick und JÜrgen Kocka, La storia comparata, in: Passato e Presente 28 (1993), S. 19-51.

154 Vgl. Heinz-Gerhard Haupt und Jürgen Kocka, Historischer Vergleich: Methoden, Aufgaben, Probleme. Eine Einleitung, in: Dies. (Hrsg.), S. 9-45, hier S. 11.

155 Vgl. John Stuart Mill, Philosophy of Scientific Method, hrsg. von E. Nagel, New York 1881, S. $211 \mathrm{ff}$. sowie Charles Tilly, Big Structures, Large Processes, Huge Comparisons, New York 1984, S. 80.

156 Отто Hintze, Soziologische und geschichtliche Staatsauffassung (1929), in: Ders., Soziologie und Geschichte. Gesammelte Abhandlungen, hrsg. von GERHARD OESTREICH, Bd. 2, Göttingen 1964, S. 251.

157 Haupt und Kocka, S. 15 f.; vgl. Stephen Kalberg, Max Weber's ComparativeHistorical Sociology, Cambridge 1994. 
lung bestätigen. Obwohl die vorliegende Untersuchung in ihren Fragestellungen vom Gang der Diskussion um einen deutschen Sonderweg mitbeeinflußt ist, folgt ihr analytisches Programm dem Ziel eines ergebnisoffenen Vergleichs ohne Postulierung von Normal- und Sonderwegen.

Erkenntnistheoretisch verfolgt die Untersuchung im weiteren Sinne das Ziel einer Typologie von historisch-semantischen Erscheinungsformen im innereuropäischen Vergleich, wobei zur Erstellung einer solchen Divergenz-Typologie ein stufentheoretisches Modell herangezogen werden soll, das das von Reinhart Koselleck entwickelte Sattelzeit-Konzept differenzieren soll. Die historischsemantische Typologie und das ihr zugeordnete Entwicklungsmodell weisen auf ein weiteres Kennzeichen der komparativen Methode hin: Ohne ein erhöhtes $\mathrm{Maß}$ an Abstraktion läßt sich der Vergleich im Hinblick auf grundlegendere Fragestellungen nicht durchführen. Daraus resultiert zugleich ein eher argumentativ-analytischer als narrativer Darstellungsstil. ${ }^{158}$ Die unterschiedlichen erkenntnistheoretischen Perspektiven des in dieser Studie angestrebten historisch-semantischen Vergleichs lassen sich in partieller Analogie zu den von Jürgen Kocka und Heinz-Gerhard Haupt beschriebenen allgemeinen Perspektiven der komparativen Methode charakterisieren:159

(1) Auf der deskriptiven Ebene dient der komparative Zugriff der deutlicheren Profilierung der einzelnen Vergleichsfälle. Die spezifischen Besonderheiten der historisch-semantischen Entwicklung des Begriffsfeldes werden deutlich und eröffnen auf der deskriptiven Grundlage weitergehende analytische Perspektiven zur Erklärung struktureller historischer Sachverhalte.

(2) In heuristischer Hinsicht führt der Vergleich zu bisher nicht gestellten Fragen und zur Erkenntnis neuartiger Probleme. Wie bereits oben gezeigt, besteht zumal für die vergleichende Liberalismus-Forschung die Gefahr des semantischen Nominalismus, also der impliziten Gleichsetzung semantisch nicht äquivalenter Bedeutungsträger. Dieses Problem setzt den Vergleich voraus, es entsteht erst unter den Bedingungen der komparativen Betrachtung. Auch die historisch-semantischen Berührungspunkte zwischen den Vergleichsfällen, der kulturelle Transfer auf dem Weg der Begriffsübersetzung, Adaption und Integration, wird erst durch die komparative Methode sichtbar. ${ }^{160}$

158 Vgl. KockA, Probleme, S. 27 sowie DeRs., Zurück zur Erzählung? Plädoyer für historische Argumentation (1984), in: DERS., Geschichte und Aufklärung, S. 8-20.

$159 \mathrm{Vgl}$. HAUPT und KOCKA, S. $12 \mathrm{ff}$.

160 Vgl. ebd., S. 10 und ferner Michel Espagne, Sur les limites du comparatisme en histoire culturelle, in: Genèses. Sciences sociales et histoire 17 (1994), S. 112-21; MiCHEL EsPagne und Michael Werner, Deutsch-französischer Kultur-Transfer im 18. und 19. Jahrhundert, in: Francia. Forschungen zur westeuropäischen Geschichte 14 (1985), S. 502-10; ESPAGNE und WERNER (Hrsg.), passim; BERND KORTLÄNDER und LOTHAR JORDAN (Hrsg.), Nationale Grenzen und internationaler Austausch. Studien zum Kultur- und Wissenschaftstransfer in Europa, Tübingen 1995; PETER SCHÖTTLER und MiCHAEL WeRnER, Transferts, voyages, transactions, in: Genèses. Sciences sociales et histoire 14 (1994), S. 2-82 sowie zuletzt JOHANNES PAULMANN, Internationaler Ver- 
(3) Sobald der Vergleich über die rein deskriptive Gegenüberstellung von Unterschieden und Gemeinsamkeiten zwischen den ausgewählten Vergleichsfällen hinausgeht, vermag er zur Aufklärung grundlegender historischer Sachverhalte beizutragen. Die historisch-semantische Komparatistik fragt auf einer weitergehenden analytischen Ebene nach den sich in den unterschiedlichen Begriffsgeschichten niederschlagenden Erfahrungen und Erwartungen, nach Bewußtseinslagen und Wirklichkeitsstrukturen, Wahrnehmungs- und Deutungsmustern in den jeweiligen historischen Kontexten. Durch die diachrone Anlage des Vergleichs treten raum- und zeitspezifische Regelmäßigkeiten stärker als in anderen Analysen hervor. Dies führt zur Hinterfragung gängiger Hypothesen und zur Differenzierung von Argumenten. Unter dem Vorbehalt, daß der Historiker auch im Vergleich für die experimentelle Überprüfung einer Hypothese keine naturwissenschaftlichen Voraussetzungen finden kann, weil sie sich durch die komplexe Struktur historischer Ausgangsbedingungen niemals wie in einer Versuchsanordnung homogenisieren lassen, vermag die historisch-semantische Komparatistik doch zu erhellen, welche spezifischen Konstellationen in einem Vergleichsfall zu welchen semantischen Entwicklungen führen, wenn ähnliche Bedingungen in einem anderen Fall fehlen.

(4) Für die analytische Funktion des historisch-semantischen Vergleichs hat die ideologiekritische Dimension eine besondere Bedeutung. In der Gegenüberstellung von Ideen und Interessen werden die in den Begriffen und ihrer zeitgenössischen kritischen Rezeption sich niederschlagenden spezifischen Diskrepanzen zwischen Programm und sozialer Praxis in den Blick genommen.

(5) Die komparative Methode bewirkt aus der Perspektive des Historikers eine paradigmatische Verfremdung, verstärkt das „Möglichkeitsbewußtsein des Historikers" 161 und beugt der Provinzialisierung von Forschungsperspektiven vor. Kulturelle Spezifik und Historik gewinnen in vergleichenden Arbeiten eine neue Dimension, indem sie zur Reflexion über den eigenen kulturellen Standort herausfordern: Der komparative Zugriff erweitert den Standpunkt des Historikers um die Multiperspektivität seiner Vergleichsfälle.

b) Konkretisierung des Untersuchungsprogramms:

Vergleichsfälle, chronologischer Rahmen und Leitfragen

Der semantische Bezugspunkt der vorliegenden Untersuchung ist im engeren Sinne zunächst das politisch-soziale Deutungsmuster libéralisme / Liberalismus / liberalismo / liberalism, das sich aber in einer diachronen Untersuchung nicht ohne die Berücksichtigung der übrigen Teile des Begriffsfeldes analysieren läßt. Dazu gehören das Adjektiv libéral / liberal / liberale / liberal sowie die

gleich und interkultureller Transfer. Zwei Forschungsansätze zur europäischen Geschichte des 18. und 19. Jahrhunderts, in: HZ 267 (1998), S. 649-85.

161 Haupt und Kocka, S. 14. 
Substantive libéraux / Liberale / liberali / liberals und libéralité / Liberalität / liberalità / liberality. Diese Differenzierung führt zu spezifischen semantischen Definitionen, die auf unterschiedliche Bedeutungsorientierung hinweisen. ${ }^{162}$ Die hier aufgeführten vier Bedeutungsträger lassen sich vor diesem Hintergrund chronologisch anordnen und reflektieren verschiedene Entwicklungsstufen in der Genese des politischen Grundbegriffs Liberalismus.

Am Beginn steht dabei das Adjektiv liberal, das eine attributive Funktion erfüllt, indem es spezifische Bedeutungsnuancen in ein Substantiv hineinlegt oder herausnimmt, ohne dabei selbst als Zentralbegriff mit bedeutungsorientierender Wirkung zu firmieren. Die aus dieser attributiven Stellung resultierende Flexibilität nötigt zu einer Bewertung des Kontexts und der Objekte, auf die sich das Adjektiv dabei bezieht. Entscheidend ist also die syntagmatische Einbindung des Adjektivs. Der Begriff Liberalität, der wie das Adjektiv auf römisch-antike Ursprünge zurückgeht und vor allem im römischen Wertbegriff der liberalitas eine eigene semantische Vorgeschichte besitzt, ist zunächst noch im vorpolitischen Bereich angesiedelt und impliziert eine sozialpsychologische Beschreibungskategorie von Dispositionen. Zu untersuchen ist, wie in Liberalität die vorpolitische und die politische Bedeutungsebene miteinander verknüpft wurden, wie auf dieser Wortebene neue Erfahrungen einflossen und diese weitertransportiert wurden. Liberale bezieht sich auf Handlungsgruppen, die in einem konkreten politischen Handlungsfeld stehen.

Liberalismus schließlich steht in der semantischen Relevanz insofern am höchsten, weil sich hier die abstrakte Ebene der ideologisch-historischen Bewegung abbildet. Diese Abstraktion setzt eine semantische Verdichtung voraus, die auf den anderen Wortebenen angelegt ist, sie zugleich aber ab einem bestimmten Entwicklungsstadium transzendiert, so daß sich die neuen Bedeutungsaspekte weder allein durch das attributive liberal noch durch die Kategorie Liberalität ausdrücken lassen. Auch das nomen appellativum, der politische Gattungsbegriff Liberale, wird in dem neuen ideologischen nomen proprium Liberalismus aufgehoben. Für Liberalismus wird im folgenden die Bezeichnung Bewegungsbegriff verwandt; dieser als Ismus auftretende Ausdruck nimmt die semantischen Elemente des Adjektivs und der Bezeichnung der politischen Handlungsträger auf und verdichtet sie. Seine diskursive Funktion weist ihn überdies als ideologisches Schlagwort aus. ${ }^{163}$ Zugleich läßt der Bewegungsbegriff Raum für die Konturierung und Abstrahierung von Erfahrungen und Zukunftsprojektionen. Erst aus der Polarisierung zwischen diesen beiden Zeitschienen resultiert die inhärente Spannung von Liberalismus. Dessen semantische Relevanz, also seine politisch-soziale Deutungs- und Orientierungsmacht sowie seine Integrationskraft, sind abhängig vom labilen Gleichgewicht

162 Für die wertvollen methodischen Hinweise in diesem Zusammenhang danke ich Reinhart Koselleck.

163 Vgl. UtE Burmester, Schlagworte der frühen deutschen Aufklärung. Exemplarische Textanalyse zu Gottfried Wilhelm Leibniz, Frankfurt a.M. 1992, S. 390. 
zwischen Erfahrungsräumen und Erwartungshorizonten. Jede Veränderung dieses Gleichgewichts präjudiziert zugleich eine Verschiebung des Bedeutungsspektrums. Die inhärente Spannung zwischen den beiden Zeitpolen hinter dem Bewegungsbegriff läßt sich technisch gesprochen als Zentrum eines Seismographen beschreiben, der idealtypisch jede Erfahrungs- oder Projektionsverschiebung in einer semantischen Veränderung dokumentiert.

Die für diese Studie ausgewählten Vergleichsfälle sollen für das Spektrum an Ausgangslagen, Herausforderungen, politisch-konstitutionellen und sozioökonomischen Strukturbedingungen, also hinsichtlich ihrer Erfahrungsgrundlagen und Erwartungshorizonte, möglichst repräsentativ die Pole für Handlungsbedingungen und Entwicklungspotentiale europäischer Liberalismen reflektieren. Die ganz unterschiedlichen Traditionen, Krisenerfahrungen und Handlungsbedingungen der vier Vergleichsfälle können hier allenfalls grob skizziert werden.

England weist spezifische Kennzeichen auf, die in der jüngeren Forschung zu einer Diskussion um einen englischen Sonderweg geführt haben. ${ }^{164}$ Dazu zählen nicht allein die durch das im 17. Jahrhundert gescheiterte absolutistische Experiment früh etablierte konstitutionell-parlamentarische Tradition, sondern auch seine im Kontrast zu den kontinentaleuropäischen Staaten relativ schwach ausgeprägte anstaltliche Staatlichkeit, innerhalb der als Gegengewichte zum Parlament keine zentralstaatliche Bürokratie, sondern zunächst noch das königliche Patronagesystem und dann vor allem das Geflecht autonomer lokaler Verwaltungsträger fungierten. ${ }^{165}$ Die demographische und ökonomische Dynamik, also die strukturelle Seite der Doppelrevolution und die aus ihr resultierenden gesellschaftlichen Konfliktlagen, die die „Durchbruchskrise der industriellen Gesellschaft" bis zur Jahrhundertmitte begleiteten, haben ihren Ursprung in England, so daß für die Reformen des 19. Jahrhunderts eine zumindest singuläre Ausgangslage und spezifische Rahmenbedingungen vorlagen. ${ }^{166}$ Daraus resultierte eine einzigartige Konstellation: Die im 17. Jahrhundert entstandenen und im 18. Jahrhundert etablierten Formen politischer Par-

164 Vgl. Hans-Christoph Schröder, Der englische „Sonderweg“ im 17. und 18. Jahrhundert, in: K. E. JeISMANN und H. SCHISSLER (Hrsg.), Englische und deutsche Geschichte in den Schülbüchern beider Länder, Braunschweig 1982, S. 27-44; HaNSChristoph Schröder, Die Revolutionen Englands im 17. Jahrhundert, Frankfurt a.M. 1986, S. 8; Bernd WeIsBrod, Der englische „Sonderweg“ in der neueren Geschichte, in: GG 16 (1990), S. 233-52 sowie HermanN Wellenreuther, England und Europa. Überlegungen zum Problem des englischen Sonderweges in der europäischen Geschichte, in: NORberT Finzsch und Hermann Wellenreuther (Hrsg.), Liberalitas. Festschrift für Erich Angermann, Stuttgart 1992, S. 89-123.

165 Vgl. Eike Wolgast, Absolutismus in England, in: Hans Patze (Hrsg.), Aspekte des europäischen Liberalismus, Hildesheim 1983, S. 1-22, hier S. 4 sowie HANS-CHRISTOPH SCHRÖDER, Die neuere englische Geschichte im Lichte einiger Modernisierungstheoreme, in: KoselleCK (Hrsg.), Studien, S. 30-65.

166 Mommsen, Preußen/Deutschland, S. 37; vgl. GotTFried NiedHart (Hrsg.), Einführung in die englische Geschichte, München 1982, S. 155-7. 
tizipation, die in den historischen „Partei“-Namen der whigs und tories ihren Ausdruck fanden, trafen auf die Dynamik einer entstehenden Industriegesellschaft. Die damit verbundenen Herausforderungen konturierten zugleich die langfristige Transformation der überkommenen politischen Formationen in moderne Massenparteien im Kontext systemimmanenter Reformen.

Frankreich stellt zunächst die politisch-konstitutionelle Seite der Doppelrevolution dar. Die von ihm ausgehenden Impulse prägten seit 1789 direkt oder indirekt alle europäischen Staaten: Es markiert mit dem Epochendatum 1789 nicht nur den Beginn des ideologisch bestimmten „langen“ 19. Jahrhunderts, sondern wurde nicht zuletzt auf der Ebene der politisch-sozialen Sprache zum europäischen Agens, ohne das das historisch-semantisch faßbare Spannungsfeld von Kräften „progressiver Bewegung und restaurativer Beharrung" nicht denkbar wäre. Mit seiner 1789 einsetzenden Konjunktur revolutionärer Erschütterungen und Umbrüche firmierte es als europäisches Labor politisch-gesellschaftlicher Neuordnung. Nirgendwo stellte sich die Frage nach der Neubestimmung des politisch-sozialen Vokabulars drängender und häufiger, nirgendwo entstanden durch die Umbrüche, die durch die Daten 1815, 1830, 1848/49, 1851 und 1871 allenfalls angedeutet werden, mehr Zeitschichtungen. Die andauernde Frage nach Ende und Erbe der Revolution begleitete die politisch-soziale Instabilität einer bis zur Dritten Republik permanent postrevolutionären Gesellschaft, deren Zukunftsprojektionen von konstitutioneller und jakobinischer, napoleonischer und reaktionärer bis zu orleanistischer, republikanischer und schließlich bonapartistischer Neugestaltung reichten.

Deutschland und Italien nehmen gegenüber diesen beiden Polen der Doppelrevolution eine Zwischenstellung ein. Gegenüber den etablierten Nationalstaaten Frankreich und England ist beiden Ländern die Erfahrung des territorialen Partikularismus und die daraus resultierende Herausforderung der nationalen Einigung und der Definition des Verhältnisses zwischen Staat und Nation gemeinsam, die sich zunächst mit dem Kampf um politische Partizipation und konstitutionelle Verfassung zu einer doppelten Ziellinie verband. Dabei differierten gleichwohl die Ausgangsbedingungen: In Italien gab es kein Gegenstück zum Heiligen Römischen Reich bzw. seit 1815 zum Deutschen Bund oder zum Deutschen Zollverein. Der Kampf um politische Freiheit und nationale Einheit gewann hier durch den unausweichlichen Konflikt mit Habsburg und dem politischen Primatanspruch des Kirchenstaates zusätzliche Brisanz. ${ }^{167}$ Aus Formen partikularer Staatlichkeit resultierte aber in beiden Fällen eine charakteristische Heterogenität von Erfahrungen und politischen Traditionen, die ein breites Spektrum unterschiedlicher politisch-konstitutioneller und sozioökonomischer Handlungsspielräume und Entwicklungspotentiale entstehen ließ. Zumal in Deutschland führte dies zu einer spezifischen Gleichzeitigkeit des Ungleichzeitigen, etwa in der wirtschaftlich relativ fortschritt-

167 Vgl. Gaetano Salvemini, Germania e Italia dal 1814 al 1870, in: Ders., Scritti sul Risorgimento, hrsg. von Piero Pieri und Carlo Pischedda, Mailand 1961, S. 441-53. 
lichen und zugleich politisch stagnierenden, abgebrochenen und blockierten Entwicklung in Preußen oder in der konstitutionellen Vorreiterrolle Badens, die im Gegensatz zu seiner relativen wirtschaftlichen Rückständigkeit stand. ${ }^{168}$

Die chronologische Eingrenzung des Untersuchungszeitraums orientiert sich am Ziel einer wirklichen Längsschnittanalyse, um über kurz- und mittelfristige Bedeutungsverschiebungen hinaus gerade die in synchron angelegten Studien ausgeblendeten langfristigen Verschiebungen aufzudecken. Dabei ist zu betonen, daß sich die komplexe Transformation von Grundbegriffen der politisch-sozialen Sprache einem statischen chronologischen Rahmen oder der Fixierung auf einzelne Daten entzieht, die allenfalls ein bestimmtes Ereignis oder einen Zustand erfassen, nicht aber die diachronen Strukturveränderungen, deren Ergebnisse sich häufig erst im Rückblick als epochal erweisen. Zudem haben solche chronologischen Grenzen nicht für alle vier Vergleichsfälle die gleiche verbindliche Bedeutung. Es läßt sich eben kein chronologisch eindeutig bestimmbarer Anfang des politischen Bewegungsbegriffs Liberalismus definieren. Vielmehr stellt sich dessen Genese als langfristiger Prozeß von semantischer Umbewertung, Aufwertung, Neubesetzung und Politisierung bereits bestehender Teile des Begriffsfeldes dar, dessen Ursprünge zeitlich weit vor dem modernen Begriff des 19. Jahrhunderts liegen.

Nur unter diesen Vorbehalten ist der Untersuchungszeitraum neben der notwendigen Integration der vorpolitischen Bedeutungsursprünge zunächst grob vom letzten Drittel des 18. Jahrhunderts bis zur Mitte des 19. Jahrhunderts mit einem Ausblick in die zweite Jahrhunderthälfte zu begrenzen. Damit ist jene begriffsgeschichtlich zentrale Phase erfaßt, die von der vorpolitischen Bedeutungsbestimmung von liberal vor 1789 über die Politisierung und semantische Ideologisierung, über die Entstehung und Ausbreitung liberaler Bewegungen bis zur Zäsur des gesamteuropäischen Revolutionsjahres 1848/49 reicht. Für England lassen sich solche Kriterien nicht überzeugend anwenden, da die Entwicklung hier von der allmählichen Reformierung des bestehenden politischen Systems und der Entstehung moderner Massenparteien bestimmt war. ${ }^{169}$

Der komparative Untersuchungsansatz kann nur dann überzeugen, wenn der Vergleich vorurteilsfrei erfolgt, also ohne die Projektion späterer Entwicklungen auf eine zur Vorgeschichte reduzierte Betrachtungsebene. Die Übertragung von historischen „Erfolgs-“ oder „Mißerfolgskategorien“ auf die Begriffsgeschichte von Liberalismus im Sinne vermeintlich gerader Entwicklungslinien fällt genau in jene pseudokausale Kategorie einer „Kontinuitätshistorie, die das Frühere vom Späteren her erklärt“. ${ }^{170}$ Vorteile für die Entwick-

168 Vgl. HardTwig, Weg in die Moderne, S. 9ff.

169 Vgl. zum Problem der Epochenabgrenzung des Victorian liberalism JÖRN LEONHARD, Rezension zu JONATHAN PARRY, The Rise and Fall of Liberal Government in Victorian Britain, New Haven 1993, in: JbLibF 9 (1997), S. 276-9.

170 Thomas Nipperdey, 1933 und die Kontinuität der deutschen Geschichte (1978), in: DERS., Nachdenken über die deutsche Geschichte. Essays, München 1986, S. 186-205, hier S. 199. 
lung des Liberalismus in einem Land dürfen nicht gegen objektive Nachteile in einem anderen Land aufgerechnet werden: ${ }^{171}$ Verschiedenartigkeit der Voraussetzungen impliziert keine historische Über- oder Unterlegenheit, sondern liegt als fundamentale Voraussetzung für historisches Verstehen auch den folgenden Leitfragen zugrunde, die das Untersuchungsprogramm auf fünf Ebenen differenzieren:

(1) Wie entstanden, entwickelten und veränderten sich Bedeutung, Gebrauch und Verständnis des Deutungsmusters liberal, Liberalität, Liberale und Liberalismus sowie der französichen, italienischen und englischen Heteronyme dieser Ausdrücke (libéral, libéralité, libéraux, libéralisme / liberale, liberalità, liberali, liberalismo / liberal, liberality, liberals, liberalism) ${ }^{172}$ im Untersuchungszeitraum? Welche Position nahmen diese Begriffe im zeitgenössischen politischen Vokabular im Vergleich zu anderen politischen Etiketten ein?

(2) Welche Konjunkturen der Verwendung des Begriffsfeldes im politischsozialen Vokabular der vier Vergleichsfälle lassen sich aufgrund einer semantisch-quantifizierenden Analyse aufzeigen (vgl. Kapitel IX)?

(3) Wo ergaben sich begriffsgeschichtliche Berührungspunkte zwischen den Ländern, wo reflektierte die historisch-semantische Transformation einen kulturellen Transfer auf dem Weg der Übersetzung und Integration eines fremdsprachlichen Begriffs in das eigene politisch-soziale Vokabular?

(4) Welche begriffsgeschichtlichen Unterscheidungsmerkmale, also singulären Bedeutungsaspekte, Definitions-, Interpretations- und Rezeptionsmuster, sowie Gemeinsamkeiten ergeben sich aus der vergleichenden historischen Semantik von Liberalismus für die vier Vergleichsfälle? Welche Rückschlüsse erlaubt die komparative historische Semantik für eine Typologisierung „zeittypische[r] Liberalismen" 173 im europäischen Kontext?

(5) Wie bildeten sich in den untersuchten Ländern unterschiedliche geschichtliche Erfahrungshintergründe und Erwartungshorizonte in der das Reflexionsvermögen des handelnden Zeitgenossen übersteigenden historischen Semantik von Liberalismus ab?

Vor allem die Fragenkomplexe (4) und (5), die die komparative Analyse in ihrer typologischen Funktion unterstreichen, verweisen auf die in der Forschung gestellte Frage nach einem möglichen „semantischen Sonderweg“ Deutschlands. ${ }^{174}$ Ein wichtiges Indiz für einen solchen Sonderweg ergäbe sich, wenn die komparative Analyse im diachronen Längsschnitt für den historischpolitischen Grundbegriff Liberalismus belegen könnte, daß „der politische

171 Vgl. Reinhard Bendix, Kings or People. Power and the Mandate to Rule, Berkeley 1978, S. 598.

172 Wo im folgenden nur der deutsche Begriff Liberalismus oder ein Bestandteil des Begriffsfeldes (liberal, Liberalität, Liberale) genannt ist, sind die genannten nationalsprachlichen Varianten auch ohne deren explizite Nennung mitberücksichtigt.

173 LANGEWIESCHE, Handlungsbedingungen und Zielvorstellungen, S. $342 \mathrm{f}$.

$174 \mathrm{Vgl}$. BOllenBeCK, S. 20, 
Versuch eines eigenen deutschen Weges im Gegensatz zu den ,Idealen von 1789‘ von der Ausbildung einer eigenen Begriffssprache begleitet wurde."175

c) Konzeption eines Modells historisch-politischer Semantogenese:

Transformationsstufen, Untersuchungsfelder und Vergleichseinheiten

Um der vergleichenden Analyse der vier Untersuchungsfälle ein gleiches Raster von Vergleichskriterien zugrundelegen zu können, soll über die oben formulierten Leitfragen hinaus von einem Modell der Semantogenese eines historisch-politischen Grundbegriffes ausgegangen werden. Damit soll auch das von Reinhart Koselleck entwickelte Sattelzeit-Konzept differenziert werden. Das Modell geht von vier Entwicklungsstufen aus, die ein politisch-soziales Deutungsmuster im Übergang vom vorpolitischen Bedeutungskontext zum politischen Grundbegriff als Bestandteil des Vokabulars moderner Ideologien durchläuft. Dabei dienen als Kriterien historisch-semantischer Veränderung zwei Parameter, die im folgenden idealtypisch definiert werden:

(a) Die ideologische Relevanz des Begriffsfeldes bezeichnet den allgemeinen Stellenwert, der einem Begriff in einem politischen Vokabular und einem Diskurs zumal im Vergleich zu anderen Begriffen zukommt. Sie basiert zunächst auf genuin neuartigen politisch-sozialen Erfahrungen, die in einem Begriffsfeld repräsentiert werden. Sie setzt keinesfalls ideologische Eindeutigkeit voraus, sondern in erster Linie die Präsenz politisierter Begriffe in einem neuen Kontext. Um einen Maßstab für diese ideologische Relevanz zu gewinnen, kann zumal die quantifizierende Frequenzanalyse wertvolle Hinweise liefern, indem sich aus ihr spezifische Konjunkturen der Begriffsverwendung ableiten lassen.

(b) Die semantische Ligatur eines Begriffes steht für seine Fähigkeit, über die Integration politisch-gesellschaftlicher Erfahrungen hinaus auf sprachlichdiskursiver Ebene einen Erwartungshorizont zu konturieren. Die semantische Ligatur bezeichnet zugleich den zielgerichteten Anspruch, die ideologische Anziehungskraft und soziale Reichweite des Deutungsmusters. Dies geht notwendig einher mit der Bemühung um größere Eindeutigkeit des Begriffes, die durch Definition, Abgrenzung und programmatische Aufladung erreicht werden soll. Auf der Grundlage dieser beiden Kriterien lassen sich idealtypisch vier Entwicklungsstufen charakterisieren:

(1) Die Ausgangsstufe kennzeichnet die präpolitischen Bedeutungsdimensionen von bestimmten Bestandteilen des Begriffsfeldes, im vorliegenden Falle

175 Walter DieckManN, Information oder Überredung, Marburg 1964, zitiert nach SYNNÖVE CARLSON, Von Schlagwörtern zu Schimpfwörtern. Die Abwertung des Liberalismus in der Ideologiesprache der ,konservativen Revolution'. Eine wortmonographische Studie zum Sprachgebrauch einer politischen Denktradition in Deutschland bis zum Jahre 1933, in: Helmut Müssener und Hans Rossipal (Hrsg.), Impulse. Festschrift für Gustav Korlén zum 60. Geburtstag, Stockholm 1975, S. 339-76, hier S. 339. 
also die vorpolitischen Bedeutungselemente, die das Adjektiv liberal enthält sowie der ebenfalls auf antike Bedeutungsursprünge zurückreichende Begriff der liberalitas in seinen verschiedenen nationalsprachlichen Ausprägungen. Eine ideologische Relevanz oder Ligatur liegt nicht vor.

(2) Auf der zweiten Stufe werden vor dem Hintergrund eines politisierten Kontextes neue politisch-gesellschaftliche Bedeutungselemente auf überkommene Ausdrücke übertragen. Diese Fermentierungsphase ist deshalb von wesentlicher Bedeutung, weil sich hier vorpolitische und politisierte Bedeutungselemente überlagern und vermischen. Dies schließt eine eindeutige Definitionsrichtung der Begriffe aus. Daraus folgt, daß sich zwar aufgrund spezifischer Erfahrungen eine ideologische Relevanz abzuzeichnen beginnt, die ideologische Ligatur dagegen noch schwach ausgeprägt ist: Von den Begriffen geht noch keine ideologische Orientierung aus.

(3) Eine dritte Entwicklungsstufe bezeichnet die Politisierung des Begriffsfeldes, also die Zurückdrängung vorpolitischer Bedeutungselemente zugunsten politisierter Inhalte. Die ideologische Relevanz geht dabei zunehmend auch in eine semantische Ligatur des Begriffes über. Dabei ist aber das politisch-gesellschaftliche Ausdruckspotential noch keinesfalls ausgeschöpft und weist auch noch keine unumkehrbare ideologisch-programmatische Richtung auf. Zumal durch Einflüsse von außen, etwa durch den semantischen Kulturtransfer, den Begriffsimport, kann es auf dieser Stufe noch beeinflußt oder katalysiert werden.

(4) Auf der vierten Entwicklungsstufe ist die ideologische Relevanz des Begriffsfeldes am intensivsten faßbar. Nunmehr dominiert eindeutig die semantische Ligatur: Die verdichtete Repräsentation von Erfahrungen und Projektionen geht in eine programmatische Orientierung und ideologische Ausrichtung über. Im Spannungsfeld konkurrierender Interessen führt dies zu einer zeitgleichen Ideologisierung und Polarisierung von Begriffen und Gegenbegriffen, die sich besonders trennscharf etwa in der Form von Parteibezeichnungen niederschlagen kann.

Die Gliederung der Arbeit wird zum einen durch die diachrone Anlage der Analyse, zum anderen durch das Postulat bestimmt, einen systematischen Vergleich innerhalb abgrenzbarer unterschiedlicher Untersuchungsfelder zu leisten. Dies schließt eine additive Aneinanderreihung von vier national isolierten Begriffsgeschichten aus. Daher wird der Untersuchungszeitraum in einzelne Einheiten eingeteilt, in deren Bestimmung chronologische und thematische Kriterien eingehen. Innerhalb der vorgestellten analytischen Einheiten werden die historisch-semantischen Entwicklungen und Veränderungen für alle vier Fälle zunächst untersucht und in einem eigenen Vergleichskapitel dann jeweils einander gegenübergestellt. Diese Einheiten müssen noch allgemein genug sein, um für alle Vergleichsfälle Bedeutung zu haben und zugleich spezifisch genug, um den diachronen Untersuchungsrahmen überzeugend differenzieren zu können. Ergänzt wird diese Gliederung durch die quantifizierende Analyse für alle Untersuchungsfälle im Anhang, dessen Ergebnisse in die Vergleichskapitel am Ende der analytischen Einheiten miteinbezogen werden. 
Bis zur Jahrhundertmitte lassen sich fünf Untersuchungseinheiten differenzieren: Ausgehend von der Gegenüberstellung vorpolitischer Bedeutungselemente bis zum letzten Drittel des 18. Jahrhunderts stellen die Zeiträume 1789 bis $1815 / 20,1815 / 20$ bis 1830,1830 bis 1835 , sowie 1835 bis $1848 / 50$ die grundlegenden chronologischen Untersuchungseinheiten dar. Die Auswahl dieser chronologischen Grenzen orientiert sich an den historischen Umbrüchen, für die in der Analyse dann zu fragen ist, welche Auswirkungen von ihnen für die politisch-semantische Entwicklung ausgingen und ob für die vier Vergleichsfälle vor dem Hintergrund dieses chronologischen Rasters ähnliche oder unterschiedliche Sattelzeiten zu postulieren sind. Unter dem Vorbehalt dieser Frage sind die Untersuchungsfelder durch die fundamentalen politisch-gesellschaftlichen Zäsuren definiert, von denen Impulse und Wirkungen auf den Politikdiskurs zu erwarten sind: Dies gilt sowohl für die Phase der Französischen Revolution als auch für die anschließende Periode der politischen Neugestaltung, die sich nicht als Rückkehr in die Lebenswelt des Ancien régime kennzeichnen läßt, sondern in der Folge des Wiener Kongresses bis ca. 1820 und im weiteren Sinne bis 1830 eine von erheblichen Spannungen gekennzeichnete Periode darstellt. Gerade für die semantische Inkubationszeit, der Fermentierung und beginnenden Politisierung von Bedeutungen, spielt die Phase der französischen Julirevolution und ihrer Rezeption in den verschiedenen Ländern bzw. die erste Welle politisch-konstitutioneller Reformen in England eine wesentliche Rolle, so daß der Zeitraum von 1830 bis 1835 besondere Aufmerksamkeit verdient. Schließlich stellt die Welle der europäischen Revolutionen von 1848/49 eine Grenze dar, aus der sich der Untersuchungszeitraum seit Mitte der 1830er Jahre, also vom Auslaufen der 1830 aufgebrochenen Bewegungen, bis zum Ende der revolutionären Erhebungen 1848/50 ergibt. In einem Ausblick werden abschließend wesentliche Entwicklungen der zweiten Jahrhunderthälfte skizziert.

Die Bestimmung dieser Untersuchungseinheiten kann indes nur relativ überzeugen, denn die angewandten Kriterien können nicht für alle Vergleichsfälle gleiche Bedeutung reklamieren. Für England etwa sind von bestimmten kontinentaleuropäischen Zäsuren wie 1848/49 keine bestimmenden Wirkungen ausgegangen. Daher sind diese Einheiten wiederum kein statisches Raster, denn die historisch-politische Semantik entzieht sich solchen punktuellen Definitionen. Nur unter diesem Vorbehalt dürfen sie im Sinne eines allgemeinen Rahmens verstanden werden.

\section{Quellengrundlage und Texterschließung}

Die Quellenbasis muß einen möglichst hohen Repräsentationsgrad für das soziale Wissen der Zeit aufweisen. Nur dann kann es gelingen, im historischen Begriffsfeld liberal/Liberale/Liberalismus ein politisch-soziales Deutungsmuster für die vergangene Gegenwart zu rekonstruieren. Allein durch eine mög- 
lichst breit angelegte und zugleich dichte Quellengrundlage, die über bloße Zufallsfunde hinaus die langfristigen Veränderungen aufdecken kann, ist ein höherer Repräsentationsgrad in der Analyse erreichbar. Dazu gehört neben der texthermeneutischen Analyse auch die systematisch-quantifizierende Erschließung der Quellenkorpora im Hinblick auf die publizistische Präsenz des Begriffsfeldes.

\section{a) Empirisch-systematische Aufnahme}

Bei der Bestimmung des Quellenkorpus lassen sich vier Kategorien unterscheiden:

(1) Lexikalisch-enzyklopädische Quellen: Als Ausgangspunkt der Analyse wurden an erster Stelle die allgemeinsprachlichen universell ausgerichteten Wörterbücher, Lexika und großen Enzyklopädien im Hinblick auf einzelne begriffsbestimmende Artikel ausgewertet. Hinzu kommen die philosophisch, historisch bzw. im weitesten Sinne staatswissenschaftlich orientierten Fachwörterbücher und Lexika, die aufkommenden politischen Wörterbücher und insbesondere in politisch-sozialen Krisenphasen die Pamphlet-Wörterbücher. Die ermittelten lexikalisch-enzyklopädischen Quellen repräsentieren paradigmatisch das sich differenzierende soziale Wissen der vergangenen Gegenwart, das Selbstverständnis und die Öffnung des politisch-sozialen Diskurses. ${ }^{176}$ Dabei sind allerdings für die zu untersuchenden Länder verschieden ausgeprägte lexikalisch-enzyklopädische Traditionen mit unterschiedlicher publizistischer Wirkungskraft und sozialer Reichweite zu beachten, die wiederum Kennzeichen einer je eigenen Diskurskultur sind. Erinnert sei in diesem Zusammenhang an Diderots und D'Alemberts Encyclopédie als „repräsentativer Wissensträger der gehobenen Bildungsschichten in der Aufklärungszeit“, die Dynamisierung der politischen Wörterbuchpublikation seit 1789 in Frankreich oder an die mit dem Staatslexikon von Rotteck und Welcker einsetzende Reihe großer politischer Lexika als wichtiges Medium der Fokussierung politischer Theorie im deutschen Sprachraum. ${ }^{177}$ Die zu erwartende Heterogenität dieser Quellen-

176 Vgl. Kirsten HJORT, Lexikon, Wörterbuch, Enzyklopädie, Konversationslexikon. Versuch einer Begriffsklärung, in: Muttersprache 77 (1967), S. 353-65.

177 VAN DEN HEUVEL, Freiheitsbegriff, S. 24; vgl. ANNIE GEFFROY, Les dictionnares sociopolitiques 1770-1815: Une Bibliographie, in: Dictionnaire des usages socio-politique, Bd. 3, S. 7-46; zum Staatslexikon vgl. T. S. Hammerow, Restoration, Revolution, Reaction. Economics and Politics in Germany 1815-1871, 2. Aufl. Princeton 1967, S. 63; Sell, S. 121; SheEHAn, Der deutsche Liberalismus, S. 101; WeHler, Deutsche Gesellschaftsgeschichte, Bd. 2, S. 360; Hans FENSKE, Der liberale Südwesten. Freiheitliche und demokratische Traditionen in Baden und Württemberg 1790-1933, Stuttgart 1981, S. 12; NipPerdeY, Deutsche Geschichte 1800-1866, S. 299; LOTHAR Gall, Bürgertum in Deutschland, Berlin 1989, S. 255; Zunhammer, S. 9f.; Hans Puchta, Die Entstehung politischer Ideologien im 19. Jahrhundert, dargestellt am Beispiel des Staatslexikons von Rotteck-Welcker und des Staats- und Gesellschaftslexikons von Herrmann Wagener, Nürnberg 1972; MoniKa Hildegard Fassbender-Ilge, Libe- 
kategorie im Hinblick auf die vier Vergleichsfälle schließt von daher eine Beschränkung auf lexikalisch-enzyklopädische Texte aus. Die diachrone Ausrichtung der komparativen Analyse über einen Zeitraum von sieben bis acht Jahrzehnten macht aber den Rekurs auf serielle Quellen unerläßlich, in denen das Begriffsfeld in gleichem oder ähnlichem Rahmen bestimmt und interpretiert wird. Als solche Serien bieten sich vor allem lexikalische Texte an, weil sie in fortlaufenden Auflagen den Untersuchungszeitraum ganz oder zumindest teilweise abdecken. Für die komparative Analyse ermöglichen sie eine erste Orientierung, indem sie eine historisch-semantische Schneise durch das unübersichtliche Feld von Einzelbelegen schlagen.

(2) Monographische Quellen: Unter monographischen Quellen ist in der vorliegenden Untersuchung das begriffsgeschichtlich relevante politisch-soziale Schrifttum zu verstehen, das nicht in lexikalisch-enzyklopädischen Texten oder in Zeitungs- und Zeitschriftenartikeln, sondern in Form von Einzeldarstellungen vorliegt. Das umfaßt theoretisch alle Texte, die Belege enthalten, von denen auf zeitgenössische Bedeutungsbestimmungen, -reflexionen und -abgrenzungen geschlossen werden kann. Zunächst sind solche politisch-sozialen Monographien von besonderem Interesse, die sich thematisch zielgerichtet mit der Bestimmung oder Interpretation des Begriffsfeldes auseinandersetzen und deren thematische Beschäftigung mit dem Phänomen Liberalismus für die historisch-semantische Ebene relevante Aspekte liefert. Im weiteren Sinne zählen dazu auch Einzelschriften, die sich zunächst nicht ausdrücklich auf einen Bestandteil des Begriffsfeldes beziehen, aber durch ihre thematische Nähe zu politisch-gesellschaftlichen Bewegungen und Parteien oder zu politischen Positionen oder zum politischen Denken der Zeit aufschließende Funktion für die begriffsgeschichtliche Analyse haben können. Dazu gehören schließlich alle gedruckten Einzelschriften, also auch politische Traktate und Flugschriften. Im Hinblick auf den sozialen Wirkungsgrad der Begriffsbestimmungen wurden auch volksnahe Quellen wie politische Katechismen, Satiren und Lieder mitberücksichtigt. Für die zweite Jahrhunderthälfte werden Parteilehren und -programme sowie die entsprechenden Monographien aus dem Bereich der entstehenden Geschichts- bzw. Gesellschaftswissenschaft relevant.

(3) Persönliche Quellen und Quellensammlungen: Hierunter fallen die edierten Quellen von Herrschern, führenden Ministern, Diplomaten und wichtigen Repräsentanten der einzelnen politischen Strömungen, soweit sie Bezug auf die Bestimmung, Rezeption und Interpretation des Begriffsfeldes nehmen. Dabei kommt insbesondere den kritisch edierten Quellenausgaben besondere Bedeutung zu, da hier Sachregister und Begriffskonkordanzen die systematische

ralismus, Wissenschaft, Politik. Untersuchungen des Deutschen Staats-Wörterbuchs von Johann Caspar Bluntschli und Karl Brater als Beitrag zur Liberalismusgeschichte zwischen 48er Revolution und Reichsgründung, Frankfurt a. M. 1981 sowie ClaUdia M. IGELMUND, Frankreich und das Staatslexikon von Rotteck und Welcker. Eine Studie zum Frankreichbild des süddeutschen Frühliberalismus, Frankfurt a.M. 1987. 
Erfassung von Belegen ermöglichen. Hinzu treten edierte Gesandtschaftsberichte und Parlamentsprotokolle sowie allgemeine Quellensammlungen zur Geschichte politischer Strömungen. Unter Vermeidung philosophischer Gipfelwanderungen werden die Ausgaben von publizistischen Meinungsführern wie Philosophen, Staatsrechtler, Historiker und Theologen für die Zusammenstellung von Belegreihen herangezogen. Schließlich sind literarische Quellenanthologien und kritisch edierte Werkausgaben miteinzubeziehen, zum Beispiel Briefe und Tagebücher mit expliziter Bezugnahme auf politische Ereignisse.

(4) Periodische Quellen: Für alle vier Vergleichsländer wurden wichtige politische Zeitungen und Zeitschriften herangezogen und ausgewertet. Eine erschöpfende Auswertung verbot sich indes aufgrund der äußerst heterogenen systematischen Zugriffsmöglichkeiten und des überaus breit angelegten Quellenkorpus. Zeitschriften- und Zeitungsartikel stellen aber trotz dieser konkreten Schwierigkeiten eine unverzichtbare Quelle für die historisch-semantische Analyse dar, weil sie Einsichten in den aktuellen zeit- und situationsspezifischen Gebrauch des Begriffsfeldes erlauben. Nur partiell ließen vollständige Sachregister oder eine komplette Auflistung der Zeitschriftenartikel eine systematische Erfassung relevanter Artikel in den politischen Periodika zu. ${ }^{178} \mathrm{Wäh}$ rend diese Quellen des 19. Jahrhunderts für England vorbildlich erschlossen sind, fehlen für Deutschland, Frankreich und Italien vergleichbare Instrumente. Für Deutschland und Italien stellt sich zudem das Problem der bis zur Nationalstaatsbildung regionalen Begrenzung der publizistischen Wirkung, so daß hier auf solche Organe zurückgegriffen wurde, deren Resonanz auch über den regionalen Kontext hinausreichte. Insbesondere für politische Umbruchsphasen (etwa 1815/20, 1830/35, 1848/50) wurde verstärkt auf diese Quellenkategorie zurückgegriffen.

\section{b) Semantisch-qualitative Kategorisierung der Quellen und interpretative Leitlinien}

Die Quellengrundlage darf sich nicht als impressionistisches Ergebnis von $\mathrm{Zu}$ fallsfunden oder intuitiven Suchaktionen ergeben, sondern bedarf einer angemessenen Systematisierung anhand der begriffsgeschichtlich relevanten Eigenschaften des politisch-sozialen Vokabulars. In Fortführung von Ansätzen der Wortfeldforschung lassen sich idealtypisch vier kategoriale Ebenen unterscheiden, die zusammengenommen das Begriffsfeld konkretisieren. ${ }^{179}$ Diesen Kategorien lassen sich für das dargelegte Untersuchungsprogramm einzelne Quel-

178 Vgl. die unter X.1. komplett aufgeführten, für diese Studie systematisch ausgewerteten Indices.

179 Vgl. ReIchardt, Einleitung, S. 84f. sowie Hans-JÜRgEN LÜSEBRINK und ROLF ReICHARDT, La ,Bastille“ dans l'imaginaire social de la France à la fin du XVIIIe siècle, 1774-1799, in: Revue d'histoire moderne et contemporaine 30 (1983), S. 196-234. 
lengattungen zuordnen, ohne daß diese Zuordnung aber statisch verstanden werden darf, da einzelne Gattungen immer mehrere begriffsgeschichtliche Eigenschaften aufweisen:

(1) Paradigmatisch-normative Ebene: Hier wird der Begriff mit dem Anspruch möglichst hoher Verbindlichkeit und semantischer Präzision knapp und zumeist abstrakt definiert. Solche Definitionen leisten zunächst allgemeine und philosophisch-historisch orientierte Wörterbücher sowie vor allem die zahlreichen Konversationslexika der Zeit. ${ }^{180}$ In der Regel reflektieren diese Definitionen das soziale Wissen aber mit einer charakteristischen Zeitverzögerung als Folge der oft langen Redaktionsarbeit. Neben der Ausblendung neuer Bedeutungsaspekte und möglicher Neologismen bleibt die spezifische Gebrauchssituation zumeist unberücksichtigt oder unterbewertet, so daß „der Wortschatz eines Wörterbuchs ... nur die Totenkammer der Sprache enthalten" kann. ${ }^{181}$

(2) Syntagmatische Ebene: Nicht im Sinne einer kürzeren normativen Definition, sondern durch ausführlichere Erklärung und Ausdifferenzierung erfährt der Begriff hier eine inhaltlich-programmatische Bestimmung, die längere historische Exkurse, Reflexionen über gerechtfertigten und ungerechtfertigten Gebrauch des Begriffes in der Gegenwart, aber auch schon Abgrenzungen zu anderen Etiketten einschließt. Zu dieser Kategorie, die sich häufig als Reaktion auf bestimmte Ereignisse oder Kritik ergibt, zählen idealtypisch längere programmatische Lexikonartikel, Essays und Denkschriften. Der Vorteil dieser Kategorie besteht in begriffsgeschichtlicher Hinsicht im möglichen Rückschluß auf den zeit-, situations- und gruppenspezifischen Umgang mit dem Begriff, der anders als in Wörterbüchern und Konversationslexika keine oder eine erheblich geringere semantische Filterung erfährt. Die ausführlichere und häufig auch konkretere Auseinandersetzung mit dem Begriffsfeld läßt außerdem die Bedeutung von Komplementärbegriffen erkennbar werden.

(3) Antonymische Ebene: Auf dieser Ebene geht es um die programmatische Bestimmung von Gegenbegriffen durch Kritik an und Abgrenzung von Liberalismus. Bestimmend hierfür sind Prozesse der Ausdifferenzierung des politischen Massenmarktes. Der Kampf der politischen Richtungen ist dabei ganz wesentlich ein Kampf um Begriffe, der sich in polemischer Auseinandersetzung, offensiver Infragestellung oder defensiver Reaktion niederschlägt. Diese Prozesse werden insbesondere von der unterschiedlichen Erfahrung in politischen und sozioökonomischen Krisenphasen geprägt. Beispiele für diese Kategorie sind alle Äußerungen radikaldemokratischer und konservativer Gruppen,

180 Vgl. Utz Haltern, Politische Bildung und bürgerlicher Liberalismus. Zur Rolle des Konversationslexikons in Deutschland, in: HZ 223 (1976), S. 61-97 sowie DiETER LANGEWIESCHE, Bürgerliche Adelskritik zwischen Aufklärung und Reichsgründung in Enzyklopädien und Lexika, in: ElisabeTH FeHrenBACH (Hrsg.), Adel und Bürgertum in Deutschland 1770-1848, München 1994, S. 11-28.

181 W. Kraus, Macht und Ohnmacht der Wörterbücher, in: Ders., Studien und Aufsätze, Berlin 1959, S. 5-17, hier S. 12. 
wenn sie ihre programmatische Stoßkraft aus der Auseinandersetzung mit Liberalismus schöpfen.

(4) Deskriptive Konkretisierung: Gegenüber den drei bisher vorgestellten Kategorien, in denen sich Zeitgenossen reflektierend mit dem Begriffsfeld auseinandersetzten, geht es auf dieser Ebene um den Gebrauch von Liberalismus ohne die Reflexion und Diskussion der semantischen Aktualisierung. Aber auch diese alltagssprachlichen, publizistischen oder literarischen Konkretisierungen reflektieren die Aufnahme neuer Aspekte und den Wandel von Bedeutungen. Dieser Kategorie kommt für die Frage nach dem sozialen Geltungsgrad wesentliche Bedeutung zu, denn hier läßt sich die Reichweite der Definitionen und Rezeption gerade unterhalb des bildungsbürgerlichen Begriffsdiskurses abschätzen. Beispiele hierfür bieten etwa Briefe und Tagebücher oder Zeitungsartikel, in denen der Rückgriff auf Bestandteile des Begriffsfeldes die Analyse bestimmter Rezeptionsmuster ermöglicht.

Zunächst sind Quellenbelege nach ihrer jeweiligen Textsorte und deren spezifischen Kennzeichen zu differenzieren. Während zum Beispiel Artikel aus Wörterbüchern und Enzyklopädien durch ihre Fokussierung direkt verwendet werden können, spielt für die Konkretisierung von liberal und Liberalismus in Zeitungsartikeln oder Flugschriften der Textzusammenhang und die konkrete historische Situation eine wichtige Rolle. In persönlichen Quellen wie Briefen und Tagebüchern ist die persönliche Perspektive des Autors, in einer parlamentarischen Debatte die spezifische Diskurssituation zu beachten. Obgleich die Bedeutung des untersuchten Begriffsfeldes die konkrete historische Situation übersteigt, speist sie sich doch ,aus dem gesprochenen Kontext, sie entspringt zugleich der Situation, auf die sie sich bezieht". ${ }^{182}$ Daraus ergibt sich die Notwendigkeit einer historisch-kritischen Erschließung im weiteren Sinne, wobei es nicht um eine bloße ereignisgeschichtliche Kontextuierung geht, eine „Scheibchenhistorie', in der zunächst einleitend die politischen oder sozialen oder ökonomischen ,Rahmenbedingungen " umrissen und dann das damit mehr oder weniger verbundene, eigentliche "Thema behandelt" wird, sondern um ein geschichtswissenschaftliches „Picasso-Porträt““, 183 das „gleichzeitig die Frontansicht und das Profil "184, also konkret das Deutungsmuster in seinen komplexen Bezügen aus unterschiedlichen Perspektiven (Person, Gruppe, Situation, politisch-konstitutionelle, sozioökonomische Bezüge) zeigt, ohne andererseits die Inhalte als simple Überbauphänomene zu einem bloßen Ausdruck der sozioökonomischen Basis zu reduzieren.

182 Koselleck, Einleitung, S. XX.

183 Dieter Langewiesche, Sozialgeschichte und Politische Geschichte, in: SCHIEder und Sellin (Hrsg.), Bd. 1, S. 9-32, hier S. 26.

184 ERIC J. Hobsbawm, Von der Sozialgeschichte zur Geschichte der Gesellschaft, in: WeHLER (Hrsg.), Geschichte und Soziologie, S. 331-52, hier S. 341. 


\section{Semantischer Nominalismus und asymmetrische Übersetzung: Methodische Probleme und Perspektiven komparativer Semantik}

Das Untersuchungsprogramm und sein methodischer Zugriff kann andere Ansätze der vergleichenden Liberalismus-Forschung keinesfalls ersetzen: Die vergleichende historische Semantik des Begriffes Liberalismus stellt keinesfalls eine historiographische Synthese zur Geschichte des europäischen Liberalismus dar, aber sie will zur Substanz und zugleich zur Problematik einer solchen Synthese beitragen. Der historisch-semantische Vergleich europäischer Liberalismen macht sozialgeschichtliche oder noch stärker ideologiekritische Arbeiten zum Verhältnis von Programm und sozialer Praxis oder differenzierende Analysen zu den Zusammenhängen von Ideologie und kultureller Prägung keinesfalls überflüssig, und mit Recht hat Dieter Langewiesche darauf hingewiesen, daß Geschichte nicht allein darin aufgeht, „wie sie sprachlich erfaßt und verarbeitet wird“.185 Eine „vollständige“ Abbildung von komplexen politischen und sozialen Sachverhalten in der zeitgenössischen historischen Semantik von Liberalismus zu erwarten, überschätzte die Möglichkeiten dieses analytischen Zugriffs. Einen Anspruch auf ein semantisch vollständiges Quellenkorpus kann diese Studie nicht erheben. Weder geht es um den unbestrittenen exakten Erstbeleg noch um eine universelle lexikographische Zitatensammlung. Dies reduzierte die problemorientierte Analyse unweigerlich zum Zitatengrab. Auch wo durch die vorgestellte Quellenbasis das Ziel verfolgt wird, über signifikante Belegreihen hinaus zu abgesicherten Aussagen über die publizistische Präsenz des Begriffsfeldes zu gelangen, wäre die Annahme einer vollständigen Erfassung der semantischen Breite im Rahmen einer Mehrländerstudie illusorisch.

Die oben vorgestellten praktischen Schwierigkeiten bei der Erfassung der für die vier Vergleichsländer heterogen entwickelten Quellenkategorien und das rein quantitative Ausmaß der empirisch-systematischen Aufnahme unterstreicht einen fundamentalen Sachverhalt jeder begriffsgeschichtlichen Analyse: Die Unmöglichkeit, zu einem vollständigen Quellenkorpus zu gelangen, macht eine genauere Verortung der Erklärungsreichweite und des analytischen Anspruchs der eigenen Untersuchung unumgänglich. Es ist durchaus möglich, mit wenigen besonders elaborierten Zitaten aus verschiedenen Perspektiven eine Begriffsgeschichte von Liberalismus im deutschen politischen Diskurs des 19. Jahrhunderts zu konstruieren. Die darin deutlich werdende lediglich punktuelle Fokussierung von Bedeutungsverschiebungen hat signifikanten Charakter, aber sie läßt ohne den empirisch sehr viel weitergehenden Vergleich und die Einordnung der Belege keine nachvollziehbaren Aussagen über die Repräsentativität des historisch-semantischen Prozesses zu. Die Grenzen zwischen einer solchen begriffsgeschichtlichen Rekonstruktion eines Bedeutungswandels und 
dem dezisionistischen Konstrukt erscheinen mindestens fließend. Methodisch setzt dies im weiteren Sinne eine grundsätzliche Sensibilisierung des Historikers für die Gefahr der restrospektiven Teleologie seiner Interpretation voraus: Damit ist die einer implizit oder explizit vorgegebenen Ergebniskonstante entsprechende Interpretation gemeint, die mit der Konstruktion einer Bedeutungslinie einhergeht.

Dieser Gefahr einer Gipfelwanderung über signifikante Belege mit dem Ziel einer vom Historiker entworfenen Teleologie der historischen Prozesse ist nur dann überzeugend zu begegnen, wenn durch die quantitativ-empirische Verortung der Bedeutungsvarianten abgesicherte und nachvollziehbare Aussagen nicht allein über deren Signifikanz, sondern über deren Repräsentativität gemacht werden können. Aber auch eine auf denkbar breiter Quellengrundlage basierende historisch-semantische Analyse erlaubt niemals eine Rekonstruktion vergangener semantischer Totalität. So bleibt auch sie von dem seit Chladenius nicht überschrittenen hermeneutischen Rahmen geprägt, als der die immer vorhandene Perspektivität der historischen Urteilsbildung begriffen werden kann: Denn es gibt

einen Grund, warum wir die Sache so, und nicht anders erkennen: und dieses ist der SehePunckt von derselben Sache... Aus dem Begriff des Sehe-Puncts folget, daß Personen, die eine Sache aus verschiedenen Sehe-Puncten ansehen, auch verschiedene Vorstellungen von der Sache haben müssen ...; quot capita, tot sensus. ${ }^{186}$

Das einseitige dezisionistische Konstrukt als Folge einer retrospektiven Teleologie der Interpretation ließe sich wiederum mit Chladenius als "parteiische Erzäblung " charakterisieren, die wider "Wissen und Gewissen" die Ereignisse und Entwicklungen „vorsetzlich verdrehet oder verdunkelt. " Demgegenüber könne aber eine

unparteiische Erzäblung ... auch nicht so viel heißen, als eine Sache obne alle Sehepunkte erzäblen, denn das ist einmal nicht möglich: und parteiisch erzäblen, kann also auch nicht so viel heißen, als eine Sache und Geschichte nach seinem Sehepunkte erzäblen, denn sonst würden alle Erzäblungen parteiisch sein. 187

Entscheidend bleibt für den hier vorgestellten Anspruch auf relative Repräsentativität der Interpretation das Bewußtsein für die sich aus der Standortgebundenheit des Historikers notwendig ergebenden hermeneutischen Grenzen: Auch die vorliegende Untersuchung kann keine Rekonstruktion einer historisch-semantischen Totalität der Vergangenheit leisten. Ohne den Anspruch darauf verfolgt die Untersuchung aber das Ziel, zu typisierenden Erkenntnisaussagen beizutragen, die über die Signifikanz von Zufallsfunden hinausgeht.

186 Johann Martin Chladenius, Einleitung zur richtigen Auslegung vernünftiger Reden und Schriften, Leipzig 1742, Neudruck Düsseldorf 1969, S. 188 f.; vgl. REINHART Koselleck, Geschichte, in: BRUNNER et al. (Hrsg.), Bd. 2, S. 647-717, hier S. $696 \mathrm{f}$.

187 Johann MARTIn ChladeniUs, Allgemeine Geschichtswissenschaft, worinnen der Grund zu einer neuen Einsicht in allen Arten der Gelahrtheit geleget wird, Leipzig 1752, S. 151. 
Der Vergleich kultureller Deutungsmuster bringt spezifische Probleme mit sich. Heinz-Gerhard Haupt und Jürgen Kocka weisen in diesem Zusammenhang auf das Ungleichgewicht zwischen Empathie beim „Zugang zum Außergewöhnlichen“ und analytisch ausgefeilten Konzepten hin. Zudem rückten die narrativen Verfahren, mit deren Hilfe die Analyse von kulturellen Deutungsmustern häufig erfolgt, zu sehr in den Mittelpunkt, so daß ein Spannungsverhältnis zur komparativen Geschichtswissenschaft mit analytischer Zielsetzung vorliege. Dennoch müsse der Vergleich ohne die Einbeziehung der unterschiedlichen Wirklichkeitserfahrungen zugunsten einer vergleichenden Strukturanalyse viel von seiner Überzeugungskraft verlieren. Dies gelte zumal für das Problem der semantischen Konstruktion von Wirklichkeit. ${ }^{188}$ Während sich bestimmte kulturelle Praktiken wie Alphabetisierung, religiöse Kulte, Protest oder Erinnerung ${ }^{189}$ noch relativ leicht unter vergleichenden Fragestellungen als soziale Prozesse untersuchen lassen und sich zumal ideologische Bewegungen wie Liberalismus, Nationalismus und Faschismus im Hinblick auf Programmatik und soziale Praxis für den Vergleich geradezu anbieten, ergeben sich aus dem Kulturvergleich auf der Ebene von Sprache und Diskurs erhebliche methodische Probleme, wenn man nicht bei einer bloß deskriptiven Bestandsaufnahme stehenbleiben will.

Geht man von einem strengen methodischen Verständnis der komparativen historischen Semantik aus, dann stellt sich ein grundlegendes Übersetzungsproblem, das Reinhart Koselleck anläßlich eines semantischen Vergleichs von bürgerlicher Gesellschaft in Deutschland, England und Frankreich klarsichtig formuliert hat:

Die Untersuchung aller gesellschaftlichen Zustände und ihrer Veränderungen bleibt auf die sprachlichen Quellen verwiesen, die davon zeugen können. Jeder Vergleich muß also doppelgleisig verfahren: Die Sprachzeugnisse müssen übersetzt werden, um semantisch vergleichbar zu werden. Aber ebenso müssen die daraus erschlossenen sozialen, ökonomischen und politischen Vorgänge ihrerseits vergleichbar gemacht werden - was ohne die sprachlichen Vorgaben und ihre Übersetzungen nicht möglich ist. Insofern hängt jeder Vergleich von der Übersetzbarkeit sprachlich je verschiedenartig gespeicherter Erfahrungen ab, die aber als Erfahrungen an die Einmaligkeit der jeweiligen Sprache zurückgebunden bleiben. Wir stehen also methodisch vor einer aporetischen Situation.

Jede komparative Semantik steht vor diesem Problem, das methodisch zugleich an den Ausgangspunkt dieser Untersuchung zurückführt: Der semantische Nominalismus, also die häufig unreflektierte Übersetzung unterschiedlicher

188 HAUPT und KOCKA, S. 34.

189 Vgl. ETIENNE FrançoIs, Alphabetisierung und Lesefähigkeit in Frankreich und Deutschland, in: Helmut Berding, Etienne François und Hans-Peter Ullmann (Hrsg.), Deutschland und Frankreich im Zeitalter der Französischen Revolution, Frankfurt a. M. 1989, S. 407-25; David BlackBOURn, Marpingen. Apparitions of the Virgin Mary in Nineteenth-Century Germany, New York 1994; Charles TillY, Louise Tilly und Richard Tilly, The Rebellious Century 1830-1930, Cambridge/ Mass. 1975 sowie Charlotte TACKe, Denkmal im sozialen Raum. Nationale Symbole in Deutschland und Frankreich im 19. Jahrhundert, Göttingen 1993. 
historischer Erfahrungen und Erwartungen in einem scheinbaren Äquivalenzbegriff einer Sprache, ist seinerseits Kennzeichen des Vergleichs. Wird er als methodisches Problem reflektiert, verbirgt sich hinter ihm das von Koselleck angesprochene Problem der Übersetzung: Um die Untersuchungsfälle vergleichbar zu machen, müssen die Begriffe übersetzt werden, aber diese Übersetzung bedingt zugleich, die Einmaligkeit der Erfahrungsverdichtung in der jeweiligen Sprache zugunsten eines scheinbaren Äquivalents zu nivellieren. In dieser Differenz zwischen Übersetzungsdesiderat und semantischem Nominalismus besteht die aporetische Situation des konkreten Ansatzes. Sie ließe sich methodisch nur umgehen, wenn bei der Übersetzung „die sprachlich nicht einholbaren Differenzierungen mitreflektiert" würden, ${ }^{190}$ was für den länderübergreifenden Vergleich eine Metasprache voraussetzte, so wie eine sozialhistorische Metatheorie die Grundlage für die Analyse von sozialhistorischen Unterschieden zwischen Vergleichsfällen zu bieten vermag. Diese semantische Metaebene existiert aber nicht. Es ist nicht zu übersehen, daß dem diskurstheoretisch bestimmten Vergleich hier „systematische Schranken“ gesetzt sind.191

Die vorliegende Untersuchung geht grundsätzlich vom Primat der Einmaligkeit in der sprachlichen Verdichtung von Erfahrungsräumen und Erwartungshorizonten aus. Eine Übersetzung der Sprachzeugnisse, aus denen sich die je unterschiedliche Konnotierung von Liberalismus ergibt, verbietet sich daher grundsätzlich. Die Textinterpretation muß insofern so weit wie möglich den Versuch unternehmen, den Erfahrungsgehalt der unterschiedlichen Begriffe in den jeweiligen nationalsprachlichen Varianten nachzuvollziehen. Eine idealtypische Trennung zwischen Pragmatik und Semantik ist dabei unmöglich, denn der Stellenwert des politisch-sozialen Deutungsmusters Liberalismus erschließt sich nicht ohne seine konkreten Anbindungen an andere Bereiche vergangener Wirklichkeit, die außersprachlicher Natur sind. Im Hinblick auf die je spezifische Dynamik der bedeutungsbestimmenden nationalsprachlichen Belege ist es unumgänglich, die Analyse sehr textnah auszurichten. Dies ermöglicht auch den Nachvollzug und die kritische Überprüfung jener interpretativen Übertragung von Sachverhalten aus dem Umfeld der Bedeutungsbestimmung, die methodisch die eigentliche Problemzone jeder komparativen historischen Semantik kennzeichnet. Wo die Unmöglichkeit einer politischsozialen Metasprache konsequenterweise in der methodischen Aporie münden würde, muß die analytische Umsetzung durch bewußt textnahe Interpretation und durch ausführlicheren Rückgriff auf die Quellen die Möglichkeit einräumen, den semantischen Vergleich nachzuvollziehen.

Für den Vergleich der semantisch differenten Liberalismen gilt die gleiche methodische Prämisse, die Reinhart Koselleck auch für die Übersetzung der bürgerlichen Gesellschaft aufgestellt hat: Als historische Phänomene des Über-

190 Koselleck et al., Drei bürgerliche Welten, S. $21 \mathrm{f}$.

191 Haupt und Kocka, S. 35. 
gangs im 19. Jahrhundert sind sie analytisch nur „zwischensprachlich und diachron" zu übersetzen. ${ }^{192}$

Dabei ist die Frage, ob man mit gegenwärtigen Begriffen Vergangenes aufzuschließen vermag, der Ausgangspunkt der Analyse. Sie fokussiert das hinter jeder historischen Semantik stehende Erkenntnisproblem und verweist zugleich bereits auf den diachronen Weg der Analyse. Zugänglich scheint jede Gesellschaft in ihrer je eigenen Gegenwart nur unter den Voraussetzungen einer in den Begriffen fermentierten Vergangenheit. Mit Niklas Luhmann ließe sich fragen, ob sich die Moderne nicht als eine Gesellschaft darstellt, der es nach wie vor an einer adäquaten Beschreibung fehlt und die sich daher an ,intellektuelle Antiquitäten" hält, mit der Folge von Vertauschung und Verwechslung von Vergangenheit und Gegenwart. ${ }^{193}$ Solchen Gefahren mag eine komparative historische Semantik partiell vorbeugen. Die Tauglichkeit des Überlieferten und die interpretative Relevanz des tradierten Begriffsvorrats für die Gegenwart zu hinterfragen, erscheint vor diesem Hintergrund als wünschenswerte Konsequenz.

Mit der semantischen Differenzbestimmung europäischer Liberalismen hofft diese Untersuchung auch zur Erschließung der unterschiedlichen politisch-kulturellen Definitionen des Bürgertums als europäischer Sozialformation der Moderne beizutragen. Die pointierte Aussage bei Jürgen Kocka und Heinz-Gerhard Haupt versteht sich insofern als Anspruch und Meßlatte: „Vergleichen“ sei „die Sache expliziter, theoretisch orientierter, analytischer Geschichtswissenschaftler mit einer gewissen Distanz zur historistischen Tradition - und damit bisher die Sache einer Minderheit" ${ }^{194}$

192 Koselleck et al., Drei bürgerliche Welten, S. 22.

193 Vgl. JÜrgen KaUbe, Der Spätauswickler. Antiantiquarisch denken: Niklas Luhmann zum Siebzigsten, in: FAZ, 8. Dezember 1997.

194 HaUpT und Kocka, S. 23. 